\title{
Pseudocetherinae (Hemiptera: Reduviidae) revisited: phylogeny and taxonomy of the lobe-headed bugs
}

\author{
Stephanie CASTILLO ${ }^{\circledR 1, *}$, Dávid RÉDEI ${ }^{\circledR} 2$ \& Christiane WEIRAUCH ${ }^{\circledR} 3$ \\ ${ }^{1,3}$ University of California, Riverside, 900 University Avenue, Riverside, CA 92521, USA. \\ ${ }^{2}$ National Chung Hsing University, 145 Xingda Rd., 40227 Taichung, Taiwan. \\ *Corresponding author: scast032@ucr.edu \\ ${ }^{2}$ Email: david.redei@gmail.com \\ ${ }^{3}$ Email: christiane.weirauch@ucr.edu \\ ${ }^{1}$ urn:1sid:zoobank.org:author:802965D7-06BE-4C93-B2B4-1CF8F2C8C2DC
${ }^{2}$ urn:1sid:zoobank.org:author:74DB4DB4-E632-4CA9-B820-2070E7EB18D4
${ }^{3}$ urn:1sid:zoobank.org:author:59B6A54F-2044-4E5A-B7F7-AAC5E7D716F0
}

\begin{abstract}
The concept of the previously monogeneric subfamily Pseudocetherinae (Hemiptera: Heteroptera: Reduviidae) is revised and expanded. We here transfer Gerbelius Distant, 1903, Kayanocoris Miller, 1954, Microvarus Jeannel, 1917, Paragerbelius Miller, 1958, and Voconia Stål, 1866 from Reduviinae to Pseudocetherinae and treat Kayanocoris, Microvarus, Paragerbelius, and Pseudocethera Villiers, 1963 as junior synonyms of Voconia, resulting in new combinations for Voconia conradti (Jeannel, 1917) comb. nov., V. ifana (Villiers, 1963) comb. nov., V. monodi (Villiers, 1963) comb. nov., V. motoensis (Schouteden, 1929) comb. nov., V. ornata (Distant, 1903) comb. nov., V. schoutedeni (Villiers, 1964) comb. nov., V. typica (Miller, 1958) comb. nov., and V. wegneri (Miller, 1954) comb. nov. We also describe 23 new species of Voconia: V. bakeri sp. nov., V. bracata sp. nov., $V$. brachycephala sp. nov., $V$. chrysoptera sp. nov., $V$. coronata sp. nov., $V$. decorata sp. nov., $V$. dolichocephala sp. nov., $V$. fasciata sp. nov., $V$. grandioculata sp. nov., $V$. hemera sp. nov., $V$. isosceles sp. nov., $V$. laosensis sp. nov., $V$. lasiosoma sp. nov., $V$. lirophleps sp. nov., $V$. loki sp. nov., $V$. mexicana sp. nov., $V$. minima sp. nov., $V$. nyx sp. nov., $V$. smithae sp. nov., $V$. tridens sp. nov., $V$. trinidadensis sp. nov., $V$. tuberculata sp. nov., and $V$. vittata sp. nov. Lectotypes are designated for Gerbelius confluens Distant, 1903, G. typicus Distant, 1903, V. conradti comb. nov., V. ornata comb. nov., and V. pallidipes Stål, 1866. A revised diagnosis and description of Pseudocetherinae are provided along with photographs of the species and of the male genitalia of 13 pseudocetherine and five closely related reduviine species. An identification key to the two genera of Pseudocetherinae as well as a key to species of Voconia are presented. A phylogenetic hypothesis is proposed for the relationships of Pseudocetherinae using parsimony analyses of 77 morphological characters.
\end{abstract}

Keywords. Reduviidae, taxonomy, phylogeny, assassin bugs, lobe-headed bugs.

Castillo S., Rédei D. \& Weirauch C. 2022. Pseudocetherinae (Hemiptera: Reduviidae) revisited: phylogeny and taxonomy of the lobe-headed bugs. European Journal of Taxonomy 788: 1-95.

https://doi.org/10.5852/ejt.2022.788.1625 


\section{Introduction}

The assassin bugs, or Reduviidae Latreille, 1807 (Hemiptera: Heteroptera), are a large group of mostly predatory true bugs with approximately 7000 described species in 24 subfamilies (Maldonado 1990; Weirauch et al. 2014; Forthman \& Weirauch 2017). The subfamilial classification, however, is not settled, with multiple analyses finding that the second largest subfamily, the Reduviinae Latreille, 1807 (about 1100 spp.), is polyphyletic and falls into 11-14 separate clades (Weirauch 2008; Weirauch \& Munro 2009; Hwang \& Weirauch 2012; Zhang et al. 2016). Pseudocetherinae Villiers, 1963 have historically been treated either as a subfamily (Maldonado 1990; Weirauch et al. 2014) or a tribe within the distantly related Cetherinae Jeannel, 1919 (Putshkov \& Putshkov 1985). Hwang \& Weirauch (2012) recovered species that we here consider to be part of the expanded concept of Pseudocetherinae within their Reduvius clade of the Reduviinae. Prior to this work, Pseudocetherinae comprised only the genus Pseudocethera Villiers, 1963 that contained three rarely collected Afrotropical species (Villiers 1963b, 1964): Ps. monodi Villiers, 1963 described from a single micropterous female specimen from Belgian Congo (now the Democratic Republic of the Congo), Ps. ifana Villiers, 1963 from Sudan based on a macropterous male specimen (Villiers 1963a), and Ps. schoutedeni Villiers, 1964 based on a micropterous and a macropterous male from Belgian Congo (Villiers 1964). The natural history of Pseudocetherinae is unknown beyond a reference to the collection site of the holotype of Ps. ifana that was recorded as "underneath a piece of dead wood" by Villiers (1963a).

Pseudocetherinae were initially diagnosed by their unique trilobate head formed by the large and anteriad projecting clypeus and maxillary plates, antennal pedicel longer than scape, small or vestigial ocelli, slender labium with (visible) labial segment I long and appressed against the ventral head surface, the proximity of the coxal cavities of fore and mid legs, and the three-segmented tarsi (Villiers 1963b). Additionally, the dorsal abdominal glands on terga IV-VI are absent in Pseudocetherinae in contrast to most other Reduviidae (Weirauch 2006), the prosternum is drawn into an anteriad-directed process, and the apex of the third visible labial segment is bent and slender (Weirauch et al. 2014). While this combination of diagnostic characters sets Pseudocethera apart from the great majority of reduviid subfamilies, some or all of these features are also observed to varying degrees in five genera that are currently classified as Reduviinae: Microvarus Jeannel, 1917 (two Afrotropical species), Gerbelius Distant, 1903 (three Oriental species), Kayanocoris Miller, 1954 (one Oriental species), Paragerbelius Miller, 1958 (one Melanesian species), and Voconia Stål, 1866 (one Australian species) (Maldonado 1990). Miller (1954, 1958) was the first to suggest close relationships between three of the Oriental and Australasian genera, noting the resemblance in general habitus among Gerbelius ornatus Distant, 1903 and the members of Kayanocoris and Paragerbelius. Subsequently, a morphology-based cladistic analysis across Reduviidae recovered the reduviine species G. ornatus and Microvarus conradti Jeannel, 1917 in a well-supported clade with the pseudocetherine Ps. monodi (Weirauch 2008), and a molecular phylogenetic analysis using ribosomal data recovered Voconia loki sp. nov. (misidentified as Kayanocoris wegneri Miller, 1954) as sister to three described and undescribed species of Gerbelius (Hwang \& Weirauch 2012). Based on this morphological and molecular phylogenetic evidence, a revision of Pseudocethera and related taxa that are currently classified as Reduviinae is overdue. In addition, we have located specimens of Pseudocethera and putatively related genera in several collections that represent 23 undescribed species. These specimens most closely resemble Afrotropical species currently placed in the genus Microvarus but originate not only from the Afrotropical region but also from the Neotropical and Oriental regions. We posit that a phylogenetic hypothesis focused on Pseudocethera and related genera, with significant representation of other reduviine genera, will be the most scientifically sound way to (1) evaluate subfamilial and generic concepts and (2) infer the generic classification of existing and new species. Although we attempted to generate molecular data using non-destructive sampling of pinned museum specimens, we failed to produce a workable molecular dataset; we therefore decided to rely on morphology-based phylogenetic analyses to inform the classification of Pseudocetherinae. 
The objectives of this study are to: (1) test the monophyly of Pseudocetherinae and putatively related genera currently classified as Reduviinae using 77 morphological characters and 33 ingroup and seven outgroup taxa using parsimony analyses, (2) revise generic and subfamilial concepts of Pseudocetherinae based on phylogenetic relationships, (3) provide redescriptions of Gerbelius and Voconia, (4) provide nine species redescriptions and 23 new species descriptions for Voconia, and (5) provide keys to genera of Pseudocetherinae and species of Voconia.

\section{Material and methods}

\section{Specimens}

Sixty ingroup specimens were physically examined for this revision. Wherever it was not possible to receive type material on loan, we coded from images of the types, original descriptions, and other specimens that had been authoritatively identified where applicable - details are provided for those cases in the remarks section of the species description.

\section{Repositories}

Specimens are deposited in the following institutions:

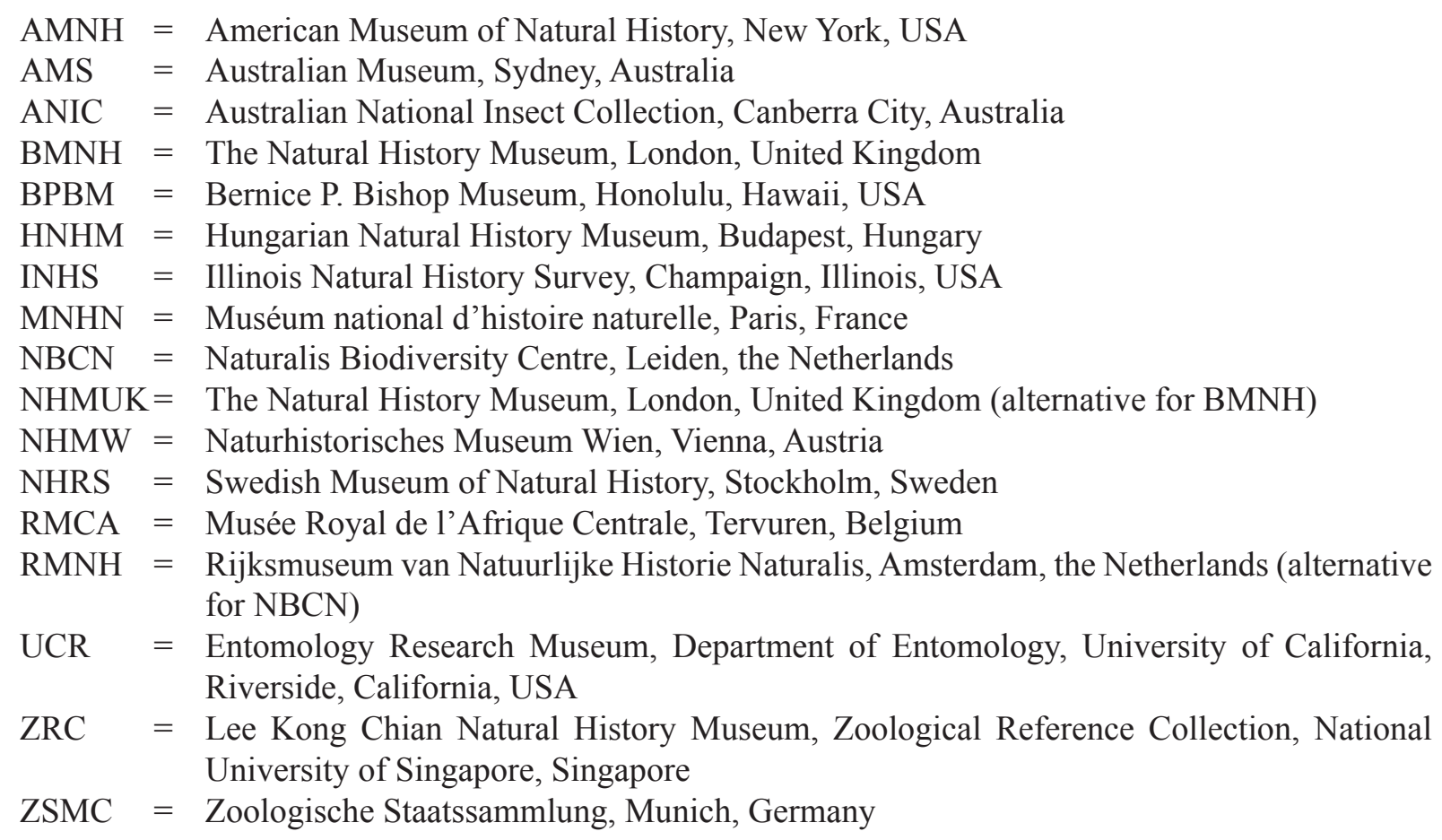

\section{Databasing and maps}

All physically examined specimens were databased using the American Museum of Natural History's Arthropod Easy Capture (AEC) instance (https://research.amnh.org/pbi/locality/index.php) of the Planetary Biodiversity Inventory for Plant Bugs project locality database (PBI database). Matrix code labels with unique specimen identifiers (USIs) were attached to all specimens examined directly. The USI numbers (e.g., AMNH_PBI 00094810) comprise an institution and a project code (AMNH_PBI) as well as a unique number (00094810) for each specimen. Distribution maps were plotted with SimpleMappr (http://www.simplemappr.net) and are based on all physically examined specimens as well as records from the literature. To plot the specimens without GPS coordinates, Google Earth ver. 9.140.0.4 (Google, LLC) was used to estimate the coordinates of the locality provided. 


\section{Imaging, morphological methods, and measurements}

Dorsal and lateral habitus photographs, as well as close-ups of the head and male genitalia were taken on a Leica DFC 450 C Microsystems camera (Leica, Wetzlar, Germany) using a Planapo 2.0× objective and a Leica Application Suite (LAS) ver. 4.3. Stacked images were assembled using LAS. Male genitalia were excised and macerated in heated $10 \%$ potassium hydroxide solution for 5-10 minutes and rinsed in distilled water. They were temporarily stored in a 96-well plate containing $100 \%$ glycerol for examination and eventually sealed in polyethylene vials containing glycerol and attached to the specimen's pin. The pygophore, eighth abdominal segment, one paramere, and the phallus were removed for examination in glycerol gelatin for imaging for Gerbelius sp., G. typicus, V. bakeri sp. nov., $V$. conradti, $V$. grandioculata sp. nov., V. lasiosoma sp. nov., V. laosensis sp. nov., V. mexicana sp. nov., $V$. nyx sp. nov., $V$. pallidipes Stål, 1866, V. tridens sp. nov., V. tuberculata sp. nov., V. typica (Miller, 1958) and $V$. vittata sp. nov. Scanning electron micrographs (SEMs) were acquired on a Hitachi TM1000 Tabletop Electron Microscope (Institute for Integrative Genome Biology, UCR) for one male V. dolichocephala sp. nov. (AMNH_PBI 00168745) to document details of the head, prothorax, labium, hemelytron, and pygophore. The specimen was not removed from the point or coated making this approach maximally non-destructive.

Measurements of selected morphological features were obtained from photographs using ImageJ2 (Rueden et al. 2017) and are provided in Table 1. Body length is recorded in dorsal view along the midline from the clypeal apex to the posteromedial margin of the abdomen. Dorsal head measurements were obtained from images of the head oriented horizontally for better accuracy. This allowed us to record head length from the maxillary plate apex to the posterior margin of the head (defined by the transition of head granulations to smooth neck) since the maxillary plates in most species are slightly longer than the clypeal apex. Head length recorded from the clypeal apex to the posterior margin of the head is recorded in Supp. file 1. The scape, pedicel, and labium were measured from the proximal and distal midpoints.

\section{Terminology}

Terminology generally follows Schuh \& Weirauch (2020). When referring to the hemelytra we refer to it in an abducted position, meaning away from the midline of the body or perpendicular to the longitudinal axis of the body. We refer to a seta on a protuberance as a setigerous tubercle, large setae as macrosetae, and short, thin macrosetae as pubescence. Abbreviations for wing cells and veins in descriptions and the cladistic analysis are as follows: $\mathrm{Cu}-\mathrm{An}_{1}$ cell, cell between cubital and first anal veins; $\mathrm{M}-\mathrm{Cu}$ cell, cell between medial and cubital veins; $M$, medial vein; $R$, radial vein. We refer to labial segments as: labial segment I, first visible segment; labial segment II, second visible segment; labial segment III, third visible segment. In reduviids the first abdominal tergum is referred to as syntergum I+II. Here, we refer to syntergum I+II individually as tergum I and tergum II since they are clearly identifiable in Pseudocetherinae.

\section{Species descriptions and redescriptions}

Descriptions are based on examination of available specimens for a given species, including type material, type images of Voconia conradti, V. pallidipes, and $V$. wegneri, and the original descriptions of $V$. ifana and $V$. monodi. Descriptions were compiled from a character matrix of 98 discrete characters assembled in Mesquite ver. 3.51 (Maddison \& Maddison 2019). This descriptive character matrix was exported as descriptions for each taxon in Mesquite and then punctuation and sentence structure were manually edited. Species descriptions are provided for all species of Voconia, including formerly recognized G. ornatus, as well as species placed in the genera Kayanocoris, Microvarus, Paragerbelius, and Pseudocethera but transferred to Voconia in this study. Because the habitus of species of Gerbelius resembles that of other small-bodied Reduviinae compared to Voconia, we suspect that our survey of 


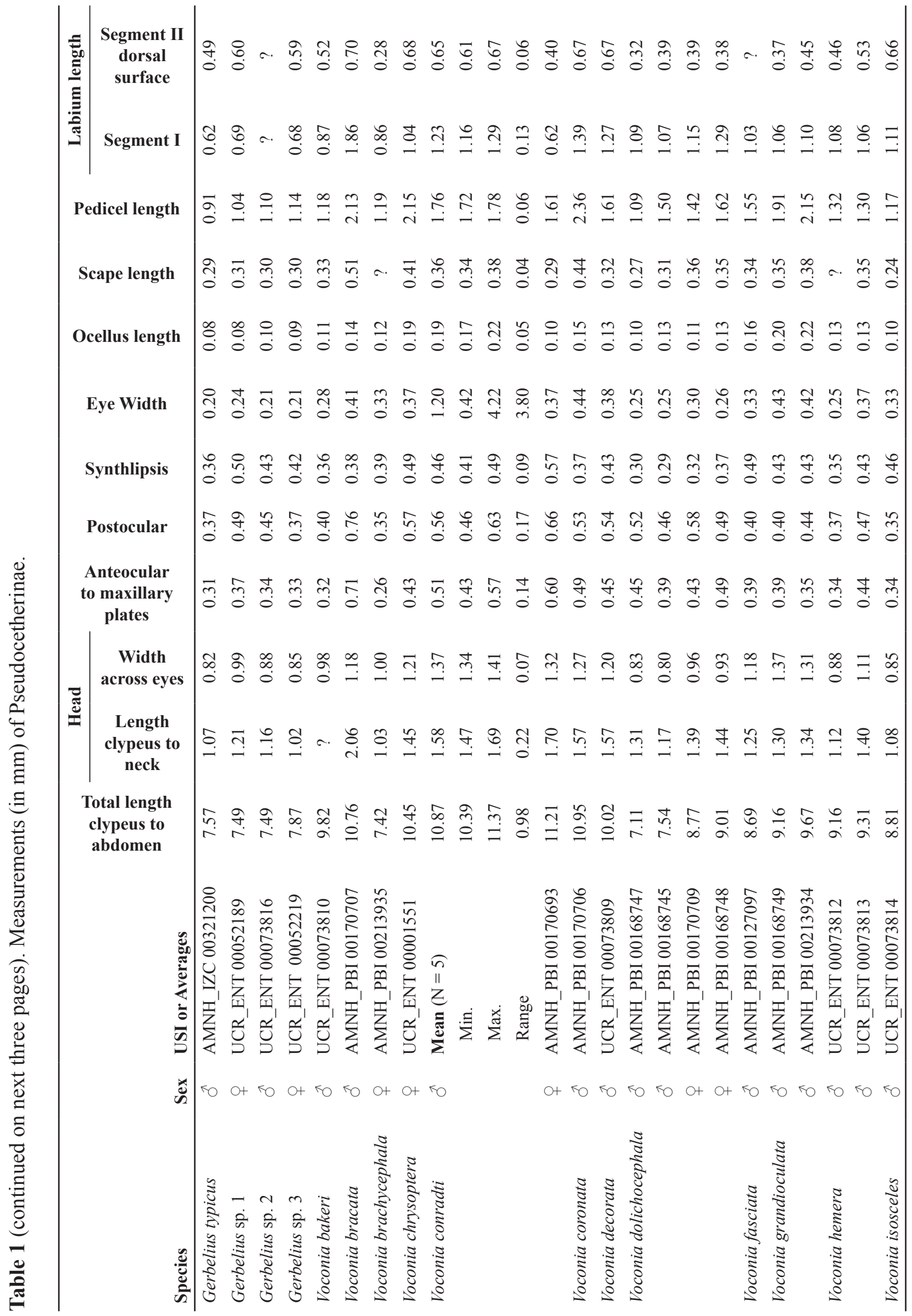




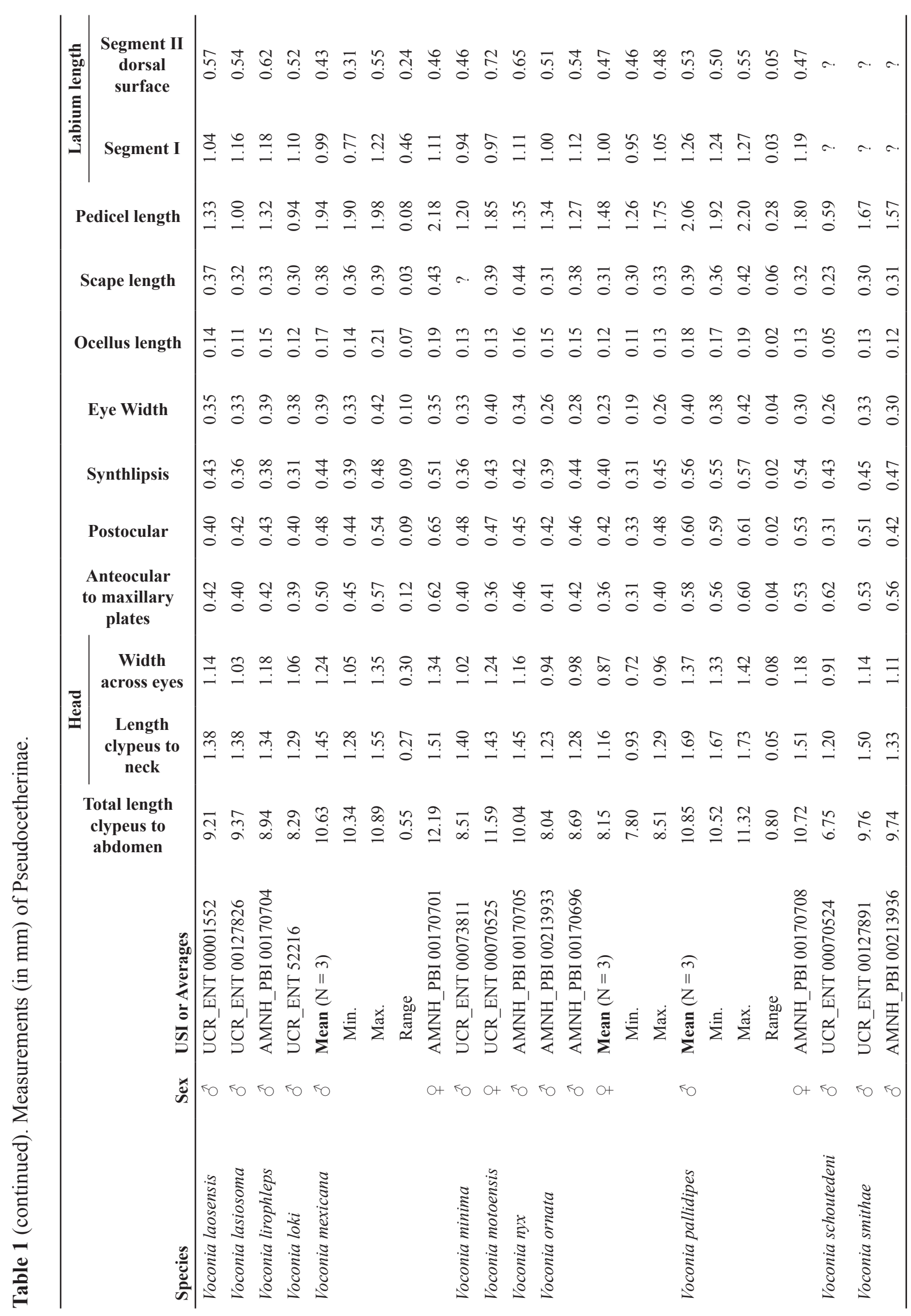




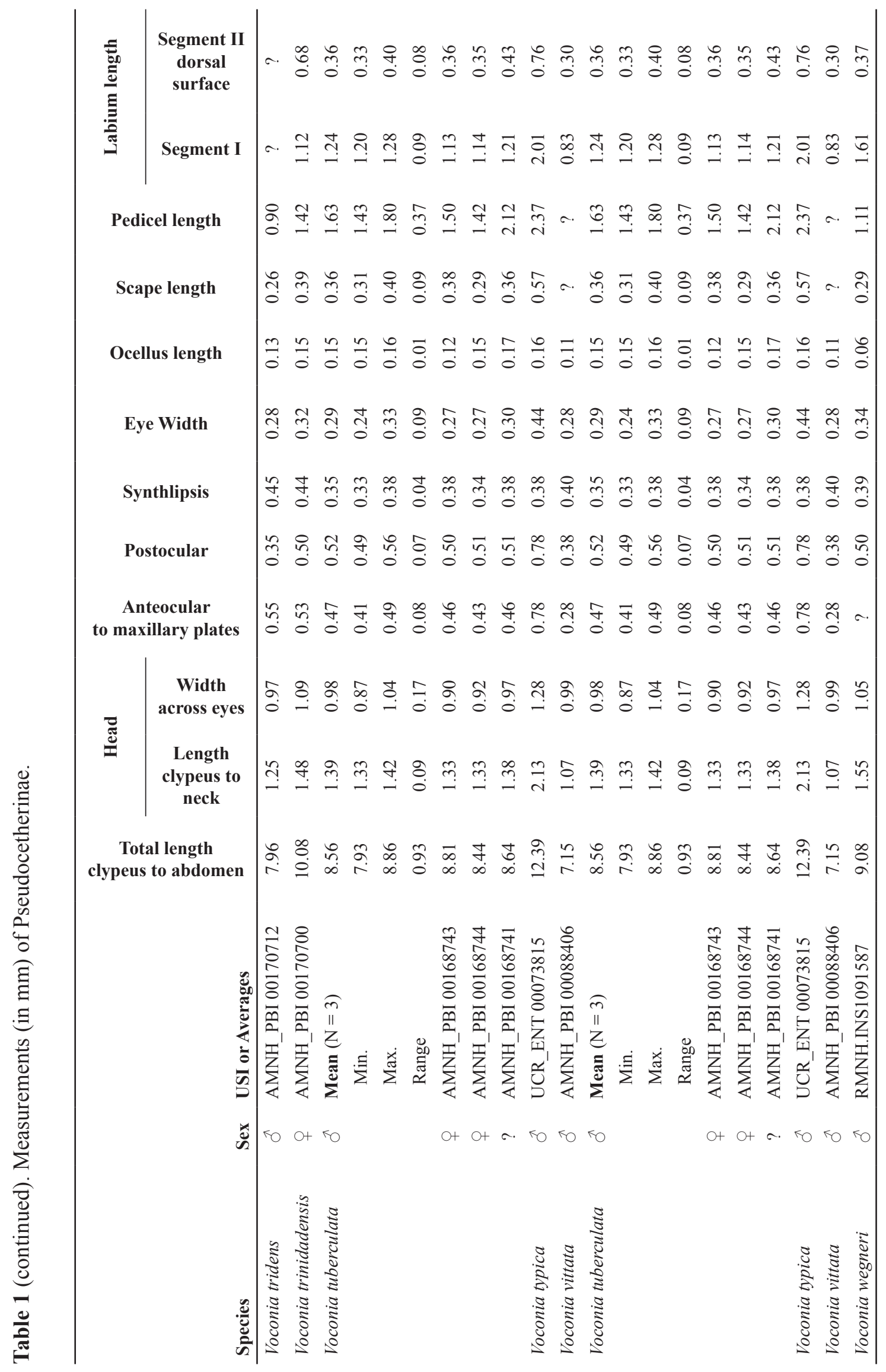


Gerbelius specimens deposited in various natural history collections has not been comprehensive. We therefore refrain from describing new species of Gerbelius as part of the present study and only provide a redescription of the genus. Data interpreted from labels (e.g., interpretation of coordinates or foreign text) in the material citations are distinguished with square brackets and verbatim citations (e.g., archaic geographic names) are encased in double quotation marks.

\section{Cladistic analysis}

Forty taxa comprising 33 ingroup species and seven outgroup species were analyzed (Figs 1-2). Outgroup selection was informed by the molecular phylogenies presented in Hwang \& Weirauch (2012) and included two Reduvius clade taxa (Reduvius personatus (Linnaeus, 1758) and Leogorrus sp. voucher UCR_ENT 00128936), as well as species representing more distantly related clades of Reduviinae (Microlestria clade: Microlestria sp. voucher UCR_ENT 00128936; Nalata clade: Nalata nr. spinicollis Champion, 1899 voucher UCR_ENT 00052188; Velitra clade: Velitra rubropicta (Amyot \& Serville, 1843) voucher UCR_ENT 00128938; Acanthaspis clade: Acanthaspis sp. voucher UCR_ENT 00128937; and Chryxus tomentosus Champion, 1898) that based on recent molecular analyses (Knyshov et al., unpubl. data) may be closely related to the Reduvius clade.

The descriptive matrix was used as the framework for this analysis by first removing non-informative (autapomorphic) characters. The 77 morphologically discrete characters (29 binary, 48 non-additive [unordered] multistate) used in the analysis are listed in the results. Characters are from the head (39), thorax (12), hemelytron (6), legs (6), abdomen (2), and male genitalia (12). We selected nine characters that rely on color patterns that are not highly variable within species given our specimen sampling. Inapplicable characters were treated as missing data and intraspecific variation coded as polymorphic. Gil-Santana et al. (2007) was used to code C. tomentosus, and male genitalic characters for Reduvius personatus are based on Weirauch et al. (2015). Since male genitalia across Reduviidae are not welldocumented (Forero \& Weirauch 2012), the pygophore and phallus dissections of the remaining outgroup taxa are made available. Characters and character states are indicated in the image plates (e.g., 2-0 in Fig. 3 refers to character 2 and state 0 in the results). The character matrix is provided as a text file in Supp. file 2 .

The equal weighting (EW) analysis was conducted in TNT ver. 1.5 (Goloboff \& Catalano 2016) using New Technology Search with the following parameters: find minimum length 100 times; ratchet (Nixon 1999) with default settings and 200 iterations; tree-drifting with default settings and 200 cycles; tree fusing with default settings. Clade support was evaluated using jackknife with default settings and 200 replicates. Tree length (L), consistency index (CI), and retention index (RI) were also calculated in TNT. The trees were then imported into WinClada ver. 1.00 .08 (Nixon 2002) to estimate the strict consensus tree (Fig. 1).

Implied weighting (IW) (Goloboff 1993) analyses were performed in TNT under the same New Technology Search parameters as mentioned above. Several concavity values, which downweigh homoplasious characters, were explored to compare tree length and tree topology under the different weighting schemes: $K=3, K=6, K=9, K=12$ (Fig. 2). The lower values penalize homoplasy more strongly, though a value of $\mathrm{K}=12$ is still relatively strong considering that a value of $\mathrm{K}=20$ weighs homoplasies "very far from mild" in certain large datasets (Goloboff et al. 2008). The matrix was resampled with symmetric resampling (Goloboff et al. 2003) under default settings and 200 replicates. The IW tree provided greater resolution for our analysis than the EW tree, with the $\mathrm{K}=12$ analysis having the best fit. We therefore used the most parsimonious tree derived from the $\mathrm{K}=12$ analysis to document and discuss character transformations. WinClada was used to illustrate unambiguous changes and treated any additional step as homoplastic (Fig. 2). To avoid local optima, we ran IW analyses with 
several random seeds $(1,10,123,1234,12345)$ and maintained the above-mentioned settings with a concavity of $\mathrm{K}=9$.

\section{Results}

\section{Cladistic analysis}

The EW analysis resulted in eight most parsimonious trees (length $=468 ; \mathrm{CI}=0.353, \mathrm{RI}=0.625)$. The strict consensus tree collapsed 12 nodes (Fig. 1). The IW analyses with four different concavities recovered one parsimonious tree each, all with the same topology. Increasing the K-values, which decreases the penalty against homoplasious characters, improved the best score and resulted in higher CI and RI values: $\mathrm{K}=3$ resulted in best score $=33.53464, \mathrm{CI}=0.348, \mathrm{RI}=0.618 ; \mathrm{K}=6$ resulted in best score $=24.58040$, $\mathrm{CI}=0.349, \mathrm{RI}=0.619 ; \mathrm{K}=9$ resulted in best score $=19.55168, \mathrm{CI}=0.353, \mathrm{RI}=0.625 ; \mathrm{K}=12$ resulted in best score $=16.26989, \mathrm{CI}=0.353, \mathrm{RI}=0.625$. Characters and character optimizations are described

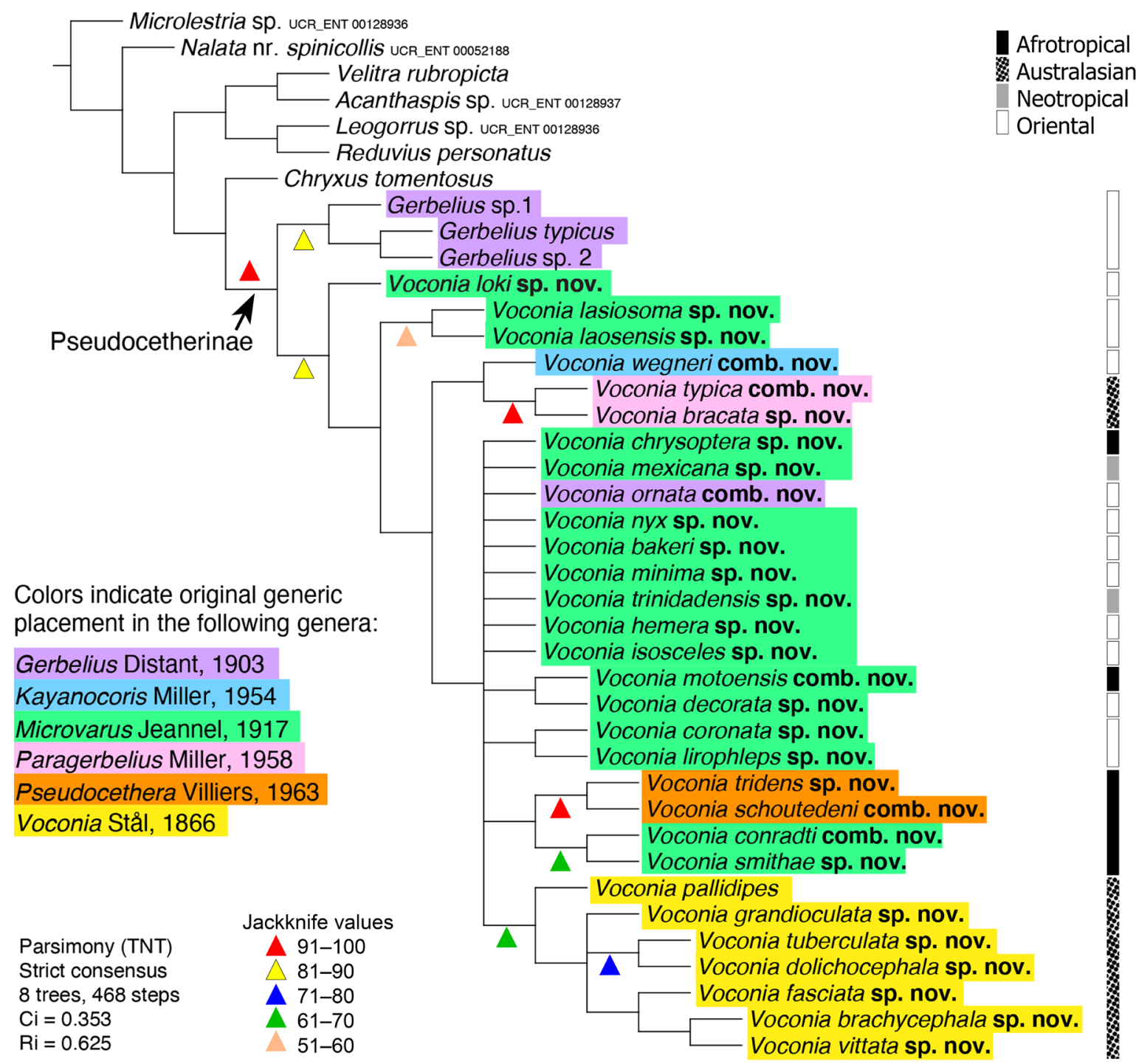

Fig. 1. Strict consensus tree resulting from equal weighting analysis. Jackknife values over 51 are reported for tree one of eight. 
and discussed in the section below using the most parsimonious tree derived from the $\mathrm{K}=12 \mathrm{IW}$ analysis. Exploring different random seeds for the IW analyses with $\mathrm{K}=9$ did not result in different tree statistics (best score $=19.55168 ; \mathrm{CI}=0.353 ; \mathrm{RI}=0.625$ ) and the topology remained the same.

Our results (Figs 1-2) corroborate prior molecular and morphological evidence that the expanded Pseudocetherinae (i.e., Pseudocethera plus five genera currently classified as Reduviinae) are a wellsupported (resampling values of $\geq 99$ ) clade with part of Gerbelius forming the sister taxon to all other Pseudocetherinae (Weirauch 2008; Hwang \& Weirauch 2012; Knyshov et al., unpubl. data). We therefore formally transfer Gerbelius, Kayanocoris, Microvarus, Paragerbelius, and Voconia from

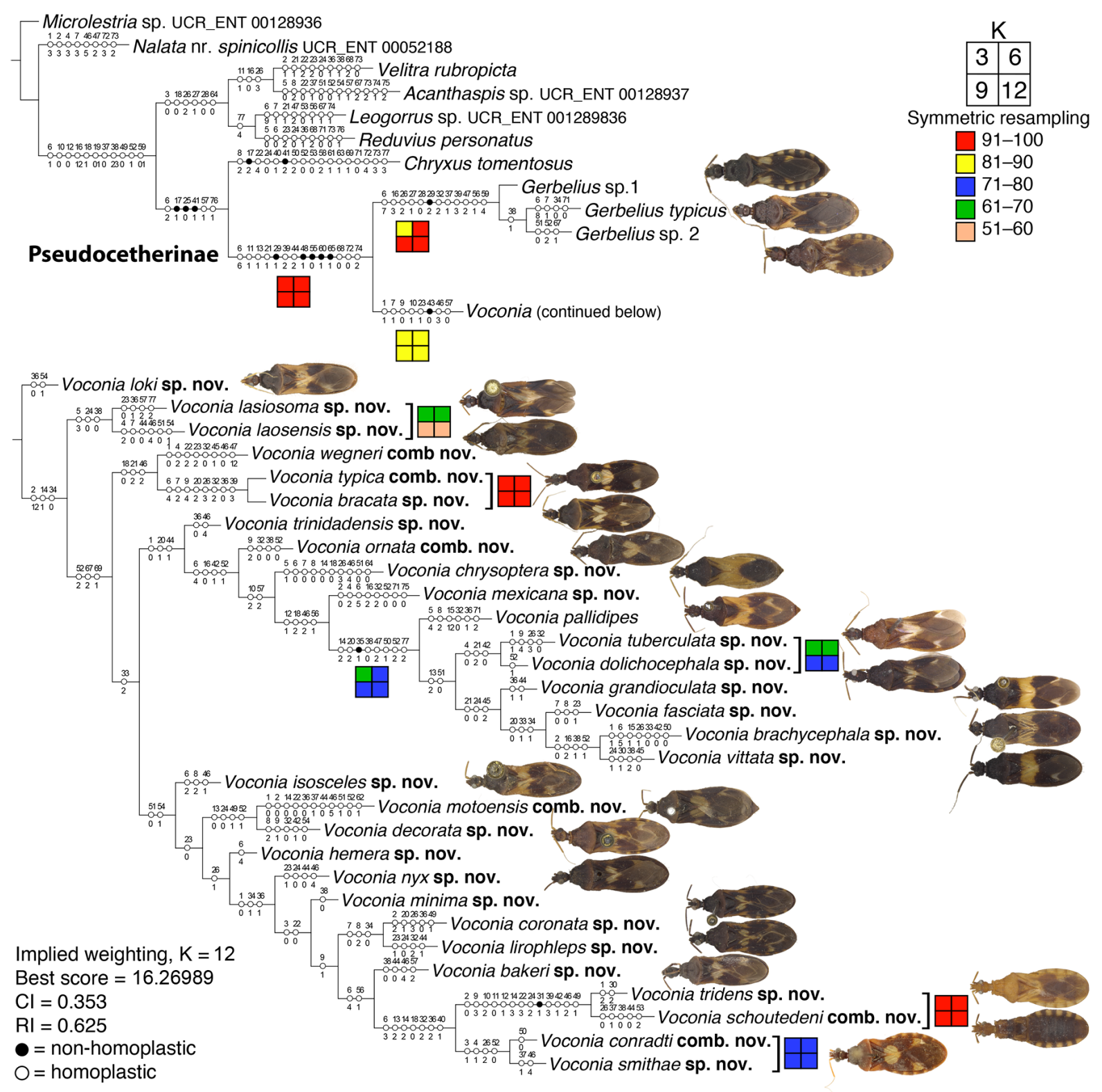

Fig. 2. Tree resulting from implied weighting analysis using $\mathrm{K}=12$ with characters unambiguously optimized. Symmetric resampling values over 51 are represented for trees obtained with $\mathrm{K}=3, \mathrm{~K}=6$, $\mathrm{K}=9$, and $\mathrm{K}=12$ analyses. Characters and character states are described in pp. 11-22. Specimens not to scale. 
Reduviinae to Pseudocetherinae in the Taxonomy section below and provide a revised diagnosis for Pseudocetherinae. Gerbelius typicus and two undescribed species of Gerbelius form a well-supported clade, but G. ornatus is nested among species that would be referred to as Microvarus under the generic concepts prior to this work. Gerbelius ornatus is therefore removed from Gerbelius. Within the nonGerbelius pseudocetherine clade, Pseudocethera and Paragerbelius are highly supported (resampling values of $\geq 99$ ) monophyletic groups, and Australasian species that would be referred to as Voconia under the current generic concept (Fig. 1, yellow highlight) form a well-supported (resampling values of 70-75) clade. However, Microvarus, as currently diagnosed, is paraphyletic in our analyses. This situation is complicated by the fact that we are here describing 23 new species of Pseudocetherinae, most of which would be classified as Microvarus under traditional diagnoses (Fig. 1, green highlight), but we are reluctant to describe new species in a paraphyletic grade. In addition, while we recovered two small, well-supported clades among these new species ( $V$. laosensis sp. nov. $+V$. lasiosoma sp. nov. from the Oriental region and $V$. conradti $+V$. smithae sp. nov. from the Afrotropical region), most relationships among non-Gerbelius Pseudocetherinae are poorly supported. We therefore decided to synonymize Microvarus, Kayanocoris, Paragerbelius, and Pseudocethera under Voconia, rather than preserving these generic concepts and describing several small or monotypic new genera that would be difficult to diagnose.

While our phylogenetic hypothesis may not be robust enough to meaningfully infer the historical biogeography of Pseudocetherinae, it is worth pointing out that with the expansion of Pseudocetherinae through the new species and taxa treated in new combinations, this subfamily is now known from the Afrotropical, Australasian, Oriental and Neotropical regions.

\section{Description and documentation of morphological characters with comments on character optimizations (Figs 3-15)}

1. Head, postocular region, coloration medially in dorsal view: uniform (0), with dark patches adjacent to ocellar margin (1), with red patches adjacent to ocellar margin (2), with dark medial stripe (3). Voconia tridens sp. nov. has red patches adjacent to the ocellar margin, while several other pseudocetherines have dark, blackish markings. Most, however, are uniformly colored.

2. Head, postocular region, coloration laterally in dorsal view: uniform $(0)$, with paired pale patches adjacent to lateral ocellar margin (Fig. 3C) (1), with a semicircular pale stripe around both ocelli (Fig. 3B) (2), pale with lateral margins dark (3). Shows homoplasy; involves multiple losses or gains of the semicircular pale stripe and yellow patches adjacent to the ocelli within Pseudocetherinae.

3. Labium, coloration: as remainder of head (0), lighter than head (Fig. 3G) (1). The labium is lighter than the head in most pseudocetherines and is the same color as the head in two clades: ( $V$. tridens sp. nov. $+V$. schoutedeni $)$ and ( . coronata sp. nov. $+(V$. lirophleps sp. nov. $+(V$. bakeri sp. nov. + V. minima sp. nov.))).

4. Scutellum, coloration: uniform (Fig. 4B) (0), dark with contrasting yellow apical spine (Fig. 4A) (1), dark with brown apical spine (2), pale with dark apical spine and pale apex (3). The color of the scutellum varies by species.

5. Clavus, coloration with hemelytron abducted: uniformly dark (0), uniformly yellow (1), dark with distal yellow stripe (Fig. 4B) (2), dark with proximal and distal yellow stripes (3), yellow with small, dark medial spot (4). Most pseudocetherines have a distal yellow stripe on the clavus. Proximal and distal yellow stripes are a non-homoplastic synapomorphy for $V$. lasiosoma sp. nov. and $V$. laosensis sp. nov. Uniformly yellow clavi are present in $V$. tridens sp. nov. and $V$. chrysoptera sp. nov. The small, dark medial spot is present in $V$. pallidipes. 

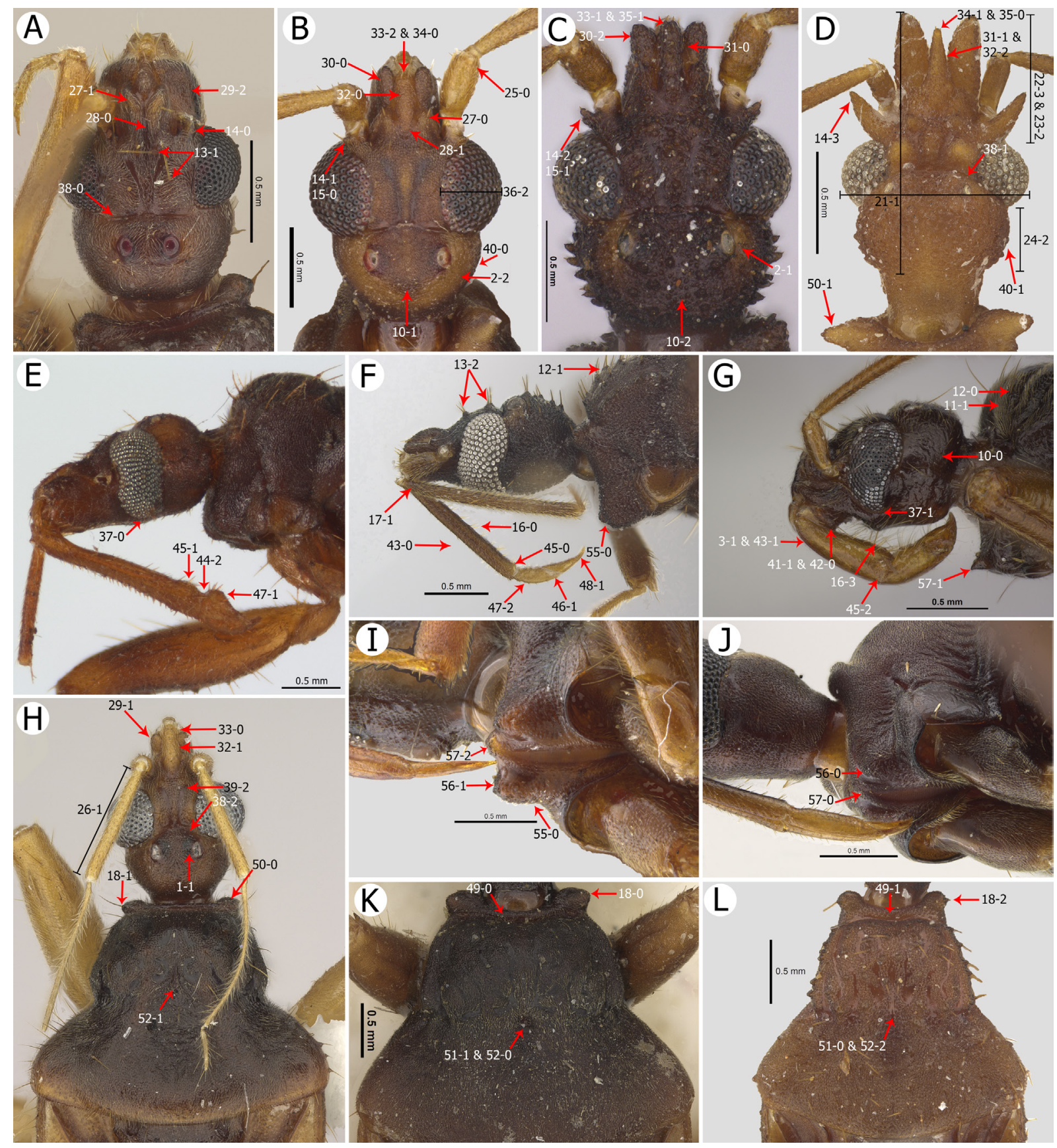

Fig. 3. Morphological characters. A-D. Head in dorsal view. A. Gerbelius nr. confluens. B. Voconia decorata sp. nov. C. Voconia pallidipes Stål, 1866. D. Voconia schoutedeni (Villiers, 1964) comb. nov. E-G. Head in lateral view. E. Voconia wegneri (Miller, 1954) comb. nov. F. Voconia dolichocephala sp. nov. G. Gerbelius typicus Distant, 1903. H. Voconia loki sp. nov., head and pronotum in dorsal view. I-J. Prosternum in ventrolateral view. I. Voconia mexicana sp. nov. J. Voconia bracata sp. nov. K-L. Pronotum in dorsal view. K. Voconia conradti (Jeannel, 1917) comb. nov. L. Voconia tuberculata sp. nov. 
6. Corium, coloration pattern with hemelytron abducted: uniformly yellow (0), dark with thick medial yellow stripe (1), proximal half mostly yellow, distal half brown with yellow spot at distal apex (2), dark with proximal, anteromedial, posteromedial, and distal yellow spots (3), dark with anteromedial, posteromedial, and distal yellow spots (Fig. 4C) (4), dark with anteromedial and posteromedial yellow spots (5), dark with anteroproximal yellow stripe and posteromedial and distal yellow spots (Fig. 4B) (6), dark with proximal, anteromedial, and distal yellow spots (7), proximal third yellow, yellow stripe along claval margin (Fig. 4A) (8), dark with posteromedial and distal yellow spots (9), uniformly dark (10), dark with proximal yellow spot and thick medial white stripe (11), dark with thick medial red stripe and red spot at distal apex (12). Corium coloration is highly variable; character state 3 is a non-homoplastic synapomorphy for $V$. conradti and $V$. smithae sp. nov. Character states 9-12 are observed in the outgroups.

7. Membrane, coloration: uniformly dark (Fig. 4A) (0), dark, pale V-shaped marking along R and M veins (1), dark, large pale patch between $\mathrm{R}$ and $\mathrm{M}$ veins (Fig. 4C) (2), dark with pale spotting (3). The pale V-shaped marking along the $\mathrm{R}$ and $\mathrm{M}$ veins is lost across Voconia several times, while a large pale spot between the $\mathrm{R}$ and $\mathrm{M}$ veins is a synapomorphy for $V$. typica and $V$. bracata sp. nov.

8. Membranal veins, coloration: as remainder of membrane (0), $\mathrm{R}$ and $\mathrm{M}$ veins proximally pale, remainder as membrane (Fig. 4A) (1), veins forming $\mathrm{Cu}-\mathrm{An}_{1}$ and $\mathrm{M}-\mathrm{Cu}$ cells paler than remainder of membrane (Fig. 4B) (2). Contrasting light colored membranal veins are present in Voconia decorata sp. nov. + Voconia isosceles sp. nov., V. coronata sp. nov., V. lirophleps sp. nov., and Voconia pallidipes. The membranal veins of most species are proximally pale on the $\mathrm{R}$ and $\mathrm{M}$ veins. Voconia chrysoptera sp. nov. and $V$. fasciata sp. nov. have uniformly dark membranal veins.

9. Abdomen, dorsal laterotergites, coloration: uniform (0), dark with yellow spots on anterior margins (Fig. 4B) (1), dark with yellow spots on posterior margins (Fig. 4A) (2), yellow with dark spots posteriorly (Fig. 4D) (3), laterotergites I and II paler than the rest (Fig. 4C) (4). The clade comprising $V$. tridens sp. nov. and $V$. schoutedeni have yellow bodies, and accordingly yellow dorsal laterotergites with dark posterior spots. The remaining pseudocetherines have dark bodies, some with yellow spots on the anterior margin and others on the posterior margin of the dorsal laterotergites.

10. Head and pronotum, surface: smooth (0), finely granulose (Fig. 3B) (1), coarsely granulose (Fig. 3C) (2), tuberculate (3). Species of Gerbelius have a smooth to corrugated head surface while all species of Voconia have granulations on the head and thorax. Course granulation is a synapomorphy for $V$. tridens sp. nov. $+V$. schoutedeni as well as the clade containing $V$. chrysoptera sp. nov., V. mexicana sp. nov., and the Australian species of Voconia containing V. pallidipes and kin.

11. Head and pronotum, vestiture, pubescence: glabrous (0), with pubescence (Fig. 3G) (1). Pseudocetherinae have a pubescent head and pronotum with varying densities. The African clade containing $V$. tridens sp. nov. and $V$. schoutedeni are less densely pubescent.

12. Head and pronotum, vestiture, setal base of macrosetae: macrosetae without tubercles (Fig. 3G) (0), setigerous tubercles (Fig. 3F) (1). Macrosetae are interspersed among the pubescence in Pseudocetherinae. These macrosetae may be on tubercles as in $V$. tridens sp. nov. $+V$. schoutedeni and the clade containing $V$. mexicana sp. nov. and the Australian species of Voconia (V. pallidipes and kin).

13. Head, interocular region, setation: without prominent, paired macrosetae (0), with two prominent pairs of macrosetae paramedially (Fig. 3A) (1), with two prominent pairs of setigerous tubercles 
paramedially (Fig. 3F) (2), with stout setigerous tubercles medially (3). This character is highly homoplastic. The interocular region usually features two paired macrosetae (except in Voconia motoensis, $V$. decorata sp. nov., $V$. mexicana sp. nov., V. pallidipes, $V$. wegneri comb. nov., and V. bracata sp. nov.). A tuberculate setal base is a synapomorphy for $V$. tridens sp. nov., V. schoutedeni, and $V$. smithae sp. nov. Both medial and paramedial setigerous tubercles are found in the Australian $V$. brachycephala sp. nov., V. fasciata sp. nov., V. grandioculata sp. nov., and V. vittata sp. nov.

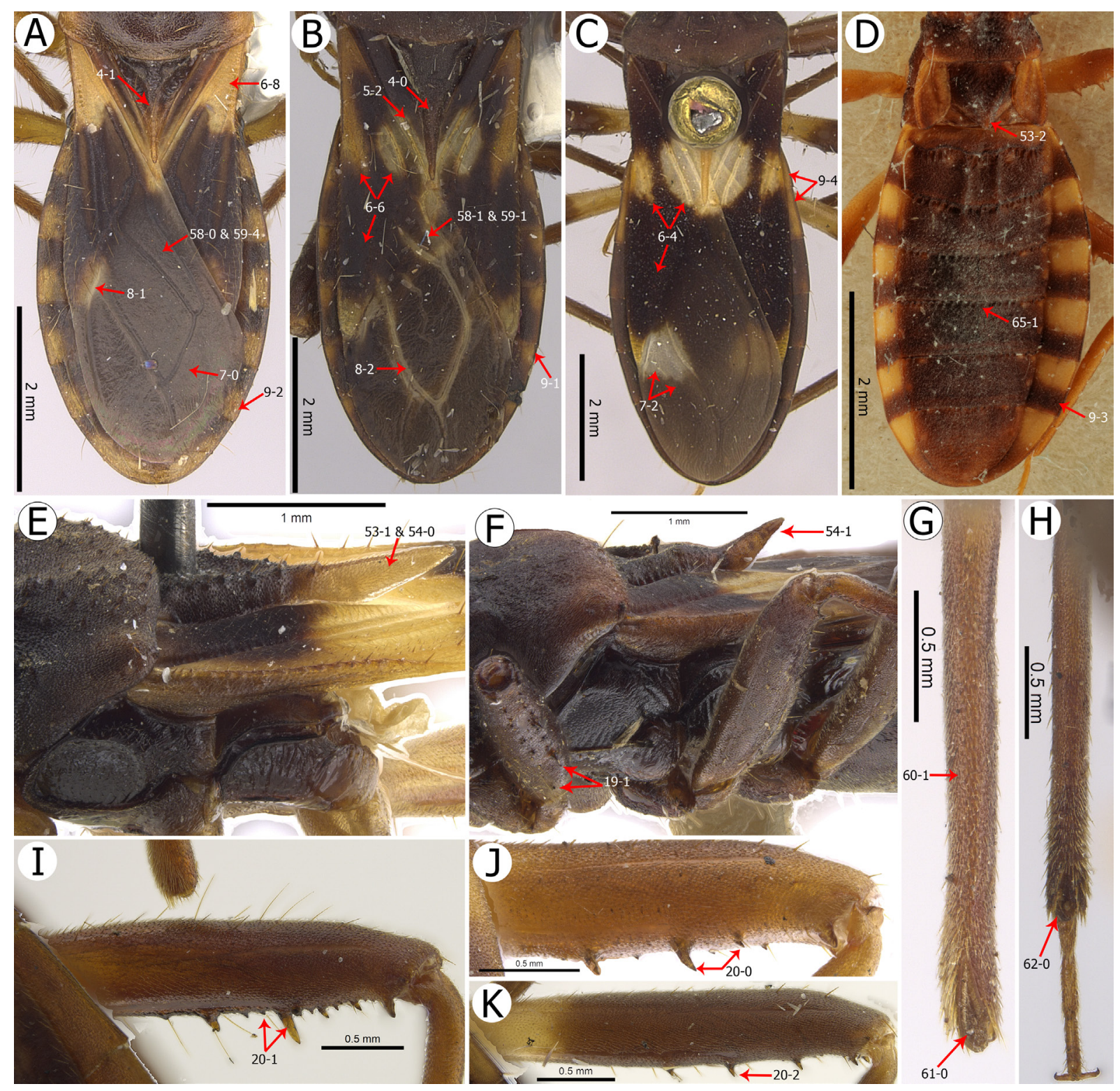

Fig. 4. Morphological characters. A-D. Scutellum and hemelytron, dorsal view. A. Gerbelius typicus Distant, 1903. B. Voconia lirophleps sp. nov. C. Voconia bracata sp. nov. D. Voconia schoutedeni (Villiers, 1964) comb. nov. E. Voconia grandioculata sp. nov., thorax, lateral view. F-H. Voconia nyx sp. nov. F. Thorax, lateral view. G. Fore tibia, ventral view. H. Mid tibia and tarsus, ventral view. I-K. Hind femur, posterior view. I. Voconia mexicana sp. nov. J. Voconia decorata sp. nov. K. Voconia bracata sp. nov. 
14. Head, antennifer, armature basolaterally: without lateral protuberance (Fig. 3A) (0), with short lateral setigerous tubercle (Fig. 3B) (1), with long lateral setigerous tubercle (Fig. 3C) (2), with long lateral spine (Fig. 3D) (3). Species of Gerbelius, V. chrysoptera sp. nov., V. loki sp. nov., and $V$. motoensis comb. nov. have a typical, unarmed antennifer. However, in the remaining species of Voconia the antennifer has either a laterally projecting setigerous tubercle or a long spine. The long spine is a synapomorphy of $V$. tridens sp. nov., $V$. schoutedeni comb. nov., $V$. ifana comb. nov. and $V$. monodi comb. nov. Although $V$. ifana comb. nov. and $V$. monodi comb. nov. were not included in the phylogenetic analysis, the laterally projecting spine on the antennifer is present in descriptions and illustrations (Villers 1963a, 1963b).

15. Head, antennifer, lateral setigerous tubercle quantity: one (Fig. 3B) (0), two (Fig. 3C) (1), three (2). Of those species with a lateral setigerous tubercle on the antennifer, $V$. brachycephala sp. nov., $V$. mexicana sp. nov., and $V$. pallidipes have more than one setigerous tubercle projecting from the antennifer. These tubercles are adjacent to one another.

16. Labium, labial segment I, morphologically ventral surface, vestiture: with sparse, short setation (Figs 3F, 6E) (0), with dense, short setation (1), with sparse, long setation (2), with dense, long setation (Fig. 3G) (3), with sparse setigerous tubercles (4). Dense, long setation on the morphologically ventral surface of the labium is a synapomorphy for Gerbelius. In Voconia the setation is short (Fig. 6E) with varying densities, except in $V$. mexicana sp. nov. where the setation is longer but is sparse, unlike in Gerbelius.

17. Antenna, scape and pedicel, vestiture: with sparse, long macrosetae (0), with dense, short macrosetae (Fig. 3F) (1), with dense, long macrosetae (2). Dense, short macrosetae on the scape and pedicel is a synapomorphy for Pseudocetherinae.

18. Pronotal collar, anterolateral angles, setal base: without macrosetae or setigerous tubercles (Fig. 3K) (0), with macrosetae (Fig. 3H) (1), with setigerous tubercles (Fig. 3L) (2). The anterolateral angles of the pronotal collar in most Pseudocetherinae have macrosetae and are absent in the African clade $(V$. schouteden $i+V$. tridens sp. nov. $)+(V$. smithae sp. nov. $+V$. conradti $))$, V. chrysoptera sp. nov., and the clade including $V$. wegneri, $V$. typica, and $V$. bracata sp. nov. Setigerous tubercles on the anterolateral angles is a synapomorphy of $V$. mexicana sp. nov. and the Australian clade (V. pallidipes and kin).

19. Legs, all femora, armature: unarmed (0), ventral surface with anterior and posterior rows of spinelike protuberances with macrosetae at base of protuberance (Fig. 4F) (1), setigerous tubercles (2). Pseudocetherinae have two rows of spine-like protuberances on the ventral surface of all femora (Fig. 4F) with macrosetae at the base of the protuberance (Fig. 4I).

20. Legs, mid and hind femora, posterior row of spine-like protuberances: with three large spines on distal half and three or fewer small spines (Fig. 4J) (0), with three large spines on distal half and many small spines (Fig. 4I) (1), with four or more large spines on distal half (Fig. 4K) (2). The number of spines on the femur is species-specific, though Pseudocetherinae typically have three large spines on the distal half of the femur with a variable number of small spines interspersed. In several species, namely $V$. bracata $+V$. typica, $V$. dolichocephala $+V$. tuberculata, $V$. grandiocula, and $V$. pallidipes, the distal half of the femur has four or more large spines.

21. Head, shape in dorsal view: globose, about as long as wide (0), elongate, less than 1.5 times as long as wide (Fig. 3D) (1), distinctly elongate, at least 1.5 times as long as wide (2). An elongate head (less than 1.5 times as long as wide) is a homoplastic synapomorphy for Pseudocetherinae. There is intraspecific variation in the head shape of $V$. conradti from globose to elongate. A globose head 
shape is a homoplastic synapomorphy for the clade containing $V$. grandioculata sp. nov., $V$. fasciata sp. nov., $V$. brachycephala sp. nov., and $V$. vittata sp. nov. A distinctly elongate head (at least 1.5 times as long as wide) is a homoplastic synapomorphy for the clade containing $V$. wegneri, $V$. typica, and $V$. bracata sp. nov. as well as the clade containing $V$. tuberculata sp. nov. and $V$. dolichocephala sp. nov.

22. Head, anteocular region, length relative to head: about one quarter of head length ( 0$)$, about one third of head length (1), about half of head length (2), two-fifths of head length (Fig. 3D) (3), less than a fifth of head length (4). The anteocular region is about one third the head length in most pseudocetherines but varies interspecifically. An anteocular region that is about two-fifths of the head length is a non-homoplastic synapomorphy for the clade containing $V$. tridens sp. nov. and V. schoutedeni.

23. Head, anteocular region, length relative to postocular region: shorter than postocular region (0), about as long as postocular region (1), longer than postocular region (Fig. 3D) (2). Anteocular length was recorded to the apex of the clypeus. An anteocular region that is shorter than the postocular region is synapomorphic for Gerbelius, though more sampling may challenge our analyses. An anteocular region that is longer than the postocular region is synapomorphic for $V$. tridens sp. nov. + V. schoutedeni.

24. Head, postocular region, length relative to eye: shorter than eye (0), about as long as eye (1), longer than eye (Fig. 3D) (2). A postocular region that is longer than the eye is synapomorphic for Gerbelius, $V$. tuberculata sp. nov. $+V$. dolichocephala sp. nov., $V$. tridens sp. nov. $+V$. schoutedeni, as well as $V$. wegneri $+(V$. typica $+V$. bracata sp. nov.). In $V$. conradti $+V$. smithae sp. nov. a postocular region that is about as long as the eye is a synapomorphy, and for $V$. lasiosoma sp. nov. $+V$. laosensis sp. nov. and $V$. motoensis $+V$. decorata sp. nov. the postocular region is shorter than the eye.

25. Antenna, scape, length: apex not reaching or slightly surpassing apex of head (Fig. 3B) (0), greatly surpassing apex of head (1). A relatively short scape is a synapomorphy for Pseudocetherinae.

26. Antenna, pedicel, length: $0.5-0.7$ times the length of head width (0), 0.8-1.2 times the length of head width (Fig. 3H) (1), 1.3-1.7 times the length of head width (2), 1.8-2.2 times the length of head width (3). These values were separated as shorter than the width of head, roughly the width of head, longer than the width of head, and those with an unusually extra-long pedicel, namely $V$. chrysoptera sp. nov., $V$. coronata sp. nov., $V$. typica $+V$. bracata sp. nov., and $V$. tuberculata sp. nov. Pedicel length, however, varies interspecifically, with $V$. schoutedeni having the shortest pedicel at about 0.6 times the length of the head width.

27. Mandibular plates, length in dorsal view: short (barely surpassing antennifer apex) (Fig. 3B) (0), long (distinctly surpassing the antennifer apex) (Fig. 3A) (1). Short mandibular plates are the ancestral condition for Pseudocetherinae and are found in Voconia, while long mandibular plates are a synapomorphy for Gerbelius.

28. Mandibular plates, shape in dorsal view: basal halves adjacent (Fig. 3A) (0), not adjacent medially (Fig. 3B) (1). Non-adjacent mandibular plates are the ancestral condition and are found in Voconia, while mandibular plates that join posteromedially is a synapomorphy for Gerbelius.

29. Maxillary plates, shape in dorsal view: not elongate anteriorly $(0)$, elongate anteriorly forming an ellipsoid projection (Fig. 3H) (1), enlarged laterally forming a flattened projection (Fig. 3A) (2). With this revision, elongate, ellipsoid maxillary plates were diagnostic for Pseudocetherinae (Villiers 
1963a). Ellipsoid maxillary plates are diagnostic of Voconia and laterally enlarged maxillary plates are a synapomorphy for Gerbelius.

30. Maxillary plates, apex in dorsal view: directed straight (Fig. 3B) (0), convergent (1), divergent (Fig. 3C) (2). The direction of the maxillary plates converges in $V$. vittata sp. nov. and the clade containing $V$. lirophleps sp. nov., $V$. bakeri sp. nov., and $V$. minima sp. nov. The direction of the maxillary plates varies intraspecifically in $V$. mexicana sp. nov., $V$. ornata, and $V$. dolichocephala sp. nov. being either straight or diverging.

31. Maxillary plates, position in dorsal view: adjacent to clypeus (Fig. 3C) (0), not adjacent to clypeus (Fig. 3D) (1). Maxillary plates are typically adjacent to the clypeus in Pseudocetherinae except in the clade containing $V$. tridens sp. nov. and $V$. schoutedeni.

32. Clypeus, width medially in dorsal view: about as wide as maxillary plates (Fig. 3B) (0), wider than maxillary plates (Fig. 3H) (1), narrower than maxillary plates (Fig. 3D) (2). Clypeus width varies interspecifically with respect to the width of the maxillary plates. It may be more slender as in $V$. schoutedeni $+V$. tridens sp. nov., which are more of an extreme example and have an acuminate clypeus and thick maxillary plates. The width is taken from the midpoint of both structures for consistency.

33. Clypeus, length in dorsal view: surpassing apex of maxillary plates (Fig. $3 \mathrm{H})(0)$, reaching apex of maxillary plates (Fig. 3C) (1), shorter than apex of maxillary plates (Fig. 3B) (2). Clypeus length varies interspecifically but is typically shorter than the ellipsoidal projecting maxillary plates in Voconia. The clypeus surpasses the maxillary plate apex in $V$. brachycephala sp. nov., V. lasiosoma sp. nov., $V$. loki sp. nov., and $V$. wegneri. A clypeal apex that reaches the apex of the maxillary plates is a homoplastic synapomorphy of $V$. bracata sp. nov. and $V$. typica.

34. Clypeus, apex, size in dorsal view: not narrowed (Fig. 3B) (0), narrowed (Fig. 3D) (1). The clypeus narrows in $V$. loki sp. nov. and three Voconia clades (V. bakeri $+V$. minima sp. nov., $V$. nyx sp. nov. $+((V$. tridens sp. nov. $+V$. schoutedeni $)+(V$. smithae sp. nov. $+V$. conradti $)), V$. fasciata sp. nov. + ( $V$. brachycephala sp. nov. $+V$. vittata $\mathrm{sp}$. nov.)).

35. Clypeus, apex, shape: round (Fig. 3D) (0), bifid (Fig. 3C) (1). A bifid clypeus is a non-homoplastic synapomorphy of the Australian Voconia clade containing V. pallidipes and kin.

36. Eyes, width in dorsal view: wider than synthlipsis (0), about as wide as synthlipsis (1), narrower than synthlipsis (Fig. 3B) (2). Reconstructed as eyes narrower than synthlipsis in the most recent common ancestor of Pseudocetherinae with several transitions (Tab. S1).

37. Eyes, position in lateral view: reaching ventral head margin (Fig. 3E) (0), not reaching ventral head margin (Fig. 3G) (1). In Gerbelius, the eye in lateral view does not reach the ventral head margin, while in most species of Voconia the eye reaches the ventral head margin. Exceptions are the African species $V$. motoensis, $V$. smithae sp. nov., and $V$. schoutedeni.

38. Head, transverse interocular sulcus, shape in dorsal view: nearly straight (Fig. 3A) (0), curved and smoothly rounded anteriorly (Fig. 3D) (1), sharp triangular bend anteriorly (Fig. 3H) (2), squarebracket shape with opening anteriorly (e.g., Acanthaspis sp. voucher UCR_ENT 00128937) (3). Our analyses recovered multiple transitions between the different shapes of the transverse sulcus. Within Pseudocetherinae, a nearly straight transverse interocular sulcus is a synapomorphy for $V$. lasiosoma sp. nov. $+V$. laosensis sp. nov. It was also reconstructed for the most recent common ancestor of the Australian clade, though the sulcus in $V$. brachycephala sp. nov. is rounded and 
triangular in $V$. vittata sp. nov. A triangular sulcus is a synapomorphy for $V$. typica $+V$. bracata sp. nov., $V$. motoensis $+V$. decorata sp. nov., as well as for $V$. coronata sp. nov. $+V$. lirophleps sp. nov.

39. Head, interocular glabrous markings, shape: single medial line (0), two parallel lines joined paramedially at interocular sulcus (1), two parallel lines, anterolaterally curved, joined paramedially at interocular sulcus (Fig. 3H) (2), V-shaped, joined medially at interocular sulcus (3). Pseudocetherinae have two longitudinal glabrous lines in the interocular region of the head. In most Voconia the two lines are parallel and curve anterolaterally. In Gerbelius, $V$. tridens sp. nov. $+V$. schoutedeni, $V$. typica $+V$. bracata sp. nov., and $V$. dolichochephala sp. nov. $+V$. tuberculata sp. nov., the glabrous lines are perpendicular and meet at the interocular sulcus.

40. Head, postocular region, shape in dorsal view: gently rounded (Fig. 3B) (0), subrectangular (Fig. 3D) (1). The postocular region of most pseudocetherines is gently rounded, except for in the African clade $((V$. tridens sp. nov. $+V$. schoutedeni $)+(V$. smithae sp. nov. $+V$. conradti $))$, where it is subrectangularly rounded.

41. Buccula, shape: flat (0), with ventrolateral swelling (Fig. 3G) (1), with ventral spine (2). In Pseudocetherinae the buccula is slightly swollen ventrolaterally.

42. Buccula, anterolateral swelling, shape in lateral view: flat buccular margin (Fig. 3G) (0), with protrusion surpassing buccular margin (1). The swelling of the buccula is either flat apically or has a protruding bump that overlaps with the labium in lateral view. This protrusion may be a small, rounded bump as in $V$. decorata sp. nov. In $V$. tridens sp. nov. and $V$. schoutedeni this protrusion is large and spine-like with small setigerous tubercles along the margin. In $V$. chrysoptera sp. nov., $V$. fasciata sp. nov., $V$. grandioculata sp. nov., $V$. mexicana sp. nov., and $V$. ornata the protrusion is rounded with setigerous tubercles along the apical margin. $V$. pallidipes has large protruding setigerous tubercles.

43. Labium, width: gracile (Fig. 3F) (0), stout (Fig. 3G) (1). A gracile labium was considered diagnostic for Pseudocetherinae (Villiers 1963a). Under the new classification that defines the subfamily more broadly, a gracile labium is a synapomorphy for Voconia and a stout labium is diagnostic for Gerbelius.

44. Labium, labial segment I, length in lateral view: not reaching posteroventral eye margin (0), reaching posteroventral eye margin (1), surpassing posteroventral eye margin (Fig. 3E) (2). The length of labial segment I varies interspecifically, but it is always the longest labial segment in Pseudocetherinae.

45. Labium, labial segment I, shape in lateral view: straight (Fig. 3F) (0), swollen subapically on morphologically ventral surface (Fig. 3E) (1), gradually widened apically (Fig. 3G) (2). Labial segment I is typically straight in Voconia. In $V$. grandioculata sp. nov., $V$. fasciata sp. nov., $V$. brachycephala sp. nov., and species of Gerbelius the labium gradually widens apically. In $V$. wegneri the morphologically ventral surface is swollen subapically.

46. Labium, morphologically dorsal surface of labial segment II, length relative to segment I: 0.2 times the length of segment I (0), 0.3 times the length of segment I (Fig. 3F) (1), 0.4 times the length of segment I (2), 0.5 times the length of segment I (3), 0.6 times the length of segment I (4), 0.7 times the length of segment I (5), 0.8 times the length of segment I (6), 0.9 times the length of segment I (7), longer than segment I (8). The length of segment I was recorded from the proximal and distal midpoints, while the length of segment II reported here is recorded from the 
morphologically dorsal surface. Measurements were rounded up for values with 0.05 and up. The morphologically ventral surface of segment II is shorter and reported in Supp. file 1. The length of the morphologically dorsal surface of segment II varies interspecifically. However, the length of segment II among members of Gerbelius ranges from 0.8-0.9 times the length of segment I and ranges between $0.2-0.7$ times the length of segment I in Voconia, with $V$. wegneri having the largest disparity between both segments ( 0.2 times the length of segment $\mathrm{I})$ and $V$. motoensis having the smallest disparity between both segments ( 0.7 times the length of segment I).

47. Labium, labial segment II, shape in lateral view: nearly straight (0), swollen ventrobasally, narrowed apically (Fig. 3E) (1), morphologically dorsal surface convex (Fig. 3F) (2). While most Voconia possess a nearly straight labial segment II, the ventrobasal swelling of segment II is uniquely diagnostic for $V$. wegneri. The morphologically dorsal surface of segment II is convex in $V$. wegneri, the Australian clade containing V. pallidipes and kin, and Gerbelius.

48. Labium, labial segment III, shape: gradually narrowing, straight (0), drawn into a bent, slender apex (Fig. 3E-G) (1). Labial segment III is drawn into a bent, slender apex in all Pseudocetherinae, even in $V$. wegneri which has an unusually short labial segment III.

49. Pronotal collar, length medially in dorsal view: narrow (Fig. 3K) (0), wide (Fig. 3L) (1). Most pseudocetherines have a narrow pronotal collar, with the exception of $V$. motoensis, $V$. decorata sp. nov., $V$. coronata sp. nov., V. tuberculata sp. nov., V. dolichocephala sp. nov., V. fasciata sp. nov., and $V$. vittata sp. nov., which have a wide pronotal collar.

50. Pronotal collar, anterolateral angles, shape: projecting forward (Fig. 3H) (0), flared laterally (Fig. 3D) (1), without projection (2). The anterolateral angles of the pronotal collar in Pseudocetherinae generally project forward, but the shape varies interspecifically. Laterally flared anterolateral angles are most prominently expressed in the clade containing $V$. tridens sp. nov. and $V$. schoutedeni sp. nov.

51. Pronotum, median apodeme depression, depth: shallow (Fig. 3L) (0), deep (Fig. 3K) (1). The depth of the pronotal apodeme depression varies. A shallow apodeme depression is a synapomorphy for part of the Australian clade ( $V$. tuberculata sp. nov. $+V$. dolichocephala sp. nov. $)+$ (V. grandioculata sp. nov. $+(V$. fasciata sp. nov. $+V$. brachycephala sp. nov. $+V$. vittata sp. nov. $))$ ). A shallow apodeme is also present in $V$. tridens sp. nov. $+V$. schoutedeni, $V$. decorata sp. nov., and $V$. isosceles sp. nov. A deep apodeme depression is a synapomorphy for $V$. conradti $+V$. smithae sp. nov. as well as $V$. wegneri $+(V$. typica $+V$. bracata sp. nov.).

52. Pronotum, median apodeme depression, shape: circular (Fig. 3K) (0), elongated longitudinally (Fig. 3H) (1), elongated transversely (Fig. 3L) (2). A circular pronotal apodeme depression is present in $V$. ornata, $V$. mexicana sp. nov., and the African species $V$. motoensis, $V$. conradti, and $V$. smithae sp. nov. Longitudinally and transversely elongated apodemes are more common and vary intraspecifically.

53. Scutellum, apical spine, length: short (e.g., Microlestria sp.) (0), long (Fig. 4E) (1), reduced (Fig. 4D) (2). All macropterous morphs in Pseudocetherinae have a long scutellar spine, while micropterous individuals, such as those of $V$. schoutedeni sp. nov., have a reduced scutellar spine.

54. Scutellum, apical spine, orientation in lateral view: subhorizontal (Fig. 4E) (0), raised (Fig. 4F) (1). The orientation of the scutellar spine varies interspecifically, and intraspecifically in V. mexicana sp. nov. where the female has a raised scutellar spine but the scutellar spine is subhorizontal in the males. 
55. Prosternum, shape in lateral view: drawn into anteriad-directed process (Figs 3F, I, 6D) (0), smoothly rounded (1). A prosternum that is drawn into an anteriad-directed process is a synapomorphy for Pseudocetherinae, corroborating previous hypotheses (Weirauch 2008; Weirauch et al. 2014).

56. Prosternum, anteriad-directed process, shape in anterolateral view: smoothly rounded, without paramedial lobes (Fig. 3J) (0), with paramedial lobes (Fig. 3I) (1). The Gerbelius clade, V. bakeri sp. nov., the African clade ((V. conradti $+V$. smithae sp. nov. $)+(V$. tridens sp. nov. $+V$. schoutedeni $))$, and the clade containing $V$. mexicana sp. nov. and Australian kin have protrusions on the prosternum that project past the margins of the stridulitrum.

57. Stridulitrum, anterior margin, shape: not elongated into protuberance (Fig. $3 \mathrm{~J})(0)$, projected into sharp spine (1), projected into small protuberance (Fig. 3I) (2). The stridulitrum of most Voconia is not elongated into a protuberance. In Gerbelius, V. grandioculata sp. nov., and V. fasciata sp. nov. the stridulitrum projects anteriorly into a sharp spine. The remaining Australian species in the clade with $V$. chrysoptera sp. nov. and $V$. mexicana sp. nov., along with $V$. lasiosoma sp. nov. and $V$. bakeri sp. nov., have a stridulitrum that protrudes into a small protuberance.

58. Hemelytron, $\mathbf{C u}-\mathrm{An}_{1}$ cell, relative length: similar length as $\mathrm{M}-\mathrm{Cu}$ cell (Fig. 4A) (0), shorter than $\mathrm{M}-\mathrm{Cu}$ cell (Fig. 4B) (1), absent (2). The $\mathrm{Cu}-\mathrm{An}_{1}$ cell is similar in length to the $\mathrm{M}-\mathrm{Cu}$ cell in Gerbelius. A short $\mathrm{Cu}-\mathrm{An}_{1}$ cell is a synapomorphy for Voconia.

59. Hemelytron, Cu-An 1 cell, shape: ovate (0), triangular (Fig. 4B) (1), square (2), wedge-shaped (3), slender and tapered apically (Fig. 4A) (4). A triangular $\mathrm{Cu}-\mathrm{An}_{1}$ cell is a synapomorphy for Voconia and a slender, apically tapered $\mathrm{Cu}-\mathrm{An}_{1}$ cell is a synapomorphy for Gerbelius.

60. Legs, tibiae in cross section: ovate (0), laterally compressed (Fig. 4G-H) (1). Laterally compressed tibiae are a synapomorphy for Pseudocetherinae.

61. Fore leg, fossula spongiosa (male): present (Fig. 4G) (0), absent or vestigial (1). A fossula spongiosa is present on the fore legs of all pseudocetherine males.

62. Mid leg, fossula spongiosa (male): present (Fig. 4H) (0), absent or vestigial (1). A fossula spongiosa is present on the mid legs of most pseudocetherine males, except that it is absent or vestigial in V. motoensis.

63. Fore leg, fossula spongiosa (female): present (0), absent or vestigial (1). Due to the scarcity of females, there is a lot of missing data for females, but the fossula spongiosa may be present on the fore legs of all pseudocetherine females.

64. Mid leg, fossula spongiosa (female): present (0), absent or vestigial (1). Due to the scarcity of females, there is a lot of missing data for females, but it appears that the fossula spongiosa is absent on the mid legs of pseudocetherine females, except in V. chrysoptera sp. nov. where it is present.

65. Dorsal abdominal glands: present (0), absent (Fig. 4D) (1). Dorsal abdominal glands are absent in Pseudocetherinae, corroborating previous hypotheses (Weirauch 2008; Weirauch et al. 2014).

66. Pygophore, transverse bridge, posterior margin shape: round (Fig. 13; V.tuberculata sp. nov.) (0), triangular (Fig. 13; V. tridens sp. nov.) (1). The posterior margin of the transverse bridge is round in most of the observed Pseudocetherinae, and triangular in V. nyx sp. nov., and the African species $V$. tridens sp. nov. and $V$. conradti. 
67. Pygophore, posterior region of ventral surface, shape in lateral view: without swelling (Fig. 12; V. laosensis sp. nov.) (0), with slight swelling (Fig. 11; V. conradti) (1), with large swelling (Fig. 12; $V$. mexicana sp. nov.) (2). The swelling of the pygophore apex varies interspecifically.

68. Pygophore, median apical process, shape in caudal view: short spine (Fig. 13; V. pallidipes) (0), long spine (Fig. 15; Nalata nr. spinicollis) (1), short and wide (Fig. 15; Velitra rubropicta) (2). A short median apical process on the the pygophore is a synapomorphy for Pseudocetherinae.

69. Pygophore, median apical process, direction in lateral view: upright (Fig. 12; V. laosensis sp. nov.) (0), sharply bent posteriorly (Fig. 13; V. pallidipes) (1). Gerbelius sp. 2, V. lasiosoma sp. nov., and $V$. laosensis sp. nov. have an upright median apical process. A posteriorly bent median apical process appears to be a putative synapomorphy for most Voconia except $V$. lasiosoma sp. nov. and $V$. laosensis sp. nov., where it is upright.

70. Dorsal pygophore margin, shape in lateral view: flat (Fig. 11; Gerbelius sp. 2) (0), with protuberance (Fig. 11; V. conradti) (1). In Voconia, the pygophore margin posterior to the paramere socket is raised into a round protuberance.

71. Posterior pygophore margin, position of macrosetae in caudal view: on flat margin (Fig. 12; V. mexicana sp. nov.) (0), on protuberance (Fig. 11; Gerbelius sp. 2) (1), on decline (Fig. 15; Acanthaspis sp.) (2). Adjacent to the median apical process are clusters of macrosetae. Some are on a protuberance (e.g., Gerbelius sp. 2), a decline (e.g., Nalata nr. spinicollis), or this posterior margin may be flat (e.g., V. mexicana sp. nov.). With the amount of missing data, it appears that the shape of the posterior pygophore might vary interspecifically.

72. Paramere, shape in dorsal view: sinusoidal (Fig. 13; V.pallidipes) (0), round (Fig. 13; V. tridens) (1), hook-shaped (Fig. 15; Acanthaspis sp.) (2), sharp bend basally (Fig. 15; Nalata nr. spinicollis) (3), round with medial protuberance (4). The parameres of Pseudocetherinae are sinusoidal (Fig. 6G), except for $V$. tridens sp. nov., in which they are gently rounded.

73. Paramere apex, shape: tapered sharply (Fig. 13; V. tuberculata sp. nov.) (0), tapered into squarely rounded tip (Fig. 11; G. typicus) (1), expanded (Fig. 15; Acanthaspis sp.) (2), round, not sharply tapered or expanded (3). Most Pseudocetherinae have a squarely rounded paramere apex. $V$. pallidipes and $V$. tuberculata sp. nov. have sharply tapered apices, and the paramere apex of $V$. grandioculata sp. nov. does not taper, it is rounded.

74. Endosoma, armature in lateral view: without spicules (0), partially covered with spicules (1), almost entirely covered with spicules (Fig. 14; V. typica) (2). The endosoma of all Pseudocetherinae is largely covered with spicules.

75. Dorsal phallothecal sclerites, apex, shape in dorsal view: round (Fig. $14 ; V$. mexicana sp. nov.) (0), tongue-shaped (Fig. 14; V. lasiosoma sp. nov.) (1), bifid (Fig. 14; V. typica) (2), serrated (Fig. 14; V. tuberculata sp. nov.) (3), absent or reduced (Fig. 16; Microlestria sp.) (4). Despite the amount of missing data, it appears that the shape of the dorsal phallothecal sclerite apex might vary interspecifically.

76. Basal plate extension, length in relation to phallotheca: short (0), long (Fig. 14; V. mexicana sp. nov.) (1). A long basal plate extension is a homoplastic synapomorphy of Pseudocetherinae. 
77. Basal plate extension, length: 1.5-3.9 times as long as wide (0), 4.0-5.4 times as long as wide (Fig. 14; V. mexicana sp. nov.) (1), 5.5-6.4 times as long as wide (2), 6.5-8.0 times as long as wide (3), as long as 8.5 times the width (4). Width is recorded from the midpoint. The range for the length to width ratio of the basal plate extension within Pseudocetherinae is between 4.4 and 5.8, with $V$.typica as the exception having a ratio of 7.9. A basal plate extension that is 4.0-5.4 times as long as wide is a synapomorphy of G. typicus + Gerbelius sp. 2 as well as $V$. lasiosoma sp. nov. + $V$. laosensis sp. nov. A basal plate extension that is 5.5-6.4 times as long as wide is a synapomorphy of the Australian clade containing $V$. pallidipes and kin.

\title{
Taxonomy
}

\author{
Class Insecta Linnaeus, 1758 \\ Order Hemiptera Linnaeus, 1758 \\ Suborder Heteroptera Latreille, 1810 \\ Infraorder Cimicomorpha Leston, Pendergrast \& Southwood, 1954 \\ Family Reduviidae Latreille, 1807
}

Subfamily Pseudocetherinae Villiers, 1963

Pseudocetherinae Villiers, 1963b: 531. Type genus: Pseudocethera Villiers, 1963 (=Voconia Stål, 1866). Reduviinae Latreille, 1807: 126-127 (in part, new concept).

\section{Diagnosis}

Distinguished from other Reduviidae by the combination of the following characters: head and pronotum pubescent with interspersed macrosetae or setigerous tubercles; labial segment II straight, as long as remaining segments, and adpressed to head (Fig. 3E-F); apex of the third visible labial segment bent and slender; antennal insertion near eye, medially in lateral view (Fig. 3E-F); pedicel longer than scape; prosternum drawn into an anteriad-directed process (Fig. 6); absence of dorsal abdominal glands on terga IV-VI; ventral surface of all femora with anterior and posterior rows of spine-like protuberances with macrosetae at base of protuberance (Fig. 4F, I); males with fossula spongiosa on fore and mid legs (except in $V$. motoensis sp. nov. where the the fossula spongiosa is absent on the midleg) (Fig. 4G-H); females with fossula spongiosa on fore leg, but fossula spongiosa usually absent or vestigial on mid leg; tibiae laterally compressed (Fig. 4H); three-segmented tarsi (Fig. 4H).

\section{Redescription}

Usually macropterous, only micropterous morphs are known in three species and one species includes both micropterous and macropterous morphs.

BODY LENGTH. 6.7-12.4 mm.

Body. Either robust (Fig. 8, e.g., V. motoensis sp. nov.) or slender (Fig. 8, e.g., V. minima sp. nov.) with variable color patterns.

HEAD. Elongate or globose; pubescent with interspersed macrosetae or setigerous tubercles; interocular region with two glabrous lines; scape and pedicel with dense, short macrosetae; scape reaching or slightly surpassing head apex, $0.2-0.3$ times length of pedicel; ocelli present in macropterous morphs and minute or absent in micropterous morphs; buccula with ventrolateral swelling; labial segment III drawn into bent, slender apex.

Thorax. Prosternum in lateral view drawn into anteriad-directed process; scutellar spine long, either sub-horizontal or raised. 
Hemelytron. In macropterous individuals, $\mathrm{Cu}-\mathrm{An}_{1}$ cell triangular, shorter than $\mathrm{M}-\mathrm{Cu}$ cell (Fig. 4B) or $\mathrm{Cu}-\mathrm{An}_{1}$ cell similar in length to M-Cu cell, slender and tapered apically (Fig. 4A).

Legs. Fossula spongiosa present on fore tibia, usually present on mid tibia of males; all femora with ventral anterior and posterior rows of spine-like protuberances with macrosetae at base of protuberance (Fig. 4I); tibiae laterally compressed (Fig. 4G-H).

Aвdomen. Posterolateral margin of dorsal laterotergites with (Fig. 5, e.g., Gerbelius sp. 2) or without single macroseta; anterior margin of terga carinulate; dorsal abdominal glands absent.

\section{Male}

Pygophore. Posterior margin with a short median apical process, either straight or bent posteriorly.

PARAMERES. Sinusoidal or rounded.

Aedeagus. Basal plate extension long in relation to phallotheca; endosoma covered in spicules.

\section{Habitat and collecting method}

Pseudocetherinae have been collected using light traps, but records on habitat and collecting methods are scarce on specimen labels.

\section{Distribution (Figs 17-20)}

Pseudocetherinae are widespread, with species distributed in the Afrotropical, Neotropical, Oriental, and Australasian regions. The highest diversity occurs in Southeast Asia (Fig. 20) and the lowest in the Neotropics (Fig. 19).

\section{Key to the genera of Pseudocetherinae}

1. $\mathrm{Cu}-\mathrm{An}_{1}$ cell of hemelytron of macropterous individuals similar in length to $\mathrm{M}-\mathrm{Cu}$ cell, slender and tapering apically (Fig. 4A). Maxillary plates enlarged laterally in dorsal view (Fig. 3A). Labium stout, morphologically ventral surface of labial segment I with dense, long macrosetae (Fig. 3G) Gerbelius Distant, 1903

- $\mathrm{Cu}-\mathrm{An}_{1}$ cell of hemelytron of macropterous individuals shorter than $\mathrm{M}-\mathrm{Cu}$ cell, triangular (Figs 4B, 6C). Maxillary plates forming ellipsoid projections in dorsal view (Figs 3B, 6B). Labium gracile, morphologically ventral surface of labial segment I with short macrosetae or few long macrosetae (Figs 3E-F, 6E) Voconia Stål, 1866

Genus Gerbelius Distant, 1903

Figs 1, 2, 3A, G, 4A, 5, 11, 14, 20

Gerbelius Distant, 1903a: 59. Type species: Gerbelius typicus Distant, 1903, by original designation.

\section{Revised diagnosis}

Distinguished from the other genus in the subfamily, Voconia, by the smooth or corrugated surface of the head and pronotum (Fig. 3G); laterally flattened shape of the maxillary plates (Fig. 3A); long, basally adjacent mandibular plates (Fig. 3A); stout labium densely covered with long macrosetae on the morphologically ventral surface of labial segment I (Fig. 3G); morphologically dorsal surface of labial segment II 0.8-0.9 times length of labial segment I (Fig. 3G); and $\mathrm{Cu}-\mathrm{An}_{1}$ cell slender and tapering apically, similar in size to the M-Cu cell (Fig. 4A). 


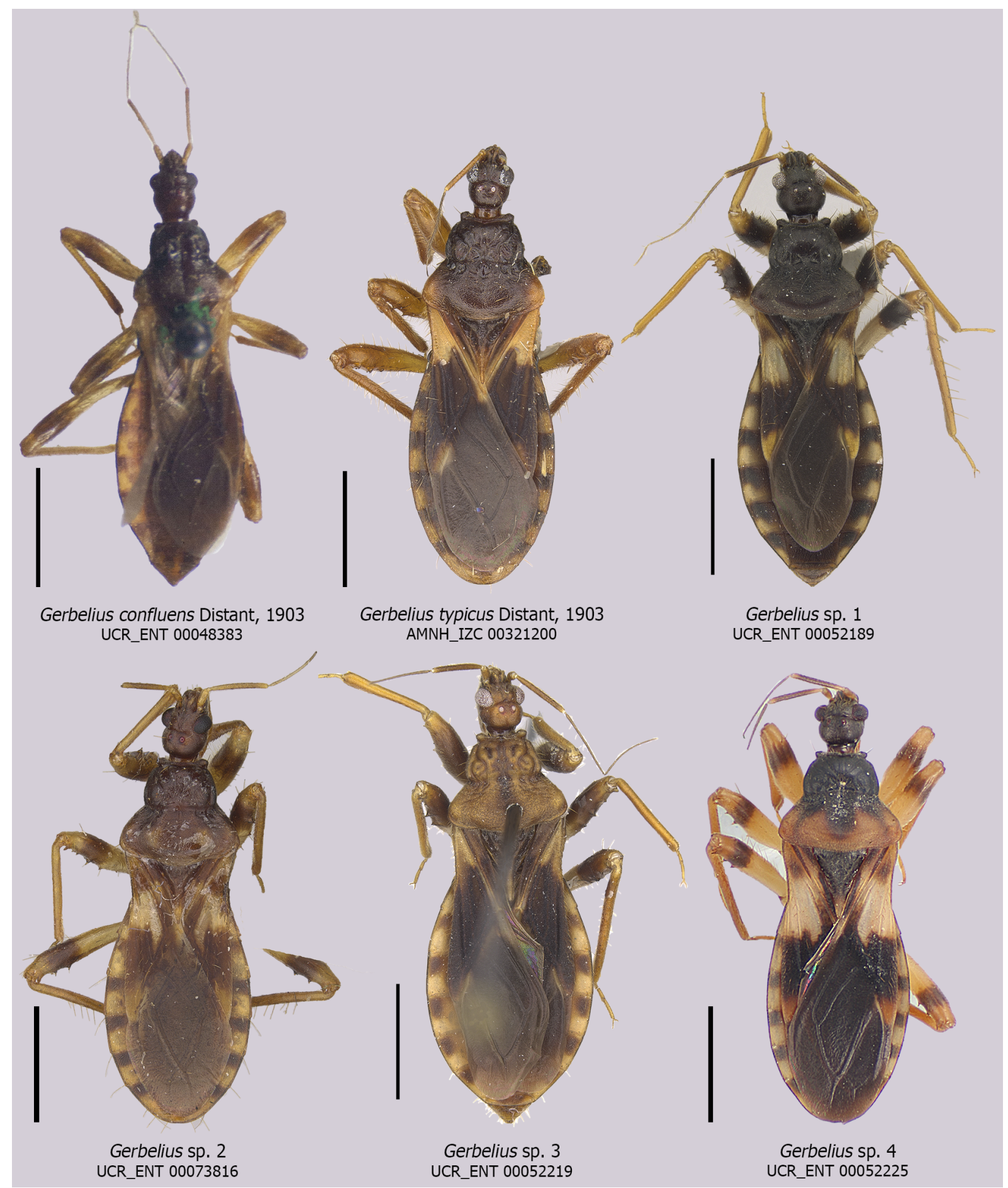

Fig. 5. Dorsal habitus of species of Gerbelius Distant, 1903. Scale bars $=2 \mathrm{~mm}$. 


\section{Redescription}

Body LeNGTH. 7.0-8.0 mm.

BoDy. Robust; only macropterous morphs known (Fig. 5).

COLORATION. Variable color patterns; scutellum uniform or with contrasting yellow scutellar spine.

INTEGUMENT AND VESTITURE. Head and pronotum: smooth to corrugated with dense pubescence and sparse, long macrosetae; antennifer with macroseta, without lateral protuberance (Fig. 3A); labium with dense, long macrosetae. Thorax: anterolateral angles of pronotal collar with macrosetae. Hemelytron: corium with dense setation. Legs: posterior row of protuberances on mid and hind femora with three large spines on distal half and three or fewer small spines. Abdomen: ventral surface pubescent with long macrosetae.

HeAD (Fig. 3A, G). Elongate, 1.2-1.3 times as long as wide; anteocular region about a third of head length and shorter than postocular region (measured to anterior margin of neck); postocular region in dorsal view globose and longer than eye; pedicel 1.1-1.3 times length of head width; mandibular plates in dorsal view long with basal half adjacent; maxillary plates in dorsal view enlarged laterally forming flattened projections, adjacent to clypeus; clypeus width in dorsal view narrower than maxillary plates; interocular glabrous markings V-shaped, joined medially at interocular sulcus; eye width in dorsal view narrower than synthlipsis, eye not reaching ventral head margin in lateral view; ventrolateral swelling of buccula without lateral protrusion that surpasses buccular margin, flat margin; labium stout; second (first visible) labial segment in lateral view surpassing posteroventral eye margin, gradually widened apically; dorsal surface of third (second visible) labial segment convex, 0.8-0.9 times length of second segment; fourth (third visible) labial segment drawn into bent, slender apex.

Thorax. Pronotal collar narrow medially with anterolateral angles short and flared laterally; anterior pronotal lobe lateral margins rounded; scutellum width 0.8 times length; scutellar spine subhorizontal; anteriad-directed process on prosternum with paramedial lobes; anterior margin of stridulitrum projected into sharp spine; proepimeron with obtuse protuberance on posteroventral margin.

Hemelytron (Fig. 4A). $\mathrm{Cu}-\mathrm{An}_{1}$ cell similar in size to $\mathrm{M}-\mathrm{Cu}$ cell; $\mathrm{Cu}-\mathrm{An}_{1}$ cell slender, tapered apically.

LeGs. Fossula spongiosa present on fore and mid legs in males, present on fore but absent or vestigial on mid legs of females.

AвDomen. Anterior margin of terga weakly carinulate; terga II and III with paired, prominent, and longitudinal carinae, almost reaching posterior margin of tergum III.

Pygophore (Fig. 11). Transverse bridge rounded on posterior margin; lateral pygophore margin flat; paramere shape in dorsal view sinusoidal, apex tapered into squarely round tip.

Aedeagus (Fig. 15). Endosoma almost entirely covered with spicules; apex of dorsal phallothecal sclerite rounded in dorsal view; basal plate extension 4.4-4.8 times as long as wide.

\section{Distribution}

This genus currently comprises two described species from India and Southeast Asia, and we are aware of at least four undescribed species distributed across India, Laos, Thailand, and Vietnam. Gerbelius typicus is the most widespread among them. 


\section{Remarks}

Photographs of type specimens in their unit trays at the BMNH were used to evaluate species concepts for G. typicus and G. confluens. This genus previously had a third described species that is now transferred to Voconia, V. ornata. Molecular phylogenetics recovered a Gerbelius clade (Gerbelius sp. $3+[$ Gerbelius sp. $1+$ Gerbelius sp. 4]) sister to Voconia wegneri sp. nov. (Hwang \& Weirauch, 2012). We also recovered a well-supported Gerbelius clade sister to Voconia (Figs 1-2). The pygophore of two specimens were dissected for this study (Figs 11, 14); however, the median apical process of G. typicus (AMNH_IZC 00321200) broke off during dissection (Fig. 11). We decided not to describe new species of Gerbelius as part of this study. Since species of Gerbelius somewhat resemble other small-bodied assassin bugs currently classified as Reduviinae, we suspect that our specimen searches in various natural history collections were not comprehensive for this genus. However, this material should be included in a future revision of this genus.

\section{Gerbelius confluens Distant, 1903}

Gerbelius confluens Distant, 1903b: 260, pl. 16 fig. 6, 6a.

\section{Type material}

Lectotype (present designation)

MALAYSIA ["SIAMESE MALAY STATES"] • $\%$; Terengganu, Bukit Besar; 1903; Annandale and Robinson leg.; USI: UCR_ENT 00048383; BMNH(E) 1255221.

\section{Gerbelius typicus Distant, 1903}

Gerbelius typicus Distant, 1903a: 59

Gerbelius typicus - Distant 1904: fig. 175.

\section{Type material}

Lectotype (present designation)

MYANMAR [“BIRMANIA”] • $q$; Bhamo; Aug. 1885; L. Fea leg.; Distant coll. 1911-383; USI: UCR_ ENT 00048382; BMNH(E) 1255220.

\section{Paralectotype}

MYANMAR • 1 \%; “Palon (Pegu)" [Palon]; Aug.-Sep. "87” [1887]; L. Fea leg.; Distant coll. 1911-383; BMNH.

\section{Additional material examined}

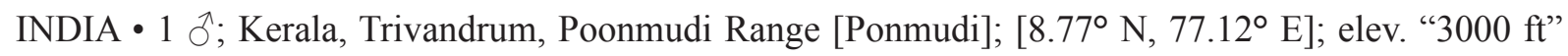
[914 m]; Sep. 1971; T.R.S. Nathan leg.; dissected genitalia in vial; USI: AMNH_IZC 00321200.

\section{Gerbelius sp. 1}

\section{Material examined}

LAOS • 1 क; Vientiane Prov., Houayang Nat. Park; $18.09815^{\circ}$ N, $102.67535^{\circ}$ E; elev. 180 m; 19-20 Jun. 2008; A. Solodovnikov and J. Pedersen leg.; collecting event: LAO08-2G; mostly secondary rainforest; DNA voucher specimen R_CW 0705; USI: UCR_ENT 00052189; UCR. 
THAILAND • 1 क; Chaiyaphum, Pa Hin Ngam; $15.63553^{\circ}$ N, $101.3987^{\circ}$ E; elev. 698 m; 11-18 Aug. 2006; Katae Sa-nog and Buakaw Adnafai leg.; collecting event: T444; ecotone between mix deciduous/ dry dipterocarp; DNA voucher specimen R_CW 1185; USI: UCR_ENT 00002541; UCR.

\section{Gerbelius sp. 2}

\section{Material examined}

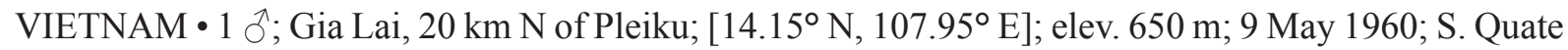
leg.; dissected genitalia in vial; USI: UCR_ENT 00073816; BPBM.

\section{Gerbelius sp. 3}

\section{Material examined}

LAOS • 1 O; Vientiane Prov., Phou Khao Khouay; $18.33948^{\circ}$ N, $102.80871^{\circ}$ E; elev. 750 m; 26-31 May 2008; A. Solodovnikov and J. Pedersen leg.; collecting event: LAO08-7b; DNA voucher specimen R_CW 0704; USI: UCR_ENT 00052219; UCR.

\section{Gerbelius sp. 4}

\section{Material examined}

THAILAND - 1 o; Phetchabun Prov., Nam Nao National Park; $16.728217^{\circ} \mathrm{N}, 101.563933^{\circ}$ E; elev. 917 m; 6-13 Nov. 2006; Leng Janteab leg.; collecting event: T1018; malaise trap; DNA voucher specimen R_CW 0552; USI: UCR_ENT 00052225; UCR.

Genus Voconia Stål, 1866

Figs 1-4, 6-14, 17-20

Voconia Stål, 1866a: 120. Type species: Voconia pallidipes Stål, 1866, by subsequent monotypy (Stål 1866b: 165). Gender feminine.

Microvarus Jeannel, 1917: 50. Type species: Microvarus conradti Jeannel, 1917, by original designation. syn. nov.

Kayanocoris Miller, 1954: 5. Type species: Kayanocoris wegneri Miller, 1954, by original designation. syn. nov.

Paragerbelius Miller, 1958: 66. Type species: Paragerbelius typicus Miller, 1958, by original designation. syn. nov.

Pseudocethera Villiers, 1963b: 532. Type species: Pseudocethera monodi Villiers, 1963, by original designation. syn. nov.

\section{Diagnosis}

Distinguished from the other genus in the subfamily, Gerbelius, by the granulose integument of the head and pronotum (Fig. 6A, D), ellipsoid shape of the maxillary plates (Fig. 6B, blue), short non-adjacent mandibular plates (Fig. 6B, green), gracile labium with short macrosetae on the morphologically ventral surface of labial segment I (Fig. 6E), and the $\mathrm{Cu}-\mathrm{An}_{1}$ cell of the fore wing shorter than the M-Cu cell and triangular (Fig. 6C).

\section{Redescription}

Body LENGTH. 6.7-12.4 mm.

BoDy. Slender or robust; macropterous or micropterous (Figs 7-10). 


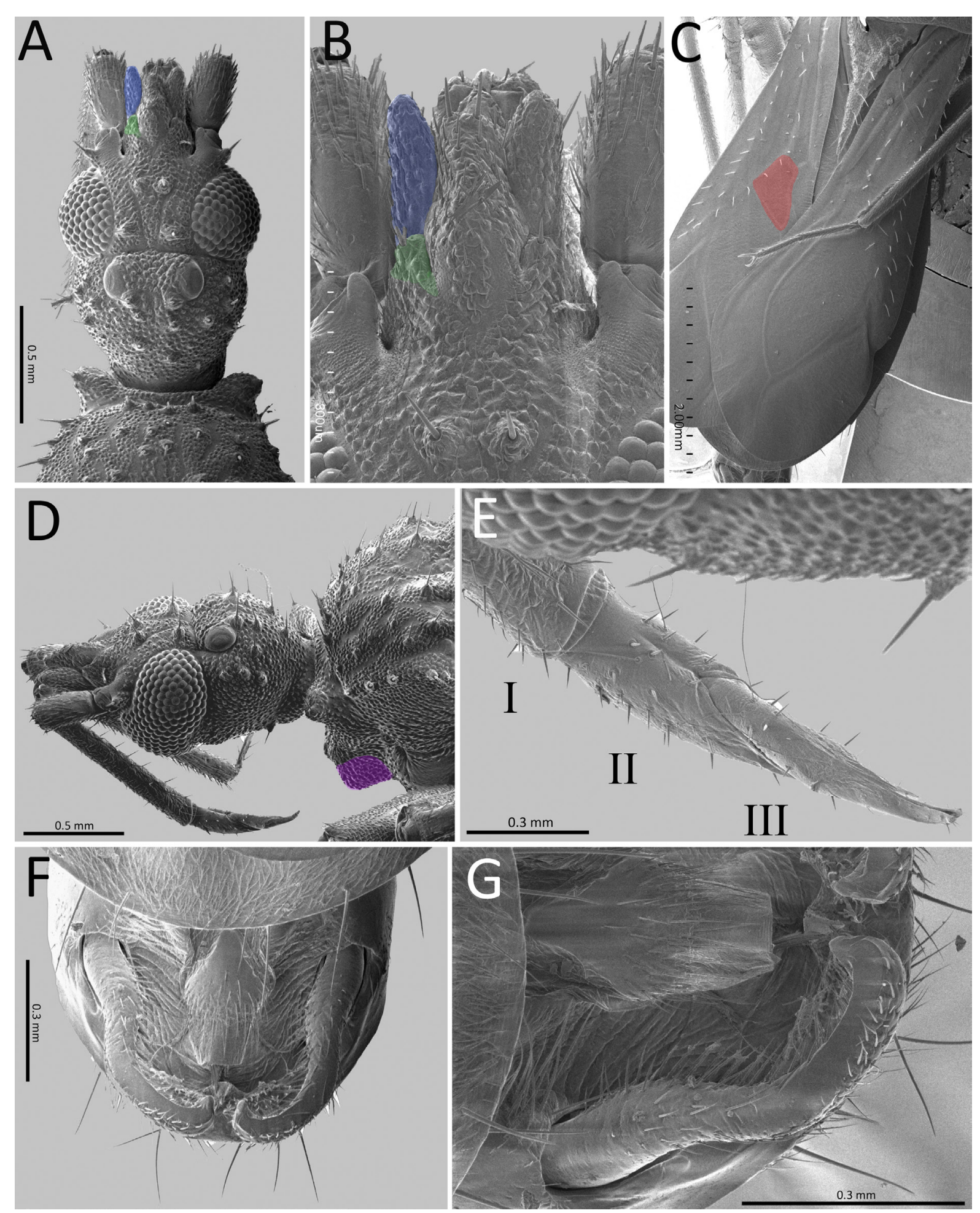

Fig. 6. Diagnostic characters of Voconia Stål, 1866 shown on Voconia dolichocephala sp. nov. (AMNH_PBI 00168745). A-B. Head, dorsal view; maxillary plates $=$ blue, mandibular plates $=$ green. C. Hemelytra, $\mathrm{Cu}-\mathrm{An}_{1}$ cell = red. D. Head and thorax, lateral view; anteriad directed process = purple; E. Labium. F. Pygophore, dorsal view. G. Paramere. 
COLORATION. Thorax: scutellum uniform or with contrasting yellow scutellar spine. Hemelytron (abducted): corium with various combinations of yellow spots on the proximal, anteromedial, posteromedial, and distal areas, with medial yellow stripe, or uniformly yellow; membrane uniformly dark or with pale $\mathrm{V}$-shaped marking along $\mathrm{R}$ and $\mathrm{M}$ veins.

INTEGUMENT AND VESTITURE. Head and pronotum: granulose with pubescence and interspersed macrosetae or setigerous tubercles; interocular region with two glabrous lines; antennifer with macroseta, with or without lateral protuberance; morphologically ventral surface of labial segment I with short macrosetae or sparse long macrosetae. Thorax: anterolateral angles of pronotal collar armed with macrosetae or setigerous tubercles. Legs: posterior row of spine-like protuberances on all femora well developed, anterior row poorly developed on ventral surface of mid and hind femora. Abdomen: ventral surface pubescent with long macrosetae.

STRUCTURE. Head: globose to elongate; mandibular plates in dorsal view short, not adjacent basally; maxillary plates in dorsal view elongate anteriorly, forming ellipsoid projections; pedicel 0.6-1.9 times length of head width; ventrolateral swelling of buccula with or without lateral protrusion that surpasses buccular margin; labium gracile; morphologically dorsal surface of labial segment II 0.2-0.7 times length of segment I; labial segment III drawn into bent, slender apex. Thorax: scutellum width $0.5-0.8$ times length; scutellar spine subhorizontal or raised; proepimeron without or with acute protuberance on posteroventral margin. Hemelytron: $\mathrm{Cu}-\mathrm{An}_{1}$ cell triangular, smaller than $\mathrm{M}-\mathrm{Cu}$ cell. Legs: fossula spongiosa present on fore and mid legs in males, either present on fore and mid legs or absent on mid legs of females.

\section{Distribution}

This genus currently comprises nine described species and 23 new species with a circumtropical distribution. The lowest known species diversity is in the Neotropics, and the highest species diversity for this genus is in Southeast Asia across India, Indonesia, Laos, Brunei, and the Philippines.

\section{Remarks}

Originally a monotypic genus. It is here expanded to include numerous new species as well as several previously described species formerly placed in Reduviinae.

\section{Key to the species of Voconia}

1. Corium of macropterous morph entirely yellow [Kenya] Voconia chrysoptera sp. nov.

- Corium of macropterous morph with various brown and pale patterns (e.g., Fig. 4B-C) or

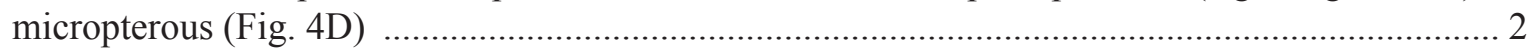

2. Micropterus; maxillary plates in lateral view about twice the width of scape [Afrotropical] .......... 3

- Macropterous; maxillary plates in lateral view cylindrical, about the width of scape [Circumtropical]

3. Maxillary plates toothed at apex; legs yellow [West Africa]

Voconia ifana (Villiers, 1963) comb. nov.

- Maxillary plates rounded at apex; legs yellow with distal half of femora brown 4

4. Paired longitudinal carinae on abdominal tergum II not prominent, not reaching posterior margin of segment; ocelli indistinct [West Africa] Voconia monodi (Villiers, 1963) comb. nov.

- Paired longitudinal carinae on abdominal tergum II prominent, reaching posterior margin of segment (Fig. 4D); ocelli distinct [Central Africa] Voconia schoutedeni (Villiers, 1964) comb. nov.

5. Head and pronotum coarsely granulose, with setigerous tubercles (Fig. 3C-D)

- Head and pronotum finely granulose, without large setigerous tubercles (Fig. 3B, H) 
6. Antennifer with large spine-like protuberance (Fig. 3D) [Afrotropical]

- Antennifer with setigerous tubercle (Fig. 3C) [New World; Australasia] ....................................... 8

7. Head and pronotum almost entirely dark brown; scutellar spine slightly raised; hemelytra blackish with pale coloration at base and apex of corium [Central Africa]

Voconia schoutedeni (Villiers, 1964) comb. nov.

- Head and pronotum yellow; scutellar spine subhorizontal; hemelytra light brown with proximal half of corium yellow and distal yellow spot [Sudan]

Voconia tridens sp. nov.

8. Clypeus round [Mexico; Honduras]

Voconia mexicana sp. nov.

- Clypeus bifid (Fig. 3C) [Australia; Papua New Guinea] .... 9

9. Hemelytron with yellow spots on corium (e.g., Fig. 4B-C) ............................................................ 10

- Hemelytron with a broad yellow band across corium (e.g., Fig. 7, V. fasciata sp. nov. and V. grandioculata sp. nov.)

10. Head globose, about as long as wide [Northern Territory, Australia; Papua New Guinea]

Voconia brachycephala sp. nov.

- Head elongate, 1.4-1.6 times as long as wide .11

11. Body dark, almost black; males small, body length 7-8 mm [Northern Territory, Australia]

Voconia dolichocephala sp. nov.

- Body light brown; males larger, body length 8-9 mm [Northern Territory and Queensland, Australia] Voconia tuberculata sp. nov.

12. Body longer, $9-11 \mathrm{~mm}$; legs entirely yellow

- Body shorter, 7-9 mm; femora dark brown, tibiae and tarsi yellowish-brown

13. Eyes as long as ante- and postocular regions in dorsal view; ocelli occupying half-length of postocular region; membranal veins forming $\mathrm{Cu}-\mathrm{An}_{1}$ and $\mathrm{M}-\mathrm{Cu}$ cells brown; proximal half of corium not entirely yellow; body length 9-10 mm [Western Australia and Queensland, Australia]

Voconia grandioculata sp. nov.

- Eyes shorter than ante- and postocular regions in dorsal view; ocelli occupying less than halflength of postocular region; membranal veins forming $\mathrm{Cu}-\mathrm{An}_{1}$ and $\mathrm{M}-\mathrm{Cu}$ cells mostly or entirely yellow; proximal half of corium entirely yellow; body length 10.5-12 $\mathrm{mm}$ [New South Wales and Queensland, Australia]

Voconia pallidipes Stål, 1866

14. Corium band is translucent yellow; body length $8-9 \mathrm{~mm}$ [Queensland, Australia]

Voconia fasciata sp. nov.

- Corium band is opaque yellow; body length approximately $7 \mathrm{~mm}$ [Queensland, Australia]

Voconia vittata sp. nov.

15. Labial segment I swollen subapically on ventral surface (Fig. 4E); labial segment II swollen ventrobasally and narrowed apically (Fig. 4E); labial segment III stout, 0.2 times length of segment II (Fig. 4E) [Borneo] Voconia wegneri (Miller, 1954) comb. nov.

- Labial segments I and II straight; labial segment III elongate, 0.4-0.7 times length of segment II ...

16. Head long, about 1.7 times as long as wide; ventral surface of hind femur with four large spines in posterior row (Fig. 4K); large pale spot between $\mathrm{R}$ and $\mathrm{M}$ veins (Fig. 4C)

- Head elongate, not more than 1.4 times as long as wide; ventral surface of hind femur with three large and $0-3$ small spines in posterior row (Fig. 4I-J) 18 
17. Mid and hind femora dark, proximal third yellow (Fig. 4K); anterior pronotal lobe convex, strongly curved inward on posterolateral margins; body length about $11 \mathrm{~mm}$ [Normanby Island]

Voconia bracata sp. nov.

- Legs uniformly dark; anterior pronotal lobe gently rounded, posterolateral margins nearly straight; body length $12-13 \mathrm{~mm}$ [New Guinea] Voconia typica (Miller, 1958) comb. nov.

18. Pronotum dark with contrasting yellow posterior margin; abducted corium dark with antero- and posteroproximal yellow stripes and posteromedial and distal white spots [Trinidad]

- Color patterns variable but combination not as above [Old World]

Voconia trinidadensis sp. nov.

19. Proepimeron with posteroventral margin rounded [Afrotropical]

- Proepimeron with acute protuberance on posteroventral margin [Oriental] 22

20. Fossula spongiosa absent or vestigial on mid leg of males and females; scutellum uniformly brown; abducted corium with an antero- and posteromedial yellow spot; uniformly brown dorsal laterotergites [Central Africa] Voconia motoensis (Schouteden, 1929) comb. nov.

- Fossula spongiosa present on mid leg of male; scutellar spine yellow (Fig. 4E); abducted corium with proximal, posteromedial, and distal yellow spots; dorsal laterotergites bicolored

21. Body longer, $10-12 \mathrm{~mm}$; dark dorsal laterotergites with strongly contrasting yellow anterior spots; eyes reaching ventral head margin in lateral view; eyes strongly bulging past postocular lateral margins in dorsal view [West and Central Africa] ...... Voconia conradti (Jeannel, 1917) comb. nov.

- Body shorter, 9-10 mm; light brown dorsal laterotergites with weakly contrasting yellow anterior spots; eyes do not reach ventral head margin in lateral view; eyes do not bulge strongly in dorsal view [Central Africa] Voconia smithae sp. nov.

22. Membrane of hemelytra dark; membranal veins forming $\mathrm{Cu}-\mathrm{An}_{1}$ and $\mathrm{M}-\mathrm{Cu}$ cells paler than remainder of membrane (Fig. 4B)

- Membrane of hemelytra dark; membranal veins dark or with $R$ and $M$ veins proximally pale in V-shape

23. Body light brown; labium lighter than head, yellow; scutellum dark with contrasting yellow apical spine [Borneo]

Voconia decorata sp. nov.

- Body dark brown, almost black; labium as dark as head; scutellum uniformly dark [Sumatra]..... 24

24. Head dark with semicircular yellow stripe encircling both ocelli; body longer, about $11 \mathrm{~mm}$; anterior pronotal lobe relatively long, posterior lobe about 1.8 times as long as than anterior lobe

Voconia coronata sp. nov.

- Head dark with yellow spots adjacent to lateral ocellar margin; body shorter, about $9 \mathrm{~mm}$; anterior pronotal lobe relatively short, posterior lobe about 2.2 times as long as anterior lobe

Voconia lirophleps sp. nov.

25. Legs yellow, distal halves of femora brown [India]

Voconia ornata comb. nov.

- Femora unicolored [Southeast Asia]

26. Legs dark brown

- Legs yellow or yellowish-brown 29 
27. Dorsal laterotergites dark with yellow spots anteriorly; anterior margin of abducted corium with a small pale spot medially; anteriad-directed process of prosternum with small paramedial lobes; stridulitrum elongated anteriorly into a small protuberance [Philippines]

Voconia bakeri sp. nov.

- Dorsal laterotergites uniformly dark; anterior margin of abducted corium with a yellow stripe along proximal half; anteriad-directed process of prosternum smoothly rounded, without paramedial lobes (Fig. 4J); stridulitrum not elongated into an anterior protuberance (Fig. 4J) [Southeast Asia] ...... 28

28. Body length about $10.0 \mathrm{~mm}$; pronotum dark, posterior margin paler [Philippines]

Voconia nyx sp. nov.

- Body length about $8.5 \mathrm{~mm}$; pronotum uniformly dark [Philippines] ......... Voconia minima sp. nov.

29. Anterior margin of abducted corium with medial and distal yellow spots; pronotum and scutellum uniformly dark [Philippines]

Voconia hemera sp. nov.

- Anterior margin of abducted corium with proximal half yellow and distal yellow spot; pronotum dark, posterior margin pale; scutellum dark with contrasting brown or yellow apical spine (Fig. 4E) ... 30

30. Clypeus coloration as rest of head; proximal half of corium entirely yellow, forming a yellow triangle [Philippines]

Voconia isosceles sp. nov.

- Clypeus lighter than rest of head, yellow; proximal half of corium not entirely yellow, with brown markings 31

31. Labial segment I short, not surpassing posteroventral eye margin in lateral view; $\mathrm{Cu}-\mathrm{An}_{1}$ cell elongate, reaching at least half the length of $\mathrm{M}-\mathrm{Cu}$ cell [Laos] Voconia laosensis sp. nov.

- Labial segment I long, surpassing posteroventral eye margin in lateral view; $\mathrm{Cu}-\mathrm{An}_{1}$ cell stout, less than half the length of $\mathrm{M}-\mathrm{Cu}$ cell

32. Abducted corium mostly dark with anteroproximal reddish-brown stripe and posteromedial and distal yellow spots; pale posterior margin of pronotum wide, a third of posterior pronotal lobe [Borneo]

Voconia lasiosoma sp. nov.

- Abducted corium with proximal half mostly yellow, distal half dark with distal yellow spot; pale posterior margin of pronotum narrow, a fifth of posterior pronotal lobe [Borneo]

Voconia loki sp. nov.

\section{Voconia bakeri sp. nov. urn:1sid:zoobank.org:act:21FEECCD-754F-4DF8-815B-E18666CE9CE5}

Figs $1-2,7,9,11,14,20$

\section{Diagnosis}

This species most closely resembles two other dark-brown Philippine species, $V$. minima sp. nov. and $V$. nyx sp. nov., with yellow posteromedial yellow spots on the abducted corium, but is differentiated by the yellow patches on the dorsal laterotergites, the faint yellow spot on the anteromedial portion of the abducted corium, the presence of small paramedial lobes on the anteriad-directed process of the prosternum, and the stridulitrum being elongated anteriorly into a small protuberance. It specifically differs from $V$. minima sp. nov. by the uniformly dark legs and short labial segment I that does not reach the posteroventral eye margin and from $V$. nyx sp. nov. by the uniformly dark pronotum.

\section{Etymology}

Named after Austin Baker, a former colleague at UCR who provided support and insightful comments on this revision. 


\section{Type material}

\section{Holotype}

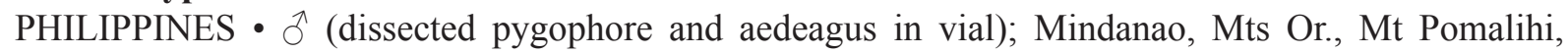
Gingoog City, 21 km W of Gingoog City; [8.81 ${ }^{\circ}$ N, $124.92^{\circ}$ E]; elev. 800-1000 m; 16 Oct. 1965; H.M. Torrevillas leg.; light trap; USI: UCR_ENT 00073810; BPBM.

\section{Description}

Male (Figs 7, 9)

Body LENGTH. About $9.8 \mathrm{~mm}$; macropterous.

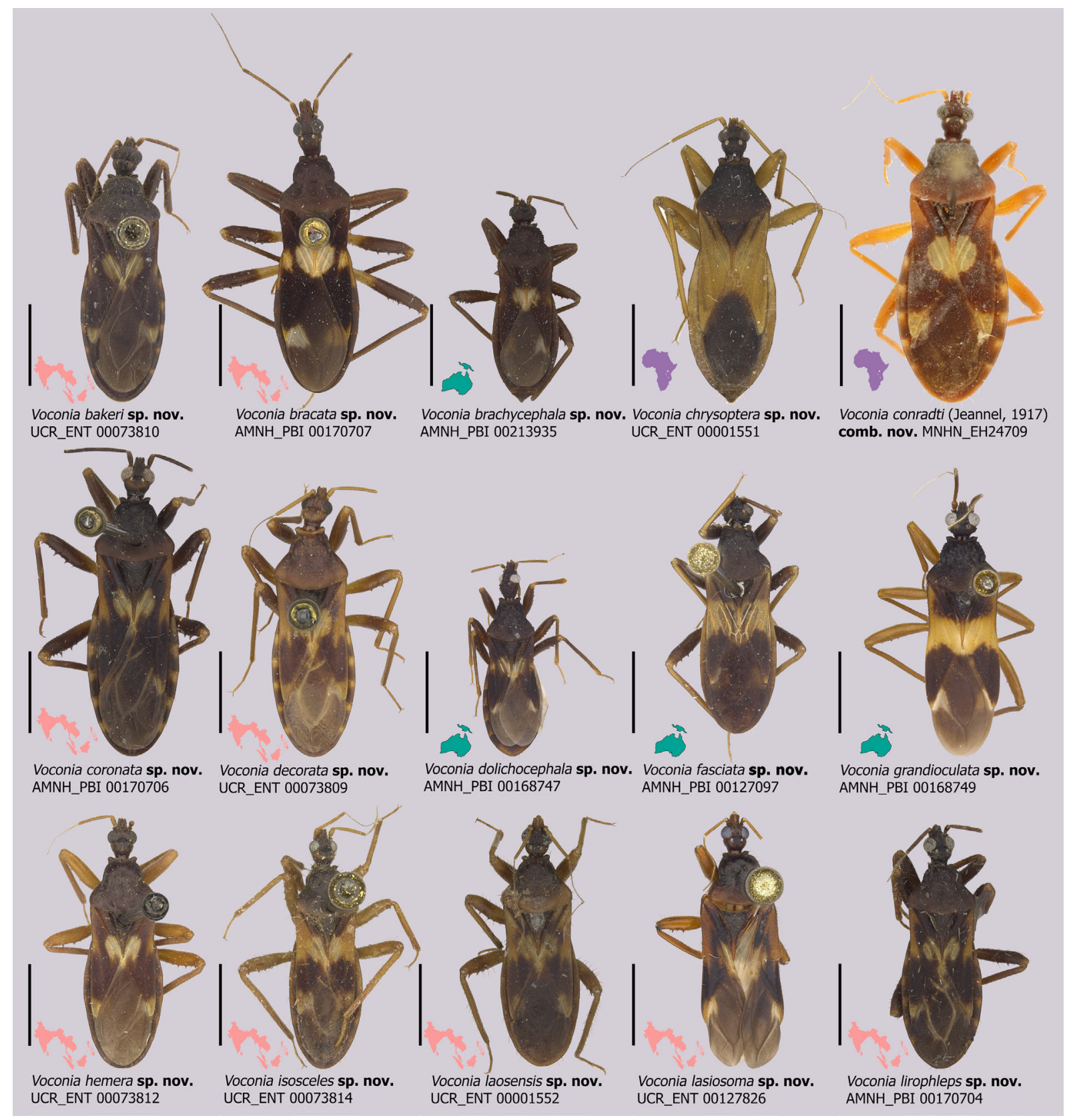

Fig. 7. Dorsal habitus of holotypes of Voconia Stål, 1866 species with distribution: purple = Afrotropical region, green $=$ Australasian region, pink $=$ Oriental region. Scale bars $=3 \mathrm{~mm}$. 
Coloration. Head: dark brown with paired pale patches adjacent to lateral ocellar margin; labium nearly as dark as head. Thorax: coloration as head; scutellum uniformly dark brown. Hemelytron (abducted): clavus dark reddish-brown, distal half yellow; corium dark reddish-brown with anteromedial, posteromedial, and distal yellow spots; membrane dark with pale $\mathrm{V}$-shaped marking along $\mathrm{R}$ and $\mathrm{M}$ veins; membranal veins $R$ and $M$ proximally pale, remainder as membrane. Legs: dark brown. Abdomen: dark reddish-brown, almost black; dorsal laterotergites dark with yellow spots anteriorly.

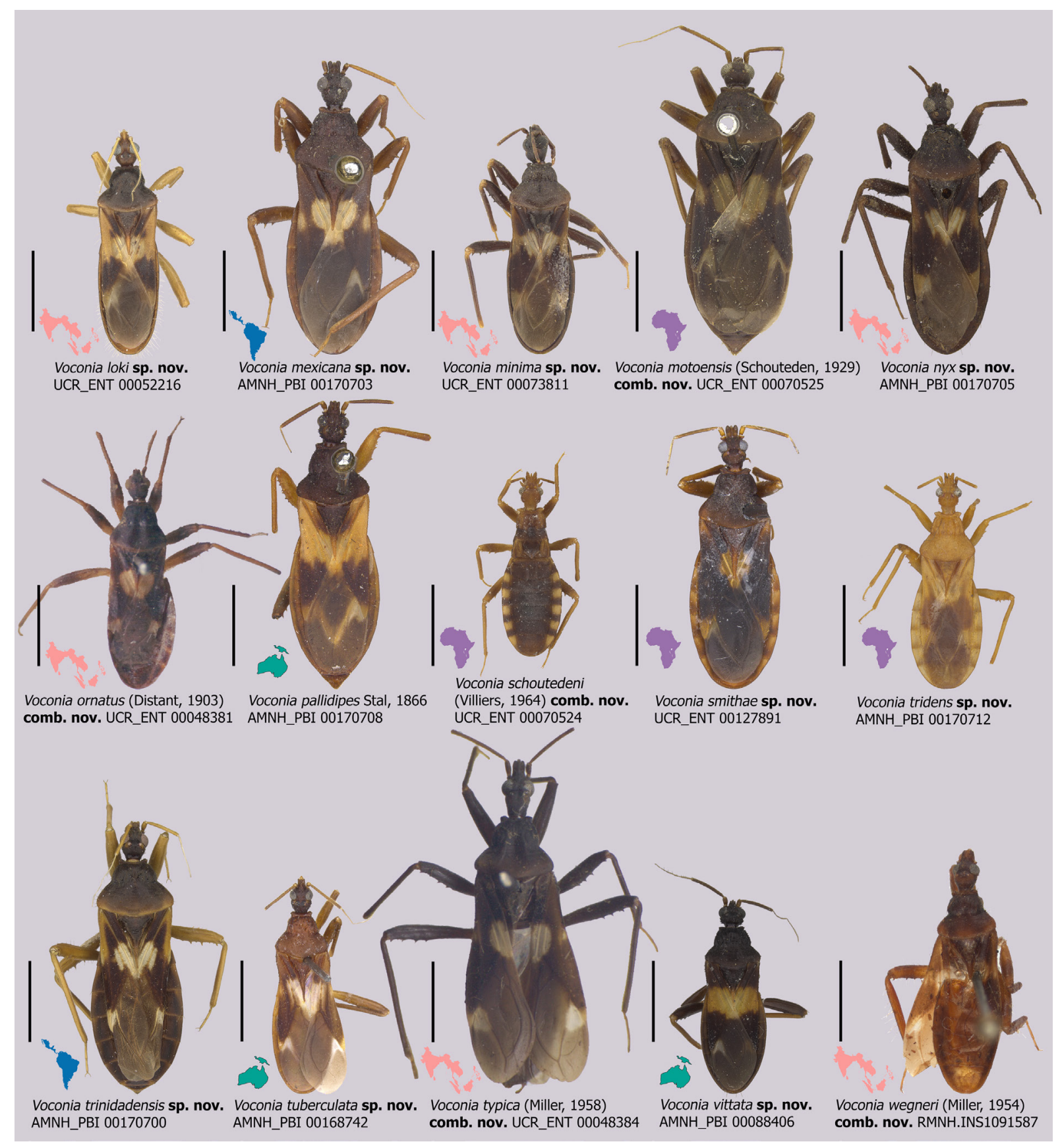

Fig. 8. Dorsal habitus of holotypes of Voconia Stål, 1866 species with distribution: purple = Afrotropical region, green $=$ Australasian region, blue $=$ Neotropical region, pink $=$ Oriental region. Scale bars $=3 \mathrm{~mm}$. 
INTEGUMENT AND VESTITURE. Head and pronotum: finely granulose with dense, long macrosetae interspersed among dense pubescence; interocular region with two pairs of macrosetae paramedially; antennifer with macroseta, base without lateral protuberance; morphologically ventral surface of labium with sparse, short macrosetae. Thorax: anterolateral angles of pronotal collar with macrosetae; scutellar lateral carinae with long setation. Hemelytron: corium with sparse long setation. Legs: posterior row of protuberances on mid and hind femora with three large and two small spines on distal half. Abdomen: ventral surface pubescent.

STRUCTURE. Head: elongate, about 1.2 times as long as wide; anteocular region about one quarter of head length, shorter than postocular region (measured to anterior margin of neck); postocular region in dorsal view about as long as eye, lateral margins in dorsal view gently rounded; pedicel about 1.2 times length of head width; maxillary plates ellipsoidal, adjacent to and longer than clypeus; apices of maxillary plates in dorsal view converging; clypeus in dorsal view wider than maxillary plates; clypeal apex round, narrowed; interocular glabrous markings anterolaterally curved, joined at interocular sulcus paramedially; interocular sulcus in dorsal view nearly straight; eye width in dorsal view about as wide as synthlipsis; eye reaching ventral head margin in lateral view; ventrolateral swelling of buccula without lateral protrusion that surpasses buccular margin, flat margin; labial segment I in lateral view straight, not reaching posteroventral eye margin; morphologically dorsal surface of labial segment II nearly straight, about 0.6 times length of segment I. Thorax: pronotal collar narrow medially with anterolateral angles short and flared laterally; anterior pronotal lobe about 0.7 times length of posterior pronotal lobe, lateral margins rounded; glabrous markings on pronotum thin and not deeply depressed; median apodeme depression of pronotum deep, elongated longitudinally; scutellar spine long, raised; anteriad-directed process of prosternum with paramedial lobes; anterior margin of stridulitrum projected into small protuberance; proepimeron with acute protuberance on posteroventral margin. Legs: fossula spongiosa present on fore and mid legs. Abdomen: anterior margin of terga weakly carinulate; terga II and III with paired prominent longitudinal carinae, reaching about two-thirds of tergum III. Pygophore (Fig. 11): transverse bridge with rounded posterior margin; posterior region of ventral surface of pygophore in lateral view straight, not swollen; lateral pygophore margin with protuberance; posterior pygophore margin with clustered macrosetae on protuberance; parameres sinusoidal, apex tapered into squarely rounded tip. Aedeagus (Fig. 14): endosoma almost entirely covered with spicules; apex of dorsal phallothecal sclerite tongue-shaped in dorsal view; basal plate extension about 4.3 times as long as wide.

\section{Female}

Unknown.

\section{Distribution (Fig. 20)}

This species is only known from the type locality in the Philippines. Based on the record of a Miridae Hahn, 1831 specimen with the same collection event, Mt Pomalihi is presumably in Mt Balatukan Range Natural Park. The type locality is also shared with $V$. isosceles sp. nov.

\section{Remarks}

The median apical process broke off during dissection (Fig. 11). It was presumably short as is the case in all Pseudocetherinae, but it was not possible to determine if it was upright or bent posteriorly.

Voconia bracata sp. nov. urn:1sid:zoobank.org:act:32D3A427-888D-4D48-B0C3-5EB69CB43B1A

Figs 1, 2, 3J, 4C, K, 7, 9, 18

\section{Diagnosis}

Distinguished from other species of the genus Voconia by its long, slender body (about $10.8 \mathrm{~mm}$ ), long head (about 1.7 times as long as wide), hind leg with four large spines in the posterior row, a large pale spot 
between $\mathrm{R}$ and $\mathrm{M}$ veins, and dorsal laterotergites I and II yellow, the remainder dark brown. This species is most similar to V. typica, but is differentiated by the yellow proximal third of the mid and hind femora as well as the anterior pronotal lobe, which is convex, strongly curved inward on the posterolateral margins.

\section{Etymology}

The specific epithet is the Latin adjective 'bracatus, $-a,-u m$ ', meaning 'wearing trousers'. It refers to the yellow coloration of the proximal half of the femora.

\section{Type material}

Holotype

PAPUA NEW GUINEA • ${ }^{\wedge}$; Milne Bay Province, Waikaiuna, Normanby Island; [10.06 $\left.{ }^{\circ} \mathrm{S}, 150.97^{\circ} \mathrm{E}\right]$; elev. 0-50 m; 14 Apr. 1956; L.J. Brass leg.; Fifth Archibold Exped. to New Guinea; USI: AMNH_PBI 00170707; AMNH.

\section{Description \\ Male (Figs 7, 9) \\ Body LENGTH. About $10.8 \mathrm{~mm}$; macropterous.}

Coloration. Head: dark brown; postocular region with dark patches adjacent to medial ocellar margin and paired pale patches adjacent to lateral ocellar margin; labial segments II and III lighter than head. Thorax: coloration as head; scutellum dark with contrasting yellow apical spine. Hemelytron (abducted): clavus dark reddish-brown with distal half yellow; corium dark reddish-brown with anteromedial, posteromedial, and distal yellow spots; membrane dark, large pale spot between $\mathrm{R}$ and $\mathrm{M}$ veins; membranal veins $\mathrm{R}$ and $\mathrm{M}$ proximally pale, remainder as membrane. Legs (Fig. 4K): dark brown with yellow mid and hind coxae, trochanter, and proximal third of femora. Abdomen (Fig. 4C): dark reddishbrown; dorsal laterotergites I and II yellow.

INTEGUMENT AND VESTITURE. Head and pronotum: finely granulose with sparse, short macrosetae interspersed among dense pubescence; antennifer with short lateral setigerous tubercle; morphologically ventral surface of labium with dense, short macrosetae; anterolateral angles of pronotal collar without macrosetae or setigerous tubercles. Legs (Fig. 4K): posterior row of protuberances on mid and hind femora with four large spines on distal half. Abdomen: ventral surface pubescent with long macrosetae.

StRUCTURE. Head: elongate, about 1.7 times as long as wide; anteocular region about one third of head length, subequal in length to postocular region (measured to anterior margin of neck); postocular region in dorsal view longer than eye, lateral margins gently rounded; pedicel about 1.8 times length of head width; maxillary plates ellipsoidal, adjacent to and reaching apex of clypeus; apex of maxillary plates in dorsal view directed straight; clypeus in dorsal view slightly narrower than maxillary plates; clypeal apex round, not narrowed; interocular glabrous markings V-shaped, joined medially at interocular sulcus; interocular sulcus in dorsal view slightly bent anteromedially, subtriangular; eye width in dorsal view wider than synthlipsis; eye reaching ventral head margin in lateral view; ventrolateral swelling of buccula without lateral protrusion that surpasses buccular margin, flat margin; labial segment I in lateral view straight, surpassing posteroventral eye margin; morphologically dorsal surface of labial segment II slightly curving apically, about 0.4 times length of segment I. Thorax: pronotal collar narrow medially with anterolateral angles short, projected forward; anterior pronotal lobe subequal in length to posterior pronotal lobe, lateral margins rounded; glabrous markings on pronotum thin and not deeply depressed; median apodeme depression of pronotum deep and elongated transversely; scutellar spine long and subhorizontal; anteriad-directed process of prosternum smoothly rounded, without paramedial lobes (Fig. 3J); anterior margin of stridulitrum not elongated into protuberance (Fig. 3J); proepimeron with smoothly rounded posteroventral margin. Legs: fossula spongiosa present on fore and mid legs. 


\section{Female \\ Unknown.}

\section{Distribution (Fig. 18)}

This species is only known from the type locality of Normanby Island off of Papua New Guinea, where no other Pseudocetherinae species are known.

\section{Remarks}

This species forms a well-supported clade with another species from Papua New Guinea, V. typica (Figs 1-2).

Voconia brachycephala sp. nov. urn:1sid:zoobank.org:act:AB497C37-1CBA-4270-AAE0-DDA9ADDCAB25

Figs $1-2,7,9,18$

Voconia pallidipes (non Stål, 1866) - Swanson 2015: 268-269, fig. 10. Misidentification.

\section{Diagnosis}

Recognized by its Australasian distribution, small size (about $7.4 \mathrm{~mm}$ ), globose head (about as long as wide), labial segment II swollen ventromedially, and coarsely granulose, tuberculate head and pronotum. Most closely resembles $V$. dolichocephala sp. nov. in size and hemelytral coloration but $V$. dolichocephala sp. nov. has a conspicuously elongate head.

\section{Etymology}

The specific epithet is the latinized Greek adjective 'brachycephalus, $-a,-u m$ ', formed from the prefix 'brachy-' (meaning 'short') and the noun 'cephale' (meaning 'head'), referring to the fact that this species has the shortest head among species of Voconia.

\section{Type material}

\section{Holotype}

PAPUA NEW GUINEA [“N. GUINEA”] • $\%$; Madang Province, Erima; [5.42 S, $145.73^{\circ}$ E]; 1896; L. Bíró leg.; “Astrolabe B.”; USI: AMNH_PBI 00213935; HNHM.

\section{Material examined from literature}

AUSTRALIA • 1 क ; Northern Territory, $2 \mathrm{~km}$ E of Saddle Creek; $15.95694^{\circ} \mathrm{S}, 129.56167^{\circ} \mathrm{E}$; elev. $75 \mathrm{~m}$; 27 Sep. 1983; E.L. Schlinger and M.E. Irwin leg.; INHS 914,917.

\section{Description}

\section{Female (Figs 7, 9)}

Body LENGTH. About $7.4 \mathrm{~mm}$; macropterous.

COLORATION. Head: dark brown, postocular region with dark patches adjacent to medial ocellar margin; labium lighter than head. Thorax: coloration as head; scutellum dark with contrasting yellow apical spine. Hemelytron (abducted): clavus reddish-brown with distal yellow stripe; corium reddish-brown with anteromedial and posteromedial yellow spots; membrane dark with pale V-shaped marking along $\mathrm{R}$ and $\mathrm{M}$ veins; membranal veins $\mathrm{R}$ and $\mathrm{M}$ proximally pale, remainder as membrane. Legs: dark yellowishbrown. Abdomen: dark brown; dorsal laterotergites uniformly dark. 
INTEGUMENT AND VESTITURE. Head and pronotum: coarsely granulose, with dense, short setigerous tubercles interspersed among sparse pubescence; interocular region with two pairs of stout setigerous tubercles paramedially and one medially; antennifer with two adjacent lateral setigerous tubercles; morphologically ventral surface of labium with sparse, long macrosetae. Thorax: anterolateral angles of pronotal collar with setigerous tubercles; scutellar lateral carinae with short macrosetae on setigerous tubercles. Legs: posterior row of protuberances on mid and hind femora with three large spines on distal half and three or fewer small spines. Abdomen: ventral surface pubescent with long macrosetae.

STRUCTURE. Head: globose, about as long as wide; anteocular region about one quarter of head length, shorter than postocular region (measured to anterior margin of neck); postocular region in dorsal view shorter than eye, lateral margins gently rounded; pedicel about 1.2 times length of head width; maxillary plates ellipsoidal, adjacent to and shorter than clypeus; apices of maxillary plates in dorsal view diverging; clypeus in dorsal view wider than maxillary plates; clypeal apex bifid, narrowed; interocular glabrous markings anterolaterally curved, joined at interocular sulcus paramedially; interocular sulcus in dorsal view curved and smoothly rounded anteriorly; eye width in dorsal view narrower than synthlipsis; eye reaching ventral head margin in lateral view; ventrolateral swelling of buccula without lateral protrusion that surpasses buccular margin, flat margin; labial segment I in lateral view gradually thickens distally,

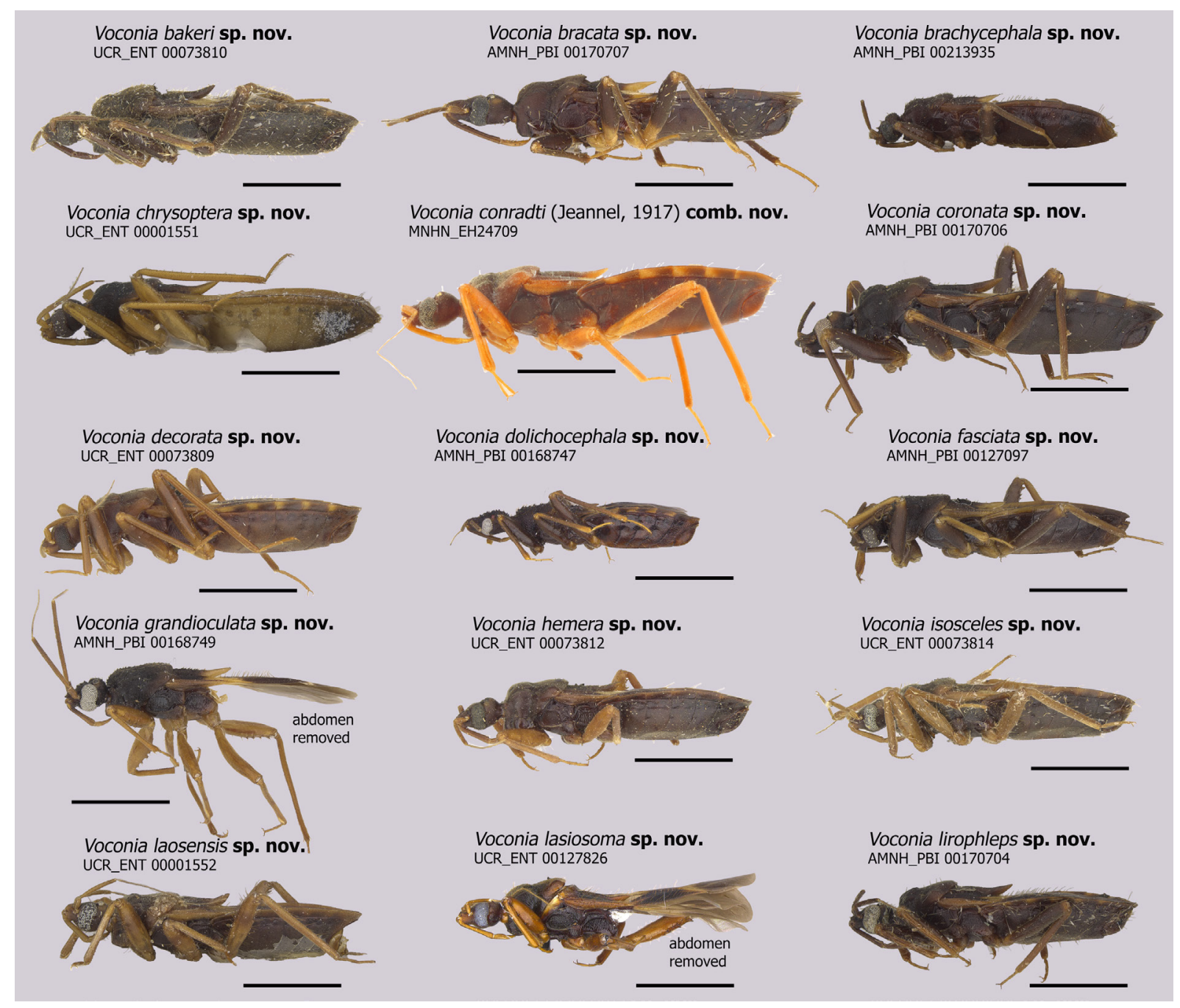

Fig. 9. Lateral habitus of species of Voconia Stål, 1866. Scale bars $=3 \mathrm{~mm}$. 
surpassing posteroventral eye margin; labial segment II swollen ventromedially; morphologically dorsal surface of labial segment II curves ventrally, about 0.3 times length of segment I. Thorax: pronotal collar narrow medially with anterolateral angles short, projected forward; anterior pronotal lobe about 0.7 times length of posterior pronotal lobe, lateral margins almost straight; glabrous markings on pronotum conspicuous and not depressed; median apodeme depression of pronotum shallow, elongated longitudinally; scutellar spine long and raised; anteriad-directed process of prosternum with paramedial lobes; anterior margin of stridulitrum projected into small protuberance; proepimeron with smoothly rounded posteroventral margin. Legs: fossula spongiosa of fore leg present.

\section{Male \\ Unknown.}

Distribution (Fig. 18)

This species has a disjunct distribution. It is known from Erima in Papua New Guinea (type locality) and the Northern Territory of Australia (Swanson 2015: 268, as V. pallidipes).

\section{Remarks}

There is little doubt that the specimen figured by Swanson $(2015: 269$, fig. 10) as $V$. pallidipes pertains to $V$. brachycephala sp. nov. Although the size of the specimen in concern is unknown, its coloration and the short, tuberculate head do not seem to differ from the condition seen in the new species. Since the specimen could not be re-examined, it is, however, not included in the type material of the new species.

Voconia chrysoptera sp. nov.

urn:1sid:zoobank.org:act:79E22180-F528-4166-8D25-02AD3BA726BE

Figs $1-2,7,9,17$

\section{Diagnosis}

Recognized from other African Voconia species by the unique coloration of the corium, abdomen, and legs which are entirely yellow. Additionally, the posterior row of spines on the mid and hind femora have three large and many small spines, and the antennifer lacks a lateral protuberance. Females possess a fossula spongiosa on the mid leg.

\section{Etymology}

The specific epithet is the Latin adjective 'chrysopterus, $-a$, -um', meaning 'golden-winged', referring to the entirely yellow corium.

\section{Type material}

\section{Holotype}

KENYA • +; Eastern Province, Mwingi, Nguni; 7 Apr. 2004; M. Snizek leg.; USI: UCR_ENT 00001551; NHMW.

\section{Description}

Female (Figs 7, 9)

Body LENGTH. $10.5 \mathrm{~mm}$; macropterous.

Coloration. Head: dark brown, maxillary plates lighter; postocular region dark brown with paired pale patches adjacent to lateral ocellar margin; labium lighter than head, yellow. Thorax: coloration as head, with posterior pronotal lobe lighter than anterior lobe; scutellum dark with contrasting yellow apical spine. Hemelytron (abducted): clavus and corium uniformly yellow; membrane uniformly dark; 
membranal veins as remainder of membrane. Legs: yellow. Abdomen: ventral surface and dorsal laterotergites yellow.

INTEGUMENT AND VESTITURE. Head and pronotum: coarsely granulose with sparse pubescence and sparse, short macrosetae; interocular region with two pairs of macrosetae paramedially; antennifer without lateral projection; labium with dense, short macrosetae. Thorax: anterolateral angles of pronotal collar without macrosetae or setigerous tubercles; scutellar lateral carinae with short macrosetae. Hemelytron: corium with dense short setation. Legs: posterior row of protuberances on mid and hind femora with three large spines on distal half and many small spines. Abdomen: ventral surface pubescent.

StRUCTURE. Head: elongate, 1.3 times as long as wide; anteocular region about one third of head length, shorter than postocular region (measured to anterior margin of neck); postocular region in dorsal view longer than eye, lateral margins gently rounded; pedicel about 1.8 times length of head width; maxillary plates ellipsoidal, adjacent to and longer than clypeus; apices of maxillary plates in dorsal view diverging; clypeus in dorsal view wider than maxillary plates, apex rounded, not narrowed; interocular glabrous markings curved anterolaterally, joined at interocular sulcus paramedially; interocular sulcus in

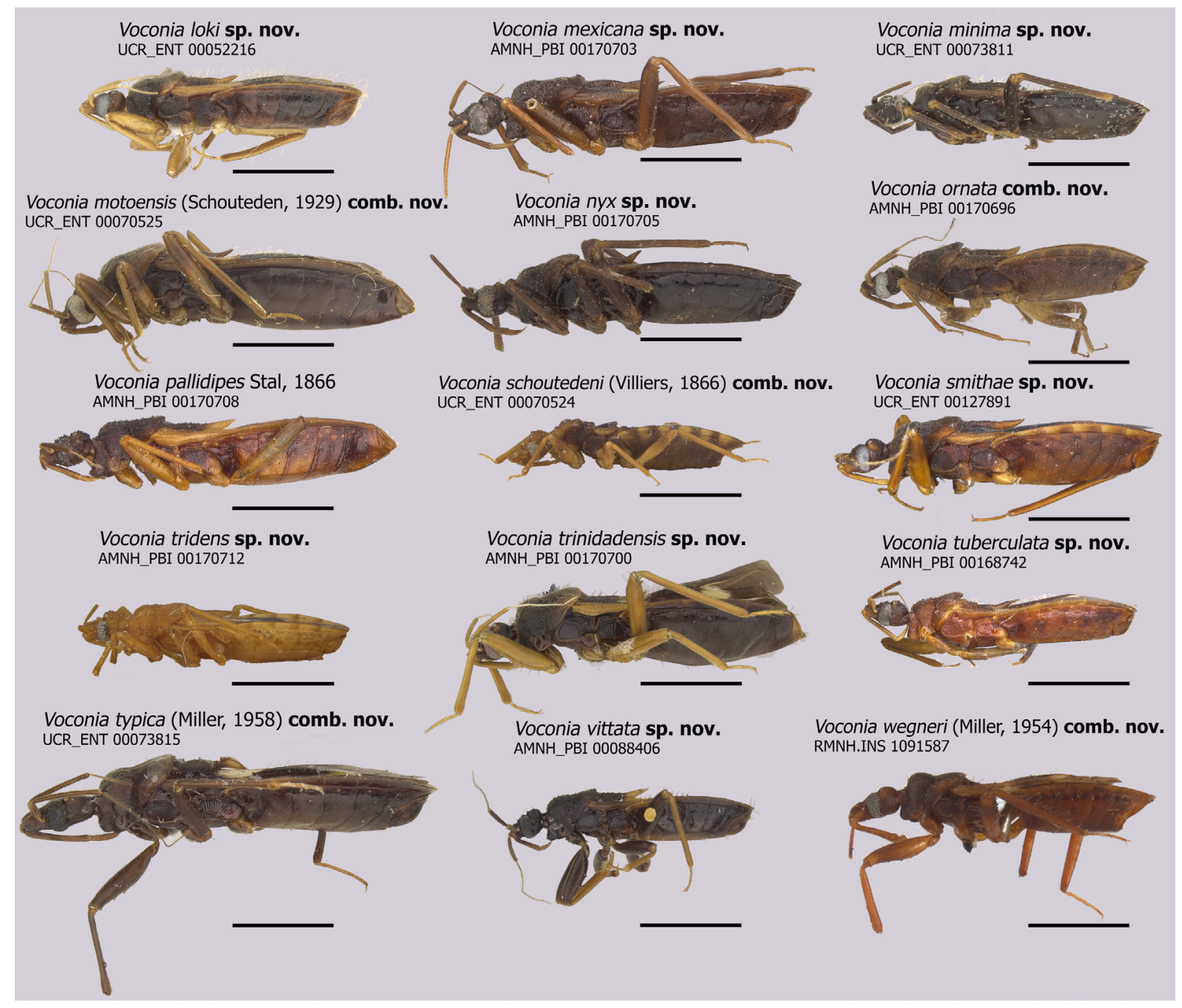

Fig. 10. Lateral habitus of species of Voconia Stål, 1866. Scale bars $=3 \mathrm{~mm}$. 
dorsal view curved and smoothly rounded anteriorly; eye width in dorsal view narrower than synthlipsis, reaching ventral head margin in lateral view; ventrolateral swelling of buccula with lateral protrusion that surpasses buccular margin, setigerous tubercles along apical margin; labial segment I in lateral view straight, reaching posteroventral eye margin; morphologically dorsal surface of labial segment II nearly straight, about 0.6 times length of segment I. Thorax: with pronotal collar narrow medially with anterolateral angles short, projected forward; anterior pronotal lobe about 0.5 times length of posterior pronotal lobe, lateral margins rounded, glabrous markings not depressed; median apodeme depression of pronotum shallow and elongated longitudinally; scutellar spine long and raised; anteriad-directed process of prosternum smoothly rounded without paramedial lobes; anterior margin of stridulitrum projecting into a small protuberance. Legs: fossula spongiosa present on fore and mid legs.

\section{Male \\ Unknown.}

Distribution (Fig. 17)

This species is only known from the type locality in Mwingi, Kenya. It is the easternmost Afrotropical species.

\section{Remarks}

This is the only female in the subfamily with fossula spongiosa present on the mid leg.

Voconia conradti (Jeannel, 1917) comb. nov.

Figs $1-2,7,9,11,17$

Microvarus conradti Jeannel, 1917: 51.

Microvarus achteni Schouteden, 1929: 252. Synonymized by Villiers (1948: 280).

\section{Diagnosis}

Distinguished from other species in Voconia by its Afrotropical distribution and stout body. This species most closely resembles $V$. motoensis and $V$. smithae sp. nov. It differs from $V$. motoensis by its distinct coloration: yellow scutellar spine, corium with a proximal and distal yellow spot, and contrasting yellow anterior spots on dark dorsal laterotergites. Despite the strong superficial resemblance to $V$. smithae sp. nov. due to its coloration and stoutness, closer examination reveals that $V$. conradti is distinguishable by the longer body $(10.4-11.4 \mathrm{~mm})$, dark dorsal laterotergites with strongly contrasting yellow anterior spots, finely granulose head, antennifer with short or absent laterally projecting setigerous tubercle, lack of paired interocular setigerous tubercles, maxillary plates with medial margins diverging, shorter anteocular region than postocular region (measured to where the posterior margin of the granulations meet the anterior margin of the smooth neck), buccula without lateral protrusion, and strongly bulging eyes that greatly surpass the postocular lateral margin in dorsal view and reach the ventral head margin in lateral view.

\section{Type material}

Lectotype (present designation)

EQUATORIAL GUINEA • \’ ; "Fernando-Po" [Bioko Island]; 1901; L. Conradt leg.; MNHN_EH24709.

\section{Additional material examined}

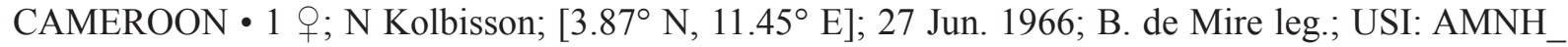

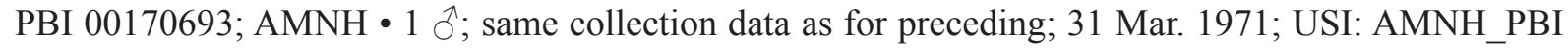
00170694; AMNH. 


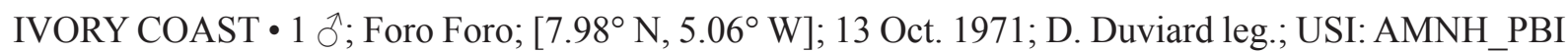
00170691; AMNH • 1 ऊ ; same locality as for preceding; 25-28 Sep. 1973; R. Linnavuori leg.; dissected pygophore in vial (Fig. 11), aedeagus lost; USI: AMNH_PBI 00170695; AMNH.

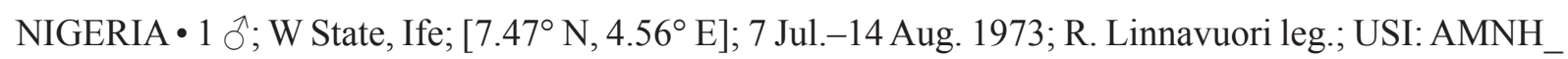
PBI 00170692; AMNH.

\title{
Redescription
}

\author{
Male (Figs 7, 9)
}

Body LENGTH. 10.4-11.4 mm; macropterous.

COLORATION. Head: dark brown; postocular region with dark patches adjacent to medial ocellar margin and pale patches adjacent to lateral ocellar margin; labium lighter than head. Thorax: coloration as head; pronotum uniformly dark (Fig. 3K) or posterior pronotal lobe lighter than anterior lobe; scutellum dark with contrasting yellow apical spine. Hemelytron (abducted): clavus dark reddish-brown with distal yellow stripe; corium dark reddish-brown with proximal, anteromedial, posteromedial, and distal yellow spots; membrane dark with pale V-shaped marking along $\mathrm{R}$ and $\mathrm{M}$ veins; membranal veins $\mathrm{R}$ and $\mathrm{M}$ proximally pale. Legs: completely yellow or yellow with distal half of femur dark brown. Abdomen: dark brown, dorsal laterotergites with yellow spots anteriorly.

INTEGUMENT AND VeSTITURE. Head and pronotum: finely granulose with sparse, short macrosetae interspersed among sparse pubescence; interocular region with two pairs of macrosetae paramedially; antennifer with short lateral setigerous tubercle; morphologically ventral surface of labium with sparse, short macrosetae. Thorax (Fig. 3K): anterolateral angles of pronotal collar without macrosetae or setigerous tubercles. Hemelytron: corium with dense long setation. Legs: posterior row of protuberances on mid and hind femora with three large spines on distal half. Abdomen: ventral surface pubescent.

StRUCTURE. Head: elongate, 1.1-1.4 times as long as wide; anteocular region about one quarter of head length, shorter than postocular region (measured to anterior margin of neck); postocular region in dorsal view about as long as eye or shorter, lateral margins subrectangular; pedicel about 1.3 times length of head width; maxillary plates ellipsoidal, adjacent to and longer than clypeus; apices of maxillary plates in dorsal view with medial margins diverging; clypeus in dorsal view narrower than maxillary plates; clypeal apex round, narrowed; interocular glabrous markings anterolaterally curved, joined at interocular sulcus paramedially; interocular sulcus in dorsal view curved and smoothly rounded anteriorly; eye width in dorsal view either wider or narrower than synthlipsis; eye reaching ventral head margin in lateral view; ventrolateral swelling of buccula without lateral protrusion that surpasses buccular margin, flat margin; labial segment I in lateral view straight, reaching posteroventral eye margin; morphologically dorsal surface of labial segment II nearly straight, about 0.5 times length of segment I. Thorax (Fig. 3K): pronotal collar in dorsal view narrow medially, with anterolateral angles short, projected forward; anterior pronotal lobe $0.5-0.6$ times length of posterior pronotal lobe, lateral margins almost straight; glabrous markings on pronotum slightly depressed; median apodeme depression of pronotum deep, circular; scutellar spine long, raised; anteriad-directed process of prosternum with paramedial lobes; anterior margin of stridulitrum not elongated into protuberance; proepimeron with smoothly rounded posteroventral margin. Legs: fossula spongiosa present on fore and mid legs. Abdomen: anterior margin of terga weakly carinulate; terga II and III with paired prominent longitudinal carinae reaching about one-third of tergum III. Pygophore (Fig. 11): transverse bridge with triangular posterior margin; posterior region of ventral surface of pygophore in lateral view with slight swelling; median apical process in caudal view short; direction of median apical process in lateral view sharply bent posteriorly; lateral pygophore margin with protuberance; posterior pygophore margin with clustered macrosetae on protuberance; parameres sinusoidal, apex tapered into squarely rounded tip. 

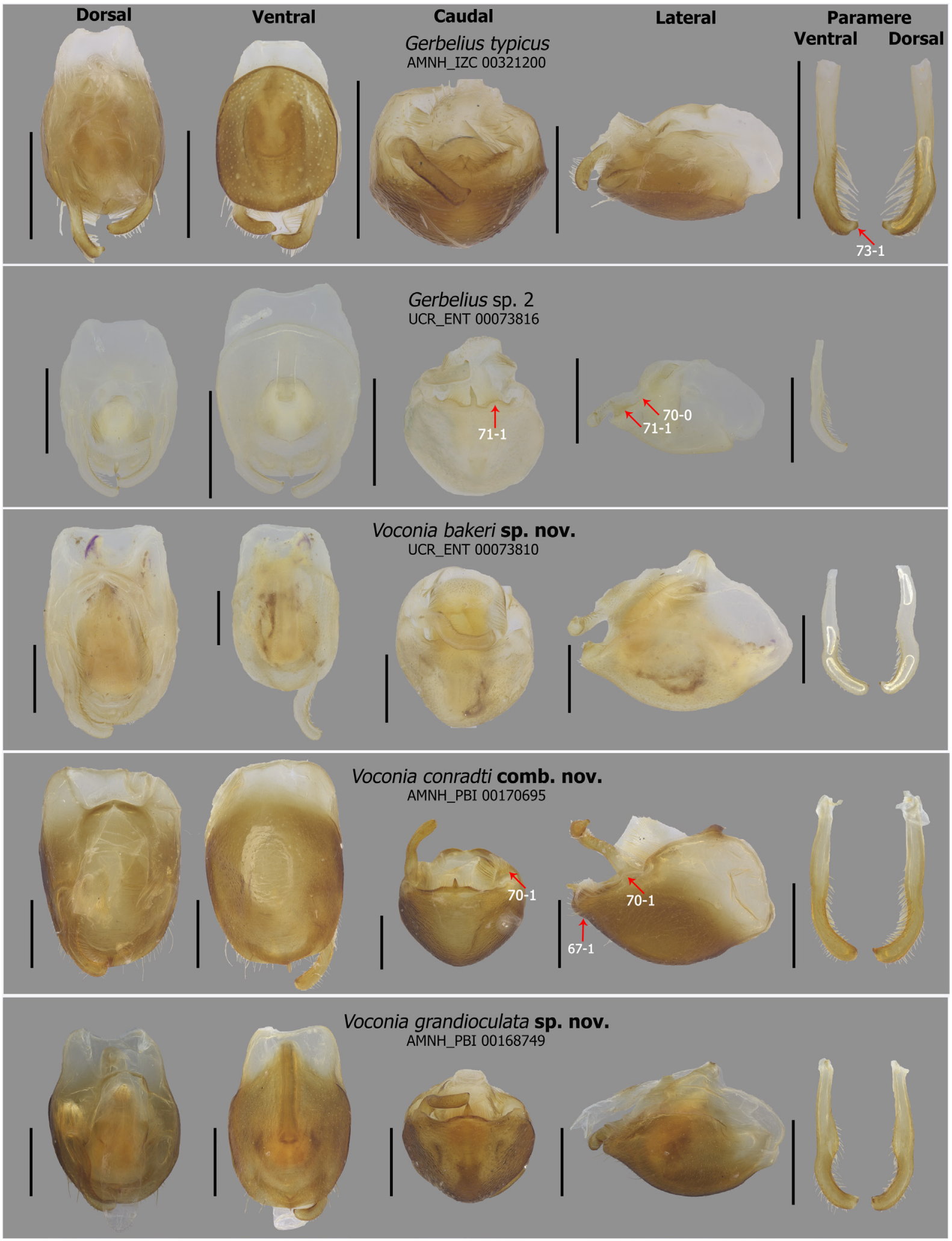

Fig. 11. Pygophore of species of Gerbelius Distant, 1903 and Voconia Stål, 1866. Median apical process of Gerbelius typicus Distant, 1903 and V. bakeri sp. nov. damaged/missing. Scale bars $=0.5 \mathrm{~mm}$. 


\section{Female}

Mostly as male but differs from males by the following. Body length: about $11.2 \mathrm{~mm}$. Head: elongate, about 1.4 times as long as wide; pedicel about 1.2 times length of head width; ocelli minute, occupying 0.15 times length of postocular region. Legs: fossula absent or vestigial on mid leg.

\section{Distribution (Fig. 17)}

This species is distributed in Western Africa. The type locality is from Bioko, an island off the west coast, north of Equatorial Guinea.

\section{Remarks}

Originally described as Microvarus conradti based on several specimens which are to be treated as syntypes (Jeannel 1917). The type material of M. conradti is deposited at the MNHN under loan restrictions; habitus photographs of one of the syntypes (Fig. 7; USI: MNHN_EH24709) were used to evaluate this species concept and this specimen is designated as the lectotype. The synonymy of M. achteni proposed by Villiers (1948) is accepted here without re-examining the type material of Schouteden (1929). This species is transferred to Voconia based on the cladistic analysis conducted in this study. Based on the phylogeny, V. conradti and V. smithae sp. nov. form a well-supported clade (Figs 1-2).

Voconia coronata sp. nov. urn:lsid:zoobank.org:act:13ED6C82-C06A-4DE4-92E3-EAD71C9B8D71

Figs $1-2,7,9,20$

\section{Diagnosis}

Distinguished from most species of Voconia by the semicircular yellow stripe encircling both ocelli, membranal veins forming $\mathrm{Cu}-\mathrm{An}_{1}$ and $\mathrm{M}-\mathrm{Cu}$ cells paler than remainder of membrane, and proepimeron with protuberance on posteroventral margin. This species is most similar to two other Oriental species, $V$. decorata sp. nov. and $V$. lirophleps sp. nov. It is distinguishable from $V$. decorata sp. nov. by its distribution in Sumatra and the dark brown, almost black coloration of the body. Despite the holotypes of $V$. coronata sp. nov. and $V$. lirophleps sp. nov. being collected within about $106 \mathrm{~km}$ of each other, there are several differences, particularly in size. Among our larger series, conspecific Voconia males do not vary more than about $\pm 1 \mathrm{~mm}$ from each other, and $V$. coronata sp. nov. is about $2 \mathrm{~mm}$ longer than V. lirophleps sp. nov. It is distinguishable by the slightly more elongate head (about 1.3 times as long as wide), the pedicel is much longer (about 1.9 times length of head width), maxillary plates directed straight in dorsal view, postocular region is about as long as the eye, labial segment I is long, almost reaching posterior margin of head, wide pronotal collar, long anterior pronotal lobe relative to posterior pronotal lobe (posterior lobe about 1.8 times as long as anterior lobe), scutellum dark with brown apical spine, inconspicuous distal yellow spot on the corium, and the presence of three large spines and many small spines on the posterior row of spines of the hind leg.

\section{Etymology}

The specific epithet is the Latin adjective 'coronatus, - $a$, -um', meaning 'crowned' or 'encircled', referring to the yellow ring around the postocular region of the head.

\section{Type material}

\section{Holotype}

INDONESIA • ; S Sumatra, "Central Atjeh" [Aceh], Ketambe; [3.68 N, 97.66 E]; elev. 400 m; 26-27 Jan. 1974; E.W. Diehl leg.; USI: AMNH_PBI 00170706; AMNH. 


\section{Description}

Male (Figs 7, 9)

Body LENGTH. About $11.0 \mathrm{~mm}$; macropterous.

Coloration. Head: dark brown; postocular region dark with a semicircular pale stripe encircling both ocelli; labium nearly as dark as head. Thorax: coloration as head; posterior pronotal lobe lighter than anterior lobe; scutellum dark with brown apical spine. Hemelytron (abducted): clavus dark with distal yellow stripe; corium dark with anteroproximal yellow stripe, posteromedial and small distal yellow spots; membrane uniformly dark; membranal veins forming $\mathrm{Cu}-\mathrm{An}_{1}$ and $\mathrm{M}-\mathrm{Cu}$ cells paler than remainder of membrane. Legs: dark brown, femora darker. Abdomen: almost black, dorsal laterotergites dark with yellow spots anteriorly.

INTEGUMENT AND VESTITURE. Head and pronotum: finely granulose with sparse, short macrosetae interspersed among sparse pubescence; interocular region with two pairs of macrosetae paramedially; antennifer with short lateral setigerous tubercle; morphologically ventral surface of labium with sparse, long macrosetae. Thorax: anterolateral angles of pronotal collar with macrosetae; scutellar lateral carinae with long setation. Hemelytron: corium with sparse long setation. Legs: posterior row of protuberances on mid and hind femora with three large spines on distal half and more than three small spines. Abdomen: ventral surface pubescent.

Structure. Head: elongate, 1.3 times as long as wide; anteocular region about one quarter of head length, shorter than postocular region (measured to anterior margin of neck); postocular region in dorsal view about as long as eye, lateral margins gently rounded; pedicel about 1.9 times length of head width; maxillary plates ellipsoidal, adjacent to and surpassing clypeal apex; apices of maxillary plates in dorsal view directed straight; clypeus in dorsal view wider than maxillary plates; clypeal apex round, not narrowed; interocular glabrous markings anterolaterally curved, joined at interocular sulcus paramedially; interocular sulcus in dorsal view bent anteromedially, subtriangular; eye width in dorsal view wider than synthlipsis; eye reaching ventral head margin in lateral view; ventrolateral swelling of buccula without lateral protrusion that surpasses buccular margin, flat margin; labial segment I in lateral view straight, surpassing posteroventral eye margin; morphologically dorsal surface of labial segment II nearly straight, about 0.5 times length of segment I. Thorax: pronotal collar in dorsal view wide medially with anterolateral angles short and flared laterally; anterior pronotal lobe about 0.6 times length of posterior pronotal lobe, lateral margins rounded; glabrous markings on pronotum deeply depressed; median apodeme depression of pronotum shallow, elongated transversely; scutellar spine long, raised; anteriad-directed process of prosternum smoothly rounded, without paramedial lobes; anterior margin of stridulitrum not elongated into protuberance; proepimeron with acute protuberance on posteroventral margin. Legs: fossula spongiosa present on fore and mid legs.

\section{Female}

Unknown.

Distribution (Fig. 20)

This species is only known from the type locality of Ketambe in the northernmost province of Sumatra, Aceh.

\section{Remarks}

The phylogenetic placement of $V$. coronata sp. nov. is uncertain (Figs 1-2). 


\section{Voconia decorata sp. nov. urn:lsid:zoobank.org:act:93BE46E2-210B-45C7-8FD6-2C38EC62B2D9}

Figs $1-2,3 \mathrm{~B}, 4 \mathrm{~J}, 7,9,20$

\section{Diagnosis}

Distinguished from most other species of Voconia by the yellow ring around the postocular region, membranal veins forming $\mathrm{Cu}-\mathrm{An}_{1}$ and $\mathrm{M}-\mathrm{Cu}$ cells paler than remainder of membrane, and proepimeron with protuberance on posteroventral margin. This species is most similar to two other Oriental species, $V$. coronata sp. nov. and $V$. lirophleps sp. nov. It is distinguishable from these species by its distribution in the Malaysian state of Sabah in Borneo, the light brown coloration of the body, the labium being lighter than the head, and the dark scutellum with a contrasting yellow apical spine.

\section{Etymology}

The specific epithet is the Latin adjective 'decoratus, $-a$, -um', meaning 'decorated, elegant', referring to its light brown coloration and yellow markings on the hemelytron and dorsal laterotergites that gives it a flashier and more elegant look.

\section{Type material}

\section{Holotype}

MALAYSIA ["NORTH BORNEO"] - + ; Sabah, Tawau, Quoin Hill, Cocoa Res. Stn, [4.42 ${ }^{\circ}$ N, $118.02^{\circ}$ E]; elev. 225 m; 16 Sep. 1962; K.J. Kuncheria leg.; USI: UCR_ENT 00073809; BPBM.

\section{Description}

Male (Figs 7, 9)

BoDY LENGTH. About $10.0 \mathrm{~mm}$; macropterous.

Coloration. Head (Fig. 3B): light brown, yellowish; postocular region with dark patches adjacent to medial ocellar margin, semicircular pale stripe encircling both ocelli; labium lighter than head. Thorax: coloration as head; posterior margin of posterior pronotal lobe lighter; scutellum dark with contrasting yellow apical spine. Hemelytron (abducted): clavus reddish-brown with distal yellow stripe; corium reddish-brown with anteroproximal yellow stripe, posteromedial and distal yellow spots; membrane light brown with pale $\mathrm{V}$-shaped marking along $\mathrm{R}$ and $\mathrm{M}$ veins; membranal veins forming $\mathrm{Cu}-\mathrm{An}_{1}$ and $\mathrm{M}-\mathrm{Cu}$ cells paler than remainder of membrane. Legs: yellowish-brown, distal half of femora darker. Abdomen: yellowish-brown, dorsal laterotergites with yellow spots anteriorly.

Integument And Vestiture. Head (Fig. 3B) and pronotum: finely granulose with sparse, short macrosetae interspersed among sparse pubescence; antennifer with short lateral setigerous tubercle; morphologically ventral surface of labium with dense, short macrosetae. Thorax: anterolateral angles of pronotal collar with macrosetae. Hemelytron: corium with sparse, long setation. Legs (Fig. 4J): posterior row of protuberances on mid and hind femora with three large spines on distal half and one small spine. Abdomen: ventral surface pubescent.

Structure. Head (Fig. 3B): elongate, 1.3 times as long as wide; anteocular region about one third of head length, shorter than postocular region (measured to anterior margin of neck); postocular region in dorsal view shorter than eye, lateral margins gently rounded; pedicel about 1.3 times length of head width; maxillary plates ellipsoidal, adjacent to and as long as clypeus; apices of maxillary plates in dorsal view directed straight; clypeus in dorsal view about as wide as maxillary plates; clypeal apex round, not narrowed; interocular glabrous markings anterolaterally curved, joined at interocular sulcus paramedially; interocular sulcus in dorsal view bent anteromedially, subtriangular; eye width in dorsal 
view narrower than synthlipsis; eye reaching ventral head margin in lateral view; ventrolateral swelling of buccula with lateral protrusion that surpasses buccular margin; labial segment I in lateral view straight, surpassing posteroventral eye margin; morphologically dorsal surface of labial segment II nearly straight, about 0.5 times length of segment I. Thorax: pronotal collar in dorsal view wide medially with anterolateral angles short, projected forward; anterior pronotal lobe about 0.7 times length of posterior pronotal lobe, lateral margins almost straight; glabrous markings on pronotum deeply depressed; median apodeme depression of pronotum shallow, elongated longitudinally; scutellar spine long, subhorizontal; anteriad-directed process of prosternum smoothly rounded, without paramedial lobes; anterior margin of stridulitrum not elongated into protuberance; proepimeron with acute protuberance on posteroventral margin. Legs: fossula spongiosa present on fore and mid legs.

\section{Female}

Unknown.

Distribution (Fig. 20)

This species is only known from the type locality of Quoin Hill in the Malaysian state of Sabah on the island of Borneo.

\section{Remarks}

The phylogenetic placement of $V$. decorata sp. nov. is uncertain (Figs 1-2).

Voconia dolichocephala sp. nov. urn:lsid:zoobank.org:act:7528828E-ADAD-49A4-BA42-98BCE32BF011

Figs $1-2,6-7,9,18$

\section{Diagnosis}

Distinguished from most other species of Voconia by its tuberculate and coarsely granulose head and pronotum. This species most closely resembles another Australian species, $V$. tuberculata sp. nov. These two species are recognized from other Australian species by the acute protuberance on the posteroventral margin of the proepimeron, long macrosetae of the setigerous tubercles, elongate head (1.4-1.6 times as long as wide), and yellow spots antero- and posteromedially on the abducted corium. Voconia dolichocephala sp. nov. differs from $V$. tuberculata sp. nov. by its overall dark brown, almost black coloration, dorsal laterotergites uniformly dark or with yellow spots posteriorly, and males are smaller than about $7.5 \mathrm{~mm}$. Females slightly surpass the high-end range for female length of $V$. tuberculata sp. nov. $(8.4-8.8 \mathrm{~mm})$.

\section{Etymology}

The specific epithet is the latinized Greek adjective 'dolichocephalus, $-a,-u m$ ', formed from the prefix 'dolicho-' (meaning 'long') and the noun 'cephale' (meaning 'head'), referring to the long head of the type specimen, which is about a fifth of the body length.

\section{Type material}

Holotype

AUSTRALIA • P; Northern Territory, Tindal; $\left[14.52^{\circ} \mathrm{S}, 132.38^{\circ}\right.$ E]; 1-20 Dec. 1967; W. Vestjens leg.; at light; USI: AMNH_PBI 00168747; ANIC.

\section{Paratypes}

AUSTRALIA • 1 \%; Northern Territory, Kakadu NP, S Alligator River, Gungaree Rainforest; $\left[12.65^{\circ} \mathrm{S}\right.$, $132.47^{\circ}$ E]; 17 Dec. 1993; S. and J. Peck leg.; coll. S. and J Peck 93-131; at light; USI: AMNH_PBI 
00170709; deposited in AMNH • 1 q; same collection data as for holotype; USI: AMNH_PBI 00168748; AMNH $\bullet 1$; ; same collection data as for holotype; USI: AMNH_PBI 00168745; AMNH.

\section{Description}

Male (Figs 7, 9)

Body LENGTH. 7.1-7.5 mm; macropterous.

Coloration. Head (Fig. 3F): dark brown; postocular region uniformly dark with pale patches adjacent to lateral ocellar margin; labial segment I nearly as dark as head, segments II and III lighter than head. Thorax: coloration as head; scutellum uniformly dark brown. Hemelytron (abducted): clavus dark brown with distal yellow stripe; corium dark brown with anteromedial, posteromedial, and distal yellow spots; membrane dark with pale V-shaped marking along $\mathrm{R}$ and $\mathrm{M}$ veins; membranal veins $\mathrm{R}$ and $\mathrm{M}$ proximally pale. Legs: dark brown, tarsi yellow. Abdomen: dark brown; dorsal laterotergites uniformly dark or dark with yellow spots posteriorly.

INTEGUMENT AND VESTITURE. Head (Fig. 3F) and pronotum: coarsely granulose with sparse, long setigerous tubercles interspersed among sparse pubescence; interocular region with two pairs of stout setigerous tubercles paramedially; antennifer with long lateral setigerous tubercle; morphologically ventral surface of labium with sparse, short macrosetae. Thorax: anterolateral angles of pronotal collar with setigerous tubercles; scutellar lateral carinae with setigerous tubercles with long macrosetae. Hemelytron: corium with dense long setation. Legs: posterior row of protuberances on mid and hind femora with four large spines on distal half. Abdomen: ventral surface pubescent, long macrosetae interspersed.

STRUCTURE. Head (Fig. 3F): elongate, 1.5-1.6 times as long as wide; anteocular region about one third of head length, shorter than postocular region (measured to anterior margin of neck); postocular region in dorsal view as long as eye, lateral margins gently rounded; pedicel 1.3-1.5 times length of head width; maxillary plates ellipsoidal, adjacent to and as long as clypeus; apices of maxillary plates in dorsal view with medial margins diverging; clypeus in dorsal view wider than maxillary plates; clypeal apex bifid, not narrowed; interocular glabrous markings V-shaped, joined medially at interocular sulcus; interocular sulcus in dorsal view nearly straight; eye width in dorsal view narrower than synthlipsis; eye reaching ventral head margin in lateral view; ventrolateral swelling of buccula without lateral protrusion that surpasses buccular margin, flat margin; labial segment I in lateral view straight, surpassing posteroventral eye margin; morphologically dorsal surface of labial segment II curves ventrally, 0.3-0.4 times length of segment I. Thorax: pronotal collar in dorsal view wide medially with anterolateral angles long, flared laterally; anterior pronotal lobe $0.7-0.8$ times length of posterior pronotal lobe, lateral margins almost straight; glabrous markings on pronotum conspicuous and not depressed; median apodeme depression of pronotum shallow, elongated longitudinally; scutellar spine long, subhorizontal; anteriad-directed process of prosternum with paramedial lobes; anterior margin of stridulitrum projected into small protuberance; proepimeron with acute protuberance on posteroventral margin. Legs: fossula spongiosa present on fore and mid legs. Abdomen: anterior margin of terga weakly carinulate, terga II and III with deeper and longer carinules; terga II and III with paired prominent longitudinal carinae, reaching about two-thirds of tergum III.

\section{Female}

Mostly as male, distinguished from males by the following. Body length: 8.8-9.0 mm. Head: elongate, 1.5-1.6 times as long as wide; pedicel about 1.5-1.7 times length of head width. Legs: fossula spongiosa absent or vestigial on mid leg. 


\section{Distribution (Fig. 18)}

This species is only known from the Northern Territory of Australia. The nearest species of Voconia is V. tuberculata sp. nov., known from about $100 \mathrm{~km}$ southeast of the three specimens collected in Tindal.

\section{Remarks}

Voconia dolichocephala sp. nov. is nested among the Australian clade. According to the phylogeny (Figs 1-2), it is the sister taxon to V. tuberculata sp. nov.

Voconia fasciata sp. nov.

urn:lsid:zoobank.org:act:22FAB401-5B52-4866-86CD-0ED8B980A3A5

Figs 1-2, 7, 9, 18

\section{Diagnosis}

Distinguished from most other species of Voconia by its tuberculate and coarsely granulose head and pronotum, lateral protrusion of the buccula, and dorsally projecting mandibular plates. This species most closely resembles three other Australian species, $V$. grandioculata sp. nov., $V$. pallidipes, and $V$. vittata sp. nov. This species, $V$. grandioculata sp. nov., and $V$. vittata sp. nov. have a similar yellow stripe across the corium; however, the stripe in $V$. fasciata sp. nov. is pale, almost translucent and the body is larger, total length is about $8.7 \mathrm{~mm}$ long. It is easily distinguished from $V$. pallidipes by its smaller size and coloration, i.e., the membranal veins are not yellow, the proximal half of the corium is not entirely yellow, and the legs are not completely yellow as described above.

\section{Etymology}

The specific epithet is the Latin adjective 'fasciatus, - $a$, -um', meaning 'banded', referring to the pale yellow band that crosses the middle of the corium and scutellar spine.

\section{Type material}

\section{Holotype}

AUSTRALIA - $0^{\wedge}$; Queensland, Einasleigh River, $33 \mathrm{~km} \mathrm{~W}$ of Mt Surprise; [18.13 $\mathrm{S}, 143.99^{\circ} \mathrm{E}$; 10-11 Jun. 1993; M. and B. Baehr leg.; USI: AMNH_PBI 00127097; ZSMC.

\section{Description}

Male (Figs 7, 9)

Body LENGTH. About $8.7 \mathrm{~mm}$; macropterous.

COLORATION. Dark brown, maxillary plates lighter; postocular dark with pale patches adjacent to lateral ocellar margin; labium lighter than head. Thorax: coloration as head; posterior pronotal lobe with yellow posterolateral margins; scutellum dark with contrasting yellow apical spine. Hemelytron (abducted): clavus dark brown with distal yellow stripe; corium dark brown with thick medial yellow stripe; membrane and membranal veins uniformly dark. Legs: femora dark brown, tibiae and tarsi yellowishbrown. Abdomen: ventral surface light brown medially, dark brown laterally; dorsal laterotergites I and II paler than remainder.

INTEGUMENT AND VESTitURE. Head and pronotum: coarsely granulose with dense, short setigerous tubercles interspersed among sparse pubescence; interocular region with setigerous tubercles medially and two pairs paramedially; antennifer with long lateral setigerous tubercle; morphologically ventral surface of labium with sparse, short macrosetae. Thorax: anterolateral angles of pronotal collar with setigerous tubercles; scutellar lateral carinae with short macrosetae on setigerous tubercles. Hemelytron: 
corium with dense, long macrosetae. Legs: posterior row of protuberances on mid and hind femora with four spines on distal half. Abdomen: ventral surface pubescent, long macrosetae interspersed.

STRUCTURE. Head: globose, about as long as wide; anteocular region about one third of head length, about as long as postocular region (measured to anterior margin of neck); postocular region in dorsal view shorter than eye, lateral margins gently rounded; pedicel about 1.3 times length of head width; mandibular plates in anterior view projecting dorsolaterally; maxillary plates ellipsoidal, adjacent to and reaching apex of clypeus; apices of maxillary plates in dorsal view diverging; clypeus in dorsal view wider than maxillary plates; clypeal apex bifid, narrowed; interocular glabrous markings anterolaterally curved, joined at interocular sulcus paramedially; interocular sulcus in dorsal view nearly straight; eye width in dorsal view narrower than synthlipsis; eye reaching ventral head margin in lateral view; ventrolateral swelling of buccula with lateral protrusion that surpasses buccular margin, setigerous tubercles along apical margin; labial segment I in lateral view gradually thickens distally, surpassing posteroventral eye margin; morphologically dorsal surface of labial segment II curves ventrally, about 0.3 times length of segment I. Thorax: pronotal collar in dorsal view wide medially with anterolateral angles short, flared laterally; anterior pronotal lobe about 0.7 times length of posterior pronotal lobe, lateral margins almost straight; glabrous markings on pronotum depressed near posterolateral margins; median apodeme depression of pronotum shallow, elongated transversely; scutellar spine long, subhorizontal; anteriad-directed process of prosternum with paramedial lobes; anterior margin of stridulitrum projected into sharp spine; proepimeron with smoothly rounded posteroventral margin. Legs: fossula spongiosa present on fore and mid legs.

\section{Female}

Unknown.

Distribution (Fig. 18)

This species is only known from the type locality of Einasleigh River in Queensland, Australia.

\section{Remarks}

Voconia fasciata sp. nov. is nested within the Australian clade (Figs 1-2). Though poorly supported, it forms the sister taxon to $V$. brachycephala sp. nov. and $V$. vittata sp. nov.

Voconia grandioculata sp. nov. urn:lsid:zoobank.org:act:23167BBE-77C8-434F-9574-B9F59130EAAB

Figs 1-2, 4E, 7, 9, 11, 14, 18

\section{Diagnosis}

Distinguished from most other species of Voconia by its tuberculate and coarsely granulose head and pronotum, the lateral protrusion of the buccula, and notably the large ocelli that occupy half the length of the postocular region. Due to the yellow stripe across the corium, this species resembles two other Australian species, $V$. fasciata sp. nov. and $V$. vittata sp. nov. However, the yellow stripe of this species is bright and opaque, unlike that of $V$. fasciata sp. nov. Additionally, the legs are entirely yellow, and the corium has a small proximal yellow spot. It is easily distinguished from V. pallidipes by the brown membranal veins, the proximal half of the corium being not entirely yellow, and its globose head.

\section{Etymology}

The specific epithet is the Latin adjective 'grandioculatus, $-a,-u m$ ', formed from the prefix 'grandi-' (meaning 'large') combined with the adjective 'oculatus, $-a,-u m$ ' (meaning 'possessing eyes'), referring to the large ocelli of this species, occupying half the length of the postocular region. 
CASTILLO S. et al., Phylogeny and taxonomy of Pseudocetherinae

\title{
Type material
}

Holotype

AUSTRALIA - $\widehat{~}$ (dissected pygophore and aedeagus in vial); Queensland, $3 \mathrm{~km}$ NE of Mt Webb; [15.05 $\left.\mathrm{S}, 145.15^{\circ} \mathrm{E}\right] ; 30$ Apr.-3 May 1981; A. Calder leg.; at light; USI: AMNH_PBI 00168749; ANIC.

\section{Paratype}

AUSTRALIA • 1 § ; Western Australia, East York; USI: AMNH_PBI 00213934; HNHM.

\author{
Description \\ Male (Figs 7, 9) \\ Body LeNGTH. 9.2-9.7 mm; macropterous.
}

Coloration. Head: dark brown; postocular region with pale patches adjacent to lateral ocellar margin; labial segment I yellowish brown, segments II and III yellow. Thorax (Fig. 4E): coloration as head; scutellum dark with contrasting yellow apical spine. Hemelytron (abducted): clavus dark brown with distal yellow stripe; corium proximal half mostly yellow, distal half dark brown with yellow spot at distal apex; membrane dark with pale V-shaped marking along $\mathrm{R}$ and $\mathrm{M}$ veins; membranal veins $\mathrm{R}$ and M proximally pale. Legs: yellow. Abdomen: dark brown; dorsal laterotergites uniformly colored.

InTEGUMENT AND Vestiture. Head and pronotum: coarsely granulose with dense, short setigerous tubercles interspersed among sparse pubescence; interocular region with setigerous tubercles medially and two pairs paramedially; antennifer with long lateral setigerous tubercle; morphologically ventral surface of labium with sparse, short macrosetae. Thorax: anterolateral angles of pronotal collar with setigerous tubercles; scutellar lateral carinae with short macrosetae on setigerous tubercles. Hemelytron: corium with dense, long macrosetae. Legs: posterior row of protuberances on mid and hind femora with four spines on distal half. Abdomen: ventral surface pubescent.

StRUCTURE. Head: globose, about as long as wide; anteocular region about one quarter of head length, shorter than postocular region (measured to anterior margin of neck); postocular region in dorsal view shorter than eye, lateral margins gently rounded; pedicel 1.4-1.6 times length of head width; maxillary plates ellipsoidal, adjacent to and as long as clypeus; apices of maxillary plates in dorsal view diverging; clypeus in dorsal view wider than maxillary plates; clypeal apex bifid, not narrowed; interocular glabrous markings anterolaterally curved, joined at interocular sulcus paramedially; interocular sulcus in dorsal view nearly straight; eye width in dorsal view about as wide as synthlipsis; eye reaching ventral head margin in lateral view; ocelli large, occupying halflength of postocular region; ventrolateral swelling of buccula with lateral protrusion that surpasses buccular margin, setigerous tubercles along apical margin; labial segment I in lateral view gradually thickens distally, reaching posteroventral eye margin; morphologically dorsal surface of labial segment II curves ventrally, about 0.4 times length of segment I. Thorax: pronotal collar in dorsal view narrow medially with anterolateral angles short, flared laterally; anterior pronotal lobe 0.60.7 times length of posterior pronotal lobe, lateral margins almost straight; glabrous markings on pronotum depressed near posterolateral margins; median apodeme depression of pronotum shallow, elongated transversely; scutellar spine long, raised (Fig. 4E); anteriad-directed process of prosternum with paramedial lobes; anterior margin of stridulitrum projected into sharp spine; proepimeron with smoothly rounded posteroventral margin. Legs: fossula spongiosa present on fore and mid legs. Abdomen: anterior margin of tergum III weakly carinulate, remaining terga not carinulate; terga II and III with paired prominent longitudinal carinae, reaching about one-third of tergum III. Pygophore (Fig. 11): transverse bridge with rounded posterior margin; posterior region of ventral surface of pygophore in lateral view with slight swelling; median apical process short, sharply bent posteriorly in 
lateral view; lateral pygophore margin with protuberance; posterior pygophore margin with clustered macrosetae on protuberance; parameres sinusoidal, apex round, not sharply tapered or expanded. Aedeagus (Fig. 14): endosoma almost entirely covered with spicules; apex of dorsal phallothecal sclerite tongue-shaped in dorsal view; basal plate extension about 5.7 times as long as wide.

\section{Female}

Unknown.

Distribution (Fig. 18)

This species is known from Queensland and Western Australia.

\section{Remarks}

The phylogenetic placement of $V$. grandioculata sp. nov. within the Australian clade is uncertain (Figs 1-2). The abdomen of the holotype was extracted, but we did not get sufficient DNA in our NGS library for Illumina sequencing.

$$
\begin{aligned}
& \text { Voconia hemera sp. nov. } \\
& \text { urn:lsid:zoobank.org:act:A6B29189-616B-4489-BAE0-4A1F5F055DEA }
\end{aligned}
$$

Figs $1-2,7,9,20$

\section{Diagnosis}

This species is most similar to other Southeast Asian Voconia species with a finely granulose head and pronotum and yellow spots on the anteromedial, posteromedial, and distal apex of the abducted corium. Voconia hemera sp. nov. is larger than $V$. minima sp. nov. $(9.2-9.3 \mathrm{~mm})$. It is distinguished from $V$. ornata, $V$. nyx sp. nov., and $V$. bakeri sp. nov. by its uniformly yellow legs and antenna as well as its uniformly brown scutellum and dorsal laterotergites.

\section{Etymology}

Named after the Greek primordial goddess of the day, Hemera. Refers to the yellow legs and antennae of this species, which differs from a similar yet darker species, $V$. nyx sp. nov., named after the goddess of night. A proper noun in apposition.

\section{Type material}

Holotype

PHILIPPINES • ${ }^{\lambda}$; Laguna, Los Baños; [14.17º N, $121.18^{\circ}$ E]; 1925; Pemberton leg.; USI: UCR ENT 00073812; BPBM.

\section{Paratype}

PHILIPPINES • $1 \partial^{\Uparrow}$; Luzon, Camarines Sur, Mt Isarog, Pili; [13.66 N, $123.37^{\circ}$ E]; elev. 800 m; 25 Apr. 1965; H.M. Torrevillas leg.; light trap; USI: UCR_ENT 00073813; BPBM.

\section{Description}

Male (Figs 1-2)

BODY LENGTH. 9.2-9.3 mm; macropterous.

Coloration. Head: dark brown; postocular region with dark patches adjacent to medial ocellar margin, semicircular pale stripe encircling both ocelli; labium lighter than head, brownish yellow. Thorax: as head; scutellum uniformly dark brown. Hemelytron (abducted): clavus reddish-brown with distal yellow stripe; corium reddish-brown with anteromedial, posteromedial, and distal yellow spots; membrane dark 
with pale $\mathrm{V}$-shaped marking along $\mathrm{R}$ and $\mathrm{M}$ veins; membranal veins $\mathrm{R}$ and $\mathrm{M}$ proximally pale. Legs: yellowish-brown. Abdomen: dark brown.

INTEGUMENT AND VESTITURE. Head and pronotum: finely granulose with dense, long macrosetae interspersed among dense pubescence; interocular region with two pairs of macrosetae paramedially; antennifer with short lateral setigerous tubercle; morphologically ventral surface of labium with dense, short macrosetae. Thorax: anterolateral angles of pronotal collar with macrosetae; scutellar lateral carinae with long setation. Hemelytron: corium with sparse long setation. Legs: posterior row of protuberances on mid and hind femora with three large and two small spines. Abdomen: ventral surface pubescent.

Structure. Head: elongate, about 1.3 times as long as wide; anteocular region about one third of head length, shorter than postocular region (measured to anterior margin of neck); postocular region in dorsal view about as long as eye, lateral margins gently rounded; pedicel about 1.2 times length of head width; maxillary plates ellipsoidal, adjacent to and as long as clypeus; apices of maxillary plates in dorsal view directed straight; clypeus in dorsal view wider than maxillary plates; clypeal apex round, not narrowed; interocular glabrous markings anterolaterally curved, joined at interocular sulcus paramedially; interocular sulcus in dorsal view bent anteromedially, subtriangular; eye width in dorsal view narrower than synthlipsis; eye reaching ventral head margin in lateral view; ventrolateral swelling of buccula without lateral protrusion that surpasses buccular margin, flat margin; labial segment I in lateral view straight, surpassing posteroventral eye margin; morphologically dorsal surface of labial segment II nearly straight, about 0.5 times length of segment I. Thorax: pronotal collar in dorsal view narrow medially, projected forward; anterior pronotal lobe about 0.8 times length of posterior pronotal lobe, lateral margins rounded; glabrous markings on pronotum thin, gently depressed; median apodeme depression of pronotum shallow, elongated transversely; scutellar spine long, raised; anteriad-directed process of prosternum smoothly rounded, without paramedial lobes; anterior margin of stridulitrum not elongated into protuberance; proepimeron with acute protuberance on posteroventral margin. Legs: fossula spongiosa present on fore and mid legs.

\section{Female}

Unknown.

\section{Distribution}

This species is only known from the type locality on the Philippine island of Luzon.

\section{Remarks}

The holotype locality of Los Baños is about $10 \mathrm{~km}$ from the holotype locality of $V$. nyx sp. nov. at Mt Maquiling.

Voconia ifana (Villiers, 1963) comb. nov.

Fig. 17

Pseudocethera ifana Villiers, 1963a: 989, fig. 11.

\section{Revised diagnosis}

Distinguished from other species of Voconia by the following combination of characters: short body length (about $6.5 \mathrm{~mm}$ ); coarsely granulose head and pronotum; maxillary plates are not adjacent to and far surpass clypeal apex; maxillary plates in lateral view are wide, about twice the width of scape; antennifer with long lateral spine; eyes do not reach ventral head margin in lateral view. It is recognized from micropterous individuals of $V$. schoutedeni and $V$. monodi by the toothed apex of the maxillary plates. 


\section{Type material}

\section{Holotype}

SENEGAL • O̊; "Forêt classée de Tobor" [Tobor Forest]; 21 Nov. 1961; "Mission IFAN" [Institut Fondamental d'Afrique Noire exped.]; "sous un morceau de bois mort" [under a piece of dead wood]; MNHN.

\section{Description}

\section{Male}

Body Length. About $6.5 \mathrm{~mm}$; micropterous.

Coloration. As described for $V$. monodi, except legs testaceous.

INTEGUMENT AND VESTITURE. Head and pronotum: coarsely granulose with setigerous tubercles; interocular region with two pairs of large setigerous tubercles paramedially.

STRUCTURE. Head: scape not reaching head apex; antennifer with long lateral spine; postocular region in dorsal view as long as eye, lateral margins subrectangular; maxillary plates in lateral view about twice the width of scape and apex toothed; eye not reaching ventral head margin in lateral view; ventrolateral swelling of buccula with lateral protrusion that surpasses buccular margin; labial segment I in lateral view straight, surpassing posteroventral eye margin. Thorax: scutellar spine reduced, subhorizontal. Abdomen: anterior margin of terga carinulate; tergum II with paired prominent longitudinal carinae reaching posterior margin of segment.

\section{Female}

Unknown.

\section{Distribution (Fig. 17)}

This species is known from Northwest Africa.

\section{Remarks}

The holotype was on loan and not available for study at the time we requested it. Consequently, this description is based on the interpretation of the short differential diagnosis and illustration of the head in lateral view provided by Villiers (1963a). Due to the limited data that we were able to obtain, it was excluded from cladistic analyses, but we are confident that it likely forms a clade with $V$. schoutedeni and $V$. tridens sp. nov. because of the unique head morphology, microptery, and Afrotropical distribution.

Voconia isosceles sp. nov. urn:1sid:zoobank.org:act:826EFBC8-FA03-42DA-8E5E-E0D4F29A5B66

Figs $1-2,7,9,20$

\section{Diagnosis}

This species most closely resembles another Southeast Asian species, $V$. loki sp. nov., due to the finely granulose head and pronotum, yellow legs and antennae, dark pronotum with contrasting yellow posterior margin, and the proximal half of the corium being entirely yellow, distal half dark with small distal yellow spot. Voconia isosceles sp. nov. is slightly larger (about $8.8 \mathrm{~mm}$ long), the membranal veins forming the $\mathrm{Cu}-\mathrm{An}_{1}$ and $\mathrm{M}-\mathrm{Cu}$ cells are paler than the remainder of the membrane, and the postocular region is dark with a semicircular pale stripe encircling both ocelli. 


\section{Etymology}

The specific epithet is the Latin adjective 'isosceles, -, -', which has the same meaning as its equivalent geometric term used in English for a triangle having at least two sides of equal length (also known as a golden triangle). Refers to the yellow or golden isosceles triangle on the proximal half of the corium.

\section{Type material}

\section{Holotype}

PHILIPPINES • ${ }^{\top}$; Mindanao, Gingoog City, Mts Or., Mt Pomalihi, $21 \mathrm{~km} \mathrm{~W}$ of Gingoog City; [8.81 ${ }^{\circ} \mathrm{N}$, $124.92^{\circ}$ E]; elev. $800-1000$ m; 16-18 Oct. 1965; H.M. Torrevillas leg.; light trap; USI: UCR_ENT 00073814; BPBM.

\section{Description}

Male (Figs 7, 9)

Body LENGTH. About $8.8 \mathrm{~mm}$; macropterous.

COLORATION. Head: dark brown; postocular region with dark patches adjacent to medial ocellar margin, semicircular pale stripe encircling both ocelli; labium lighter than head, yellow. Thorax: as head; posterior pronotal lobe with posterior margin lighter, yellow; scutellum dark with contrasting yellow apical spine. Hemelytron (abducted): clavus reddish-brown with distal yellow stripe; corium proximal half yellow, distal half reddish-brown with yellow spot at distal apex; membrane brown with pale V-shaped marking along $\mathrm{R}$ and $\mathrm{M}$ veins; membranal veins forming $\mathrm{Cu}-\mathrm{An}_{1}$ and $\mathrm{M}-\mathrm{Cu}$ cells paler than remainder of membrane. Legs: yellow. Abdomen: dark brown ventrally; laterotergites light brown.

INTEGUMENT AND Vestiture. Head and pronotum: finely granulose with dense, long macrosetae interspersed among dense pubescence; interocular region with two pairs of macrosetae paramedially; antennifer with short lateral setigerous tubercle; morphologically ventral surface of labium with dense, short macrosetae. Thorax: anterolateral angles of pronotal collar with macrosetae; scutellar lateral carinae with long setation. Hemelytron: corium with dense long setation. Legs: posterior row of protuberances on mid and hind femora with three large spines on distal half. Abdomen: ventral surface pubescent, long macrosetae interspersed.

STRUCtURE. Head: elongate, about 1.3 times as long as wide; anteocular region about one third of head length, about as long as postocular region (measured to anterior margin of neck); postocular region in dorsal view about as long as eye, lateral margins gently rounded; pedicel about 1.4 times length of head width; maxillary plates ellipsoidal, adjacent to and as long as clypeus; apices of maxillary plates in dorsal view directed straight; clypeus in dorsal view wider than maxillary plates; clypeal apex round, not narrowed; interocular glabrous markings anterolaterally curved, joined at interocular sulcus paramedially; interocular sulcus in dorsal view bent anteromedially, subtriangular; eye width in dorsal view narrower than synthlipsis; eye reaching ventral head margin in lateral view; ventrolateral swelling of buccula without lateral protrusion that surpasses buccular margin, flat margin; labial segment I in lateral view straight, surpassing posteroventral eye margin; morphologically dorsal surface of labial segment II nearly straight, about 0.3 times length of segment I. Thorax: pronotal collar in dorsal view narrow medially with anterolateral angles short, projected forward; anterior pronotal lobe about 0.6 times length of posterior pronotal lobe, lateral margins rounded; glabrous markings on pronotum conspicuous and not depressed; median apodeme depression of pronotum shallow, elongated transversely; scutellar spine long, raised; anteriad-directed process of prosternum smoothly rounded, without paramedial lobes; anterior margin of stridulitrum not elongated into protuberance; proepimeron with acute protuberance on posteroventral margin. Legs: fossula spongiosa present on fore and mid legs. Abdomen: anterior 
margin of terga prominently carinulate; terga II and III with paired prominent longitudinal carinae, almost reaching posterior margin of tergum III.

\section{Female}

Unknown.

Distribution (Fig. 20)

This species is only known from the type locality in the Philippines.

\section{Remarks}

Based on the record of a Miridae specimen from the same collection event as the holotype, Mt Pomalihi is presumably in Mt Balatukan Range Natural Park. The type locality is also shared with V. bakeri sp. nov. Though $V$. isosceles sp. nov. and $V$. loki sp. nov. closely resemble each other, we are treating them as separate species because they were not recovered as closely related taxa in our analyses (Figs 1-2). This hypothesis should be further tested with additional material.

Voconia laosensis $\mathrm{sp}$. nov. urn:1sid:zoobank.org:act:D92E888A-8436-42C2-8316-881775941725

Figs $1-2,7,9,12,14,20$

\section{Diagnosis}

This species is distinguishable by the elongate $\mathrm{Cu}-\mathrm{An}_{1}$ cell (reaching at least half the length of M-Cu cell) and short labial segment I (not surpassing ventral eye margin in lateral view). This species most closely resembles three other Southeast Asian species, $V$. isosceles sp. nov., $V$. lasiosoma sp. nov., and $V$. loki sp. nov., due to the finely granulose head and pronotum, long setation of the body, semicircular pale stripe encircling both ocelli, and the dark pronotum with contrasting pale posterior margin. However, in $V$. laosensis sp. nov. this pale posterior margin occupies almost the entire posterior pronotal lobe.

\section{Etymology}

A proper noun with the Latin adjectival suffix '-ensis' meaning 'belonging to', referring to the country of the type locality, Laos. To be treated as an adjective.

\section{Type material}

\section{Holotype}

LAOS - $\delta^{\lambda}$ (dissected pygophore and aedeagus in vial); Khammouan Prov., Ban Khoun Ngeun; $18.11666^{\circ} \mathrm{N}, 104.48333^{\circ} \mathrm{E}$; elev. 250 m; 4-16 Nov. 2000; E. Jendek and P. Pacholátko leg.; USI: UCR_ENT 00001552; NHMW.

\section{Description}

\section{Male (Figs 7, 9)}

BoDy LENGTH. About $9.2 \mathrm{~mm}$; macropterous.

Coloration. Head: dark brown, maxillary plates and clypeus lighter; postocular region with dark patches adjacent to medial ocellar margin, semicircular pale stripe encircling both ocelli; labium lighter than head, yellow. Thorax: as head; posterior pronotal lobe lighter than anterior lobe; scutellum dark with brown apical spine. Hemelytron (abducted): clavus dark reddish-brown with proximal and distal yellow stripe; corium dark reddish-brown with anteroproximal yellow stripe, posteromedial and distal yellow spots; membrane uniformly dark; pale V-shaped marking along R and M veins. Legs: yellowish-brown. Abdomen: dark brown, laterotergites light brown. 
INTEGUMENT AND VESTITURE. Head and pronotum: finely granulose with sparse, long macrosetae interspersed among sparse pubescence; interocular region with two pairs of macrosetae paramedially; antennifer with short lateral setigerous tubercle; morphologically ventral surface of labium with dense, short macrosetae. Thorax: anterolateral angles of pronotal collar with macrosetae; scutellar lateral carinae with long setation. Hemelytron: corium with sparse long setation. Legs: posterior row of protuberances on mid and hind femora with three large and one small spines on distal half. Abdomen: ventral surface pubescent.

STRUCTURE. Head: elongate, about 1.2 times as long as wide; anteocular region about one third of head length, about as long as postocular region (measured to anterior margin of neck); postocular region in dorsal view shorter than eye, lateral margins gently rounded; pedicel about 1.2 times length of head width; maxillary plates ellipsoidal, adjacent to and reaching apex of clypeus; apices of maxillary plates in dorsal view directed straight; clypeus in dorsal view wider than maxillary plates; clypeal apex round, not narrowed; interocular glabrous markings anterolaterally curved, joined at interocular sulcus paramedially; interocular sulcus in dorsal view nearly straight; eye width in dorsal view narrower than synthlipsis; eye reaching ventral head margin in lateral view; ventrolateral swelling of buccula without lateral protrusion that surpasses buccular margin, flat margin; labial segment $I$ in lateral view straight, not reaching posteroventral eye margin; morphologically dorsal surface of labial segment II nearly straight, about 0.6 times length of segment I. Thorax: pronotal collar in dorsal view narrow medially, anterolateral angles short, flared laterally; anterior pronotal lobe about 0.5 times length of posterior pronotal lobe, lateral margins rounded; glabrous markings on pronotum thin and not deeply depressed; median apodeme depression of pronotum shallow, elongated longitudinally; scutellar spine long, raised; anteriad-directed process of prosternum smoothly rounded, without paramedial lobes; anterior margin of stridulitrum not elongated into protuberance. Hemelytron: $\mathrm{Cu}-\mathrm{An}_{1}$ cell elongate, reaching at least half the length of $\mathrm{M}-\mathrm{Cu}$ cell. Legs: fossula spongiosa present on fore and mid legs. Pygophore (Fig. 12): transverse bridge with rounded posterior margin; posterior region of ventral surface of pygophore in lateral view straight, not swollen; short median apical process upright in lateral view; lateral pygophore margin with protuberance; posterior pygophore margin with clustered macrosetae on protuberance; parameres sinusoidal, apex tapered into squarely rounded tip. Aedeagus (Fig. 14): endosoma almost entirely covered with spicules; apex of dorsal phallothecal sclerite tongueshaped in dorsal view; basal plate extension 4.4 times as long as wide.

\section{Female}

Unknown.

\section{Distribution (Fig. 20)}

This species is only known from the type locality in Laos. This is the only known species of Voconia on mainland Southeast Asia.

\section{Remarks}

The pygophore was dissected from this pinned holotype and used to extract DNA, for which we acquired the lowest DNA concentration $(0.124 \mathrm{ng} / \mu \mathrm{L})$ and did not sequence.

Voconia lasiosoma sp. nov. urn:1sid:zoobank.org:act:C5495703-AEE2-49FC-8B08-099ED0F398D3

Figs $1-2,7,9,12,14,20$

\section{Diagnosis}

Recognized from other Voconia by the densely long setation on the pronotum, corium, legs, and abdomen. This species most closely resembles two other Southeast Asian species, $V$. isosceles sp. nov. and $V$. loki sp. nov. due to the finely granulose head and pronotum and dark pronotum with contrasting pale posterior margin. While V. loki sp. nov. is also hairy, V. lasiosoma sp. nov. is larger (about $9.4 \mathrm{~mm}$ ) than these 
two species; legs, antennae, and corium are dark yellowish-brown rather than yellow; dark portions of corium and clavus are black rather than reddish-brown; $\mathrm{Cu}-\mathrm{An}_{1}$ cell stout (less than half the length of $\mathrm{M}-\mathrm{Cu}$ cell); and proximal half of corium not entirely yellow (abducted corium with anteroproximal yellowish-brown stripe and posteromedial yellow spot).

\section{Etymology}

Derived from the Latinized Greek prefix 'lasio-' meaning 'hairy' combined with the Latinized Greek noun '-soma' meaning 'body'. Refers to the long macrosetae covering the body and hemelytra. A noun in apposition.
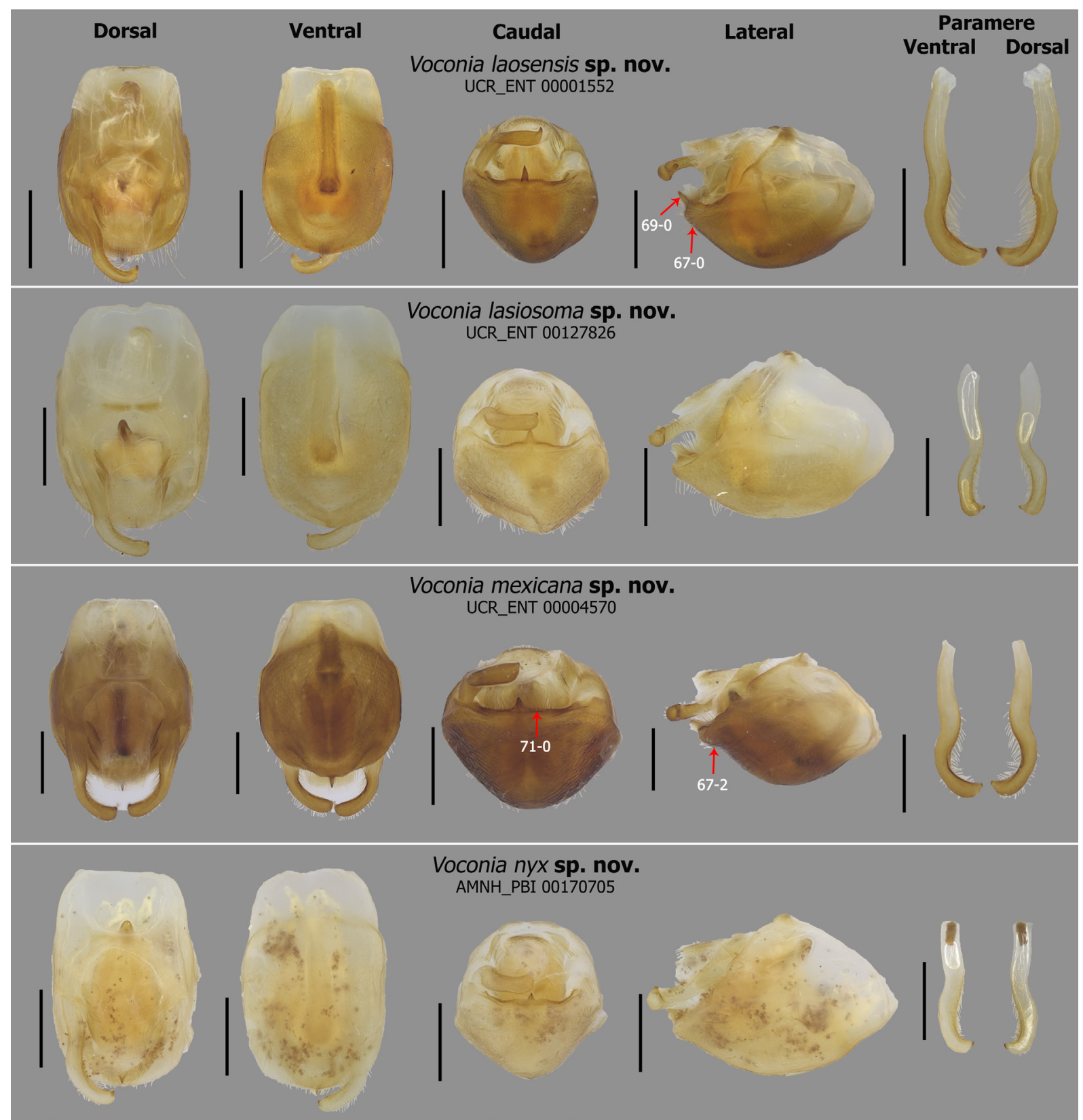

Fig. 12. Pygophore of species of Voconia Stål, 1866. Scale bars $=0.5 \mathrm{~mm}$. 


\section{Type material}

Holotype

MALAYSIA - $\widehat{o}$ (dissected pygophore and aedeagus in vial); Sarawak, Lanjak Entimau Wildlife Sanctuary; [1.55 ${ }^{\circ}$ N, $110.36^{\circ}$ E]; [elev. 3 m]; 9-10 Oct. 2017; W. Hwang et al. leg.; collecting event: SW17_L_27; MV light trap in dipterocarp forest; DNA voucher R_CW 5472; USI: UCR_ENT 00127826; ZRC.

\section{Description \\ Male (Figs 7, 9) \\ BODY LENGTH. About $9.4 \mathrm{~mm}$; macropterous.}

Coloration. Head: dark brown; postocular region with dark patches adjacent to medial ocellar margin, semicircular pale stripe encircling both ocelli; labium lighter than head, yellow. Thorax: anterior pronotal lobe darker than head and posterior pronotal lobe; posterior pronotal lobe with dark yellowish-brown gradient; scutellum dark with contrasting dark yellowish-brown apical spine. Hemelytron (abducted): clavus black with proximal dark yellowish-brown spot and distal yellow stripe; corium black with anteroproximal dark yellowish-brown stripe, posteromedial and distal yellow spots; membrane mostly dark with pale stripe along most of $M$ vein; membranal veins $\mathrm{R}$ and $\mathrm{M}$ proximally pale. Legs: yellowishbrown. Abdomen: dark brown.

Integument AND vestiture. Head and pronotum: finely granulose with dense, long macrosetae interspersed among sparse pubescence; interocular region with two pairs of macrosetae paramedially; antennifer with short lateral setigerous tubercle; morphologically ventral surface of labium with dense, short macrosetae. Thorax: anterolateral angles of pronotal collar with macrosetae; scutellar lateral carinae with long setation. Hemelytron: corium with dense long setation. Legs: posterior row of protuberances on mid and hind femora with three large and three small spines on distal half. Abdomen: ventral surface pubescent, long macrosetae interspersed.

StRUCTURE. Head: elongate, about 1.3 times as long as wide; anteocular region about one third of head length, shorter than postocular region (measured to anterior margin of neck); postocular region in dorsal view shorter than eye, lateral margins gently rounded; length of pedicel subequal to head width; maxillary plates ellipsoidal, adjacent to and shorter than clypeus; apices of maxillary plates in dorsal view directed straight; clypeus in dorsal view wider than maxillary plates; clypeal apex round, not narrowed; interocular glabrous markings anterolaterally curved, joined at interocular sulcus paramedially; interocular sulcus in dorsal view nearly straight; eye width in dorsal view about as wide as synthlipsis; eye reaching ventral head margin in lateral view; ventrolateral swelling of buccula without lateral protrusion that surpasses buccular margin, flat margin; labial segment I in lateral view straight, surpassing posteroventral eye margin; morphologically dorsal surface of labial segment II nearly straight, about 0.5 times length of segment I. Thorax: pronotal collar in dorsal view narrow medially, with anterolateral angles short, flared laterally; anterior pronotal lobe about 0.7 times length of posterior pronotal lobe, lateral margins rounded; glabrous markings on pronotum conspicuous and not depressed; median apodeme depression of pronotum deep, elongated longitudinally; scutellar spine long, subhorizontal; anteriad-directed process of prosternum smoothly rounded, without paramedial lobes; anterior margin of stridulitrum projected into small protuberance; proepimeron with acute protuberance on posteroventral margin. Legs: fossula spongiosa present on fore and mid legs. Abdomen: anterior margin of terga prominently carinulate; terga II and III with paired prominent longitudinal carinae, reaching posterior margin of tergum III. Pygophore (Fig. 12): transverse bridge with rounded posterior margin; posterior region of ventral surface of pygophore in lateral view straight, not swollen; short median apical process, upright in lateral view; lateral pygophore margin with protuberance; posterior pygophore margin with clustered macrosetae on protuberance; parameres sinusoidal, apex tapered into squarely rounded tip. Aedeagus 
(Fig. 14): endosoma almost entirely covered with spicules; apex of dorsal phallothecal sclerite tongueshaped in dorsal view; basal plate extension 5.6 times as long as wide.

\section{Female}

Unknown.

Distribution (Fig. 20)

This species is only known from the type locality in Sarawak, Malaysia.

\section{Remarks}

The holotype was preserved in ethanol when the abdomen was dissected for DNA extraction. We acquired sufficient DNA in our NGS library for Illumina sequencing for future phylogenomic studies, referred to as DNA voucher R_CW 5472.

Voconia lirophleps sp. nov. urn:lsid:zoobank.org:act:66547E0B-D2F8-46E0-B1F7-CC2DD12BFC2A

Figs 1-2, 4B, 7, 9, 20

\section{Diagnosis}

Distinguished from most species of Voconia by the pale membranal veins. This species is most similar to two other Oriental species, $V$. decorata sp. nov. and $V$. coronata sp. nov. It is distinguishable from $V$. decorata sp. nov. by its distribution in Sumatra; the dark brown, almost black coloration of the body; and uniformly brown scutellum. $V$. lirophleps sp. nov. is about $2 \mathrm{~mm}$ shorter than $V$. coronata sp. nov. It is also distinguishable by the yellow spots adjacent to the lateral ocellar margin; slightly more globose head (about 1.2 times as long as wide); pedicel much shorter (about 1.1 times length of head width); maxillary plates converge in dorsal view, postocular region is shorter than eye; narrow pronotal collar; short anterior pronotal lobe relative to posterior pronotal lobe (about 2.2 times shorter than posterior lobe); conspicuous distal yellow spot on the corium; and only three large spines and two small spines on the posterior row of spines of the hind leg.

\section{Etymology}

Derived from the Latinized Greek prefix 'liro-' meaning 'pale' combined with the Latinized Greek noun 'phleps' meaning 'vein'. Refers to the prominent pale coloration of the membranal veins. To be treated as a noun in apposition, ending not to be changed.

\section{Type material}

Holotype

INDONESIA - Õ; Sumatra, Djulu, Rajeu, 250 km N of Medan; elev. 50 m; E.W. Diehl leg.; USI: AMNH_PBI 00170704; AMNH.

\section{Description}

Male (Figs 7, 9)

BoDY LENGTH. About $8.9 \mathrm{~mm}$; macropterous.

Coloration. Head: dark brown; postocular region uniformly dark with pale patches adjacent to lateral ocellar margin; labium nearly as dark as head. Thorax: coloration as head; scutellum uniformly dark brown. Hemelytron (Fig. 4B; abducted): clavus dark reddish-brown with distal yellow stripe; corium dark reddishbrown with anteroproximal yellow stripe, posteromedial and distal yellow spots; membrane uniformly dark; 
membranal veins forming $\mathrm{Cu}-\mathrm{An}_{1}$ and $\mathrm{M}-\mathrm{Cu}$ cells paler than remainder of membrane. Legs: dark brown, femora darker. Abdomen (Fig. 4B): dark brown; dorsal laterotergites dark with yellow spots anteriorly.

INTEGUMENT AND VESTITURE. Head and pronotum: finely granulose with sparse, short macrosetae interspersed among sparse pubescence; interocular region with two pairs of macrosetae paramedially; antennifer with short lateral setigerous tubercle; morphologically ventral surface of labium with sparse, long macrosetae. Thorax: anterolateral angles of pronotal collar with macrosetae; scutellar lateral carinae with long setation. Hemelytron: corium with sparse long setation. Legs: posterior row of protuberances on mid and hind femora with three large and three small spines on distal half. Abdomen: ventral surface pubescent.

STRUCTURE. Head: elongate, 1.2 times as long as wide; anteocular region about one quarter of head length, about as long as postocular region (measured to anterior margin of neck); postocular region in dorsal view shorter than eye, lateral margins gently rounded; pedicel about 1.1 times length of head width; maxillary plates ellipsoidal, adjacent to and as long as clypeus; apices of maxillary plates in dorsal view converging; clypeus in dorsal view narrower than maxillary plates; clypeal apex round, not narrowed; interocular glabrous markings anterolaterally curved, joined at interocular sulcus paramedially; interocular sulcus in dorsal view bent anteromedially, subtriangular; eye width in dorsal view about as wide as synthlipsis; eye reaching ventral head margin in lateral view; ventrolateral swelling of buccula without lateral protrusion that surpasses buccular margin, flat margin; labial segment I in lateral view straight, reaching posteroventral eye margin; morphologically dorsal surface of labial segment II nearly straight, about 0.5 times length of segment I. Thorax: pronotal collar in dorsal view narrow medially with anterolateral angles short, projected forward; anterior pronotal lobe about 0.5 times length of posterior pronotal lobe, lateral margins rounded; glabrous markings on pronotum deeply depressed; median apodeme depression of pronotum shallow, elongated longitudinally; scutellar spine long, raised; anteriad-directed process of prosternum smoothly rounded, without paramedial lobes; anterior margin of stridulitrum not elongated into protuberance; proepimeron with acute protuberance on posteroventral margin. Legs: fossula spongiosa present on fore and mid legs.

\title{
Female
}

Unknown.

\section{Distribution (Fig. 20)}

This species is only known from the type locality in North Sumatra.

\section{Remarks}

Despite the holotypes of $V$. coronata sp. nov. and $V$. lirophleps sp. nov. being collected within about $106 \mathrm{~km}$ of each other, there are several differences, particularly in size. Among our larger series, conspecific Voconia males do not vary much in size, and $V$. lirophleps sp. nov. is about $2 \mathrm{~mm}$ shorter than $V$. coronata sp. nov.; thus, we are keeping them as separate species.

\author{
Voconia loki sp. nov. \\ urn:lsid:zoobank.org:act:BBC757E0-8E3F-4CCC-9B5F-8E7FA5FAB7A2
}

Figs $1-2,3 \mathrm{H}, 8,10,20$

\section{Diagnosis}

This species most closely resembles two other Southeast Asian species, $V$. isosceles sp. nov. and $V$. lasiosoma sp. nov., due to the finely granulose head and pronotum; legs and antennae yellow; pronotum dark with contrasting yellow posterior margin; and relatively denser and longer setation. Voconia loki sp. nov. is smaller (about $8.3 \mathrm{~mm}$ long) than these two species. It is also recognized from $V$. isosceles sp. nov. by the stout $\mathrm{Cu}-\mathrm{An}_{1}$ cell (less than half the length of the $\mathrm{M}-\mathrm{Cu}$ cell), brown membranal veins 
that form the $\mathrm{Cu}-\mathrm{An}_{1}$ and $\mathrm{M}-\mathrm{Cu}$ cells, and the postocular region brown having dark patches adjacent to the medial ocellar margin. Apart from its smaller size, this species is distinguished from V. lasiosoma sp. nov. by the almost entirely yellow proximal half of the corium, reddish-brown distal half of the corium instead of black, and yellow legs instead of a darker yellowish-brown.

\section{Etymology}

Named after the cunning trickster from Norse mythology and from the Marvel Comics' character, Loki, since this specimen deceived and tricked authors in a previous study (Hwang \& Weirauch 2012) who misidentified it as "Kayanocoris wegneri" ( $V$. wegneri comb. nov.). A proper noun in apposition.

\section{Type material}

\section{Holotype}

BRUNEI - ${ }^{\top}$; Belait District, $21.5 \mathrm{~km}$ N of Labi on Labi Rd, Karanga Forest; $4.58244^{\circ} \mathrm{N}, 114.50508^{\circ} \mathrm{E}$; elev. 40 m; 28 Jun. 2010; C. Weirauch and W. Hwang leg.; collecting event: BR10_L18; hand collected; low-elevation dipterocarp forest; DNA voucher R_CW 1590; USI: UCR_ENT 00052216; UCR.

\section{Description}

Male (Figs 8, 10)

Body Length. About $8.3 \mathrm{~mm}$; macropterous.

Coloration. Head (Fig. 3H): light brown; clypeus yellow; postocular region with dark patches adjacent to medial ocellar margin; labium lighter than head, yellow. Thorax: pronotum darker than head; posterior pronotal lobe with posterior margin lighter; scutellum dark with contrasting yellow apical spine. Hemelytron (abducted): clavus reddish-brown with distal yellow stripe; proximal half of corium mostly yellow with small black spot, distal half reddish-brown with distal yellow spot; membrane dark with proximally pale $\mathrm{V}$-shaped marking along $\mathrm{R}$ and $\mathrm{M}$ veins; membranal veins $\mathrm{R}$ and $\mathrm{M}$ proximally pale, veins forming $\mathrm{Cu}-\mathrm{An}_{1}$ cell pale. Legs: yellow. Abdomen: dark brown; dorsal laterotergites yellow.

InTEGUMENT AND VESTituRE. Head and pronotum (Fig. 3H): finely granulose with dense, long macrosetae interspersed among sparse pubescence; interocular region with two pairs of macrosetae paramedially; antennifer with strong macroseta, base not protruded laterally; morphologically ventral surface of labium with dense, short macrosetae. Thorax: anterolateral angles of pronotal collar with macrosetae; scutellar lateral carinae with long setation. Hemelytron: corium with dense long setation. Legs: posterior row of protuberances on mid and hind femora with three large and three small spines on distal half. Abdomen: ventral surface pubescent, long macrosetae interspersed.

StruCtuRe. Head (Fig. 3H): elongate, about 1.2 times as long as wide; anteocular region about one third of head length, about as long as postocular region (measured to anterior margin of neck); postocular region in dorsal view as long as eye, lateral margins gently rounded; pedicel about 0.9 times length of head width; maxillary plates ellipsoidal, adjacent to and shorter than clypeus; apices of maxillary plates in dorsal view directed straight; clypeus in dorsal view wider than maxillary plates; clypeal apex round, narrowed; interocular glabrous markings anterolaterally curved, joined at interocular sulcus paramedially; interocular sulcus in dorsal view bent anteromedially, subtriangular; eye width in dorsal view wider than synthlipsis; eye reaching ventral head margin in lateral view; ventrolateral swelling of buccula without lateral protrusion that surpasses buccular margin, flat margin; labial segment I in lateral view straight, surpassing posteroventral eye margin; morphologically dorsal surface of labial segment II nearly straight, about 0.5 times length of segment I. Thorax: pronotal collar in dorsal view narrow medially with anterolateral angles short, projected forward; anterior pronotal lobe about 0.7 times length of posterior pronotal lobe, lateral margins almost straight; glabrous markings on pronotum conspicuous 
and not depressed; median apodeme depression of pronotum deep, elongated longitudinally; scutellar spine long, raised; anteriad-directed process of prosternum smoothly rounded, without paramedial lobes; anterior margin of stridulitrum not elongated into protuberance; proepimeron with acute protuberance on posteroventral margin. Legs: fossula spongiosa present on fore and mid legs.

\section{Female}

Unknown.

Distribution (Fig. 20)

This species is only known from the type locality in Brunei on the island of Borneo.

\section{Remarks}

The holotype is referred to as Kayanocoris wegneri R_CW 1590 in Hwang \& Weirauch's (2012) molecular phylogeny, where it is recovered as the sister taxon to all other species of Gerbelius.

Voconia mexicana sp. nov. urn:Isid:zoobank.org:act:2FAEA443-4F17-4ABE-9F77-C28792F7D5D0

Figs 1-2, 3I, 4I, 8, 10, 12, 14, 19

\section{Diagnosis}

One of two New World species of Voconia. Recognized by the coarsely granulose head and prothorax; wide anteocular region; morphologically ventral surface of labium with sparsely long macrosetae; buccula with lateral tubercles protruding past buccular margin; and yellow antero- and posteromedial spots on the abducted corium.

\section{Etymology}

The specific epithet is the Latin adjective 'mexicanus, $-a,-u m$ ', meaning 'from or pertaining to Mexico', referring to the country of the type locality.

\section{Type material}

\section{Holotype}

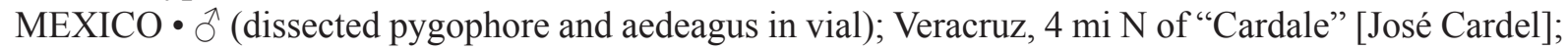
30 Oct. 1982; G. Gordh leg.; DNA voucher R_CW 2768; USI: UCR_ENT 00004570; UCR.

\section{Paratypes}

HONDURAS • 1 q; El Paraíso, 13 km NW of El Zamorano; [14.15 N, 86.47 W]; 27 Jul. 1977; C.W. and L.B. O’Brien and Marshall leg.; USI: AMNH_PBI 00170701; AMNH.

MEXICO • 1 ○; Oaxaca, Tehuantepec; $\left[16.33^{\circ}\right.$ N, 95.23 W]; 11 Jun. 1964; J.C. and D. Pallister leg.; USI: AMNH_PBI 00170702; AMNH. 10 ; same collection data as for preceding; USI: AMNH_PBI 00170703; AMNH.

\section{Description}

Male (Figs 8, 10)

Body LENGTH. 10.3-10.9 mm; macropterous.

Coloration. Head: uniformly dark brown; labium lighter than head, yellow brown. Thorax: as head; posterior pronotal lobe with posterior margin lighter; scutellum dark with brown apical spine. Hemelytron (abducted): clavus dark reddish-brown with distal yellow stripe; corium dark reddish- 
brown with anteromedial and posteromedial yellow spots; membrane dark with pale V-shaped marking along $\mathrm{R}$ and $\mathrm{M}$ veins; membranal veins $\mathrm{R}, \mathrm{M}$, and $\mathrm{An}_{1}$ proximally pale. Legs: dark brown. Abdomen: dark brown, laterotergites light brown.

INTEGUMENT AND VESTITURE. Head and pronotum: coarsely granulose with sparse pubescence on setigerous tubercles; interocular region unarmed with macrosetae; antennifer with 1-3 short lateral setigerous tubercles; morphologically ventral surface of labium with sparse, long macrosetae. Thorax: anterolateral angles of pronotal collar with setigerous tubercles. Hemelytron: corium with dense, short setation. Legs: posterior row of protuberances on mid and hind femora with three large spines on distal half and two to five small spines. Abdomen: ventral surface pubescent.

Structure. Head: elongate, 1.2-1.3 times as long as wide; anteocular region about one third of head length, longer than postocular region (measured to anterior margin of neck); postocular region in dorsal view about as long as eye, lateral margins gently rounded; pedicel 1.4-1.9 times length of head width; maxillary plates ellipsoidal, adjacent to and longer than clypeus; apices of maxillary plates in dorsal view directed straight or diverging; clypeus in dorsal view narrower than maxillary plates; clypeal apex round, not narrowed; interocular glabrous markings anterolaterally curved, joined at interocular sulcus paramedially; interocular sulcus in dorsal view curved and smoothly rounded anteriorly; eye width in dorsal view narrower than synthlipsis; eye reaching ventral head margin in lateral view; ventrolateral swelling of buccula with lateral protrusion that surpasses buccular margin; labial segment I in lateral view straight, reaching or slightly shorter than posteroventral eye margin; morphologically dorsal surface of labial segment II nearly straight, about 0.4 times length of segment I. Thorax: pronotal collar in dorsal view narrow medially with anterolateral angles short, projected forward; anterior pronotal lobe about 0.5-0.6 times length of posterior pronotal lobe, lateral margins rounded; glabrous markings on pronotum thin and gently depressed; median apodeme depression of pronotum deep, circular; scutellar spine long, subhorizontal or raised; anteriad-directed process of prosternum with paramedial lobes (Fig. 3I); anterior margin of stridulitrum projected into small protuberance (Fig. 3I); proepimeron with acute protuberance on posteroventral margin. Legs: fossula spongiosa present on fore and mid legs. Abdomen: anterior margin of terga weakly carinulate; terga II and III with paired prominent longitudinal carinae, reaching about one-third of tergum III. Pygophore (Fig. 12): transverse bridge with rounded posterior margin; posterior region of ventral surface of pygophore in lateral view with large swelling; short median apical process sharply bent posteriorly in lateral view; lateral pygophore margin with protuberance; posterior pygophore margin with clustered macrosetae on flat margin; parameres sinusoidal, apex tapered into squarely rounded tip. Aedeagus (Fig. 14): endosoma almost entirely covered with spicules; apex of dorsal phallothecal sclerite rounded in dorsal view; basal plate extension about 4.3 times as long as wide.

\section{Female}

Distinguished from males by the following. Body length: about $12.2 \mathrm{~mm}$. Head: elongate, about 1.2 times as long as wide; anteocular region shorter than postocular region (measured to anterior margin of neck); with sparse, short macrosetae on setigerous tubercles and sparse pubescence on setigerous tubercles; pedicel about 1.6 times length of head width; apices of maxillary plates in dorsal view directed straight; labium lighter than head, brown; labial segment I in lateral view surpassing posteroventral eye margin. Thorax: pronotal collar in dorsal view narrow, almost absent medially; anterolateral angles of pronotum long, projected forward. Hemelytron: corium dark with thick medial yellow stripe; with dense, long macrosetae. Legs: posterior row of protuberances on mid and hind femora with three large spines on distal half and many small spines (Fig. 4I); fossula spongiosa absent or vestigial on mid leg.

\section{Distribution (Fig. 19)}

This species is distributed in Southern Mexico and Honduras. 


\section{Remarks}

The female from Honduras is considerably different from the males from Mexico as the description states above. We keep them as a single species until this hypothesis can be further tested with additional material. Specimen voucher UCR_ENT 00004570 was mis-labelled as collected "4 mi N of Cardale", though it should be " $4 \mathrm{mi} \mathrm{N}$ of José Cardel" as recorded by other collectors on the same trip.

Voconia minima sp. nov. urn:lsid:zoobank.org:act:CFBDCF33-C855-47F0-9945-98BE6E37A338

Figs $1-2,8,10,20$

\section{Diagnosis}

This species is recognized from other Philippine species such as $V$. bakeri sp. nov. and $V$. nyx sp. nov. by its short body length (about $8.5 \mathrm{~mm}$ long); dark tibiae with proximal and distal ends yellow; and abducted corium with yellow stripe occupying half of the anteroproximal margin and expanding medially to become adjacent to posteromedial yellow spot.

\section{Etymology}

The specific epithet is the Latin adjective 'minimus, $-a$, -um', meaning 'smallest'. Refers to the fact that this is among the smallest species of Voconia.

\section{Type material}

\section{Holotype}

PHILIPPINES - O; $^{\circ}$ Mindanao, Zamboanga del Sur, Lemesahan; [7.84 N, $123.30^{\circ}$ E]; elev. $600 \mathrm{~m}$; 7 Sep. 1958; H.E. Milliron leg.; tight trap; USI: UCR_ENT 00073811; BPBM.

\section{Description}

Male (Figs 8, 10)

Body LENGTH. About $8.5 \mathrm{~mm}$; macropterous.

Coloration. Head: dark brown; postocular region with pale patches adjacent to lateral ocellar margin; labium nearly as dark as head. Thorax: as head; scutellum dark, tip of apical spine contrasting yellow. Hemelytron (abducted): clavus dark reddish-brown with distal yellow stripe; corium dark reddishbrown with anteroproximal yellow stripe, posteromedial and distal yellow spots; membrane dark with pale $\mathrm{V}$-shaped marking along $\mathrm{R}$ and $\mathrm{M}$ veins; membranal veins $\mathrm{R}$ and $\mathrm{M}$ proximally pale. Legs: dark brown, proximal and distal ends of tibiae and tarsi yellow. Abdomen: dark brown.

INTEGUMENT AND VESTITURE. Head and pronotum: finely granulose with sparse, long macrosetae interspersed among dense pubescence; interocular region with two pairs of macrosetae paramedially; antennifer with short lateral setigerous tubercle; morphologically ventral surface of labium with dense, short macrosetae. Thorax: anterolateral angles of pronotal collar with macrosetae; scutellar lateral carinae with long setation. Hemelytron: corium with sparse, long setation. Legs: posterior row of protuberances on mid and hind femora with three large and two small spines on distal half. Abdomen: ventral surface pubescent.

Structure. Head: elongate, about 1.4 times as long as wide; anteocular region about one quarter of head length, shorter than postocular region (measured to anterior margin of neck); postocular region in dorsal view about as long as eye, lateral margins gently rounded; pedicel about 1.2 times length of head width; maxillary plates ellipsoidal, adjacent to and longer than clypeus; apices of maxillary plates in dorsal view converging; clypeus in dorsal view about as wide as maxillary plates; clypeal apex 
round, narrowed; interocular glabrous markings anterolaterally curved, joined at interocular sulcus paramedially; interocular sulcus in dorsal view nearly straight; eye width in dorsal view about as wide as synthlipsis; eye reaching ventral head margin in lateral view; ventrolateral swelling of buccula without lateral protrusion that surpasses buccular margin, flat margin; labial segment I in lateral view straight, surpassing posteroventral eye margin; morphologically dorsal surface of labial segment II nearly straight, about 0.5 times length of segment I. Thorax: pronotal collar in dorsal view narrow medially with anterolateral angles short, projected forward; anterior pronotal lobe about 0.6 times length of posterior pronotal lobe, lateral margins rounded; glabrous markings on pronotum thin and not deeply depressed; median apodeme depression of pronotum shallow, elongated transversely; scutellar spine long, raised; anteriad-directed process of prosternum smoothly rounded, without paramedial lobes; anterior margin of stridulitrum not elongated into protuberance; proepimeron with acute protuberance on posteroventral margin. Legs: fossula spongiosa present on fore and mid legs.

\section{Female}

Unknown.

Distribution (Fig. 8)

This species is only known from the type locality on the Philippine island of Mindanao.

\section{Remarks}

The carinules on the dorsal surface of the abdomen were not examined in order to prevent damage to the holotype.

Voconia monodi (Villiers, 1963) comb. nov.

Fig. 17

Pseudocethera monodi Villiers, 1963b: 532, figs 14-15.

\section{Revised diagnosis}

Distinguished from other species of Voconia by the following combination of characters: short body length (about $7.0 \mathrm{~mm}$ long); coarsely granulose head and pronotum; maxillary plates not adjacent to and far surpass clypeal apex; maxillary plates in lateral view wide, about twice the width of the scape and not toothed apically; antennifer with long lateral spine. It is recognized from the micropterous $V$. schoutedeni by the paired, short, and not prominent longitudinal carinae on tergum II, not reaching the posterior margin of the segment; reliefs of the anterior lobe of the pronotum less strong, effaced in front; and indistinct ocelli.

\section{Type material}

Holotype

GUINEA • O; "Région du Mont Nimba" [Mount Richard-Molard region], "Camp du Gouan" [Guinea camp]; 5 Apr. 1957; L.A.V. leg.; prairie; MNHN.

\section{Redescription}

\section{Female}

Body LengTh. About $7.0 \mathrm{~mm}$; micropterous.

Coloration. Head: yellowish brown. Thorax: Pronotum yellowish in front and on the sides, brown on the rest of the surface; scutellum brown. Micropterous wing: yellowish. Legs: brown with proximal and 
distal part of femur and tarsus testaceous. Abdomen: dark brown, dorsal laterotergites with anterior half yellow.

INTEGUMENT AND VESTITURE. Head and pronotum: coarsely granulose with setigerous tubercles; interocular region with two pairs of large setigerous tubercles paramedially; antennifer with long lateral spine. Legs: posterior row of protuberances on mid and hind femora with three or four spines.

STRUCTURE. Head: scape not reaching head apex and longer than clypeus; apices of maxillary plates in dorsal view directed straight; clypeus in dorsal view narrower than maxillary plates; clypeal apex round, narrowed; eye width in dorsal view narrower than synthlipsis; ocelli absent; postocular region in dorsal view longer than eye, lateral margins subrectangular; labial segment I in lateral view straight, surpassing posteroventral eye margin; pronotal anterolateral angles long, flared laterally; scutellar spine reduced, slightly raised. Abdomen: anterior margin of terga carinulate; tergum II with paired, short, and not prominent longitudinal carinae.

\section{Male \\ Unknown.}

Distribution (Fig. 17)

This species is known from Northwest Africa.

\section{Remarks}

Specimens were on loan and not available for this study. Consequently, this description and localities were inferred from the French description, illustrations, and key provided by Villiers (Villiers 1963b, 1964). Villiers (1963b) includes an additional specimen from Guinea that was not treated as type material that we could not examine and have limited information for. We therefore refrain from including it. A drawer image of two specimens from the BMNH in 2011 suggests that this species may be distributed in Sierra Leone (collection event: 11 May 1926) and Nigeria, but their identification is difficult to confirm without better images and without the holotype.

Voconia motoensis (Schouteden, 1929) comb. nov.

Figs 1-2, 8, 10, 17

Microvarus motoensis Schouteden, 1929: 252.

Microvarus inermiceps Villiers, 1964: 107, fig. 27. Synonymized by Villiers (1976: 171).

\section{Revised diagnosis}

Distinguished from other species in Voconia by its finely granulose head; short labial segment I that does not reach posteroventral eye margin; anterior margin of buccula with dense, long macrosetae; and stout body. This species most closely resembles $V$. conradti and $V$. smithae sp. nov. in its stout body plan and Afrotropical distribution. It is easily recognized from these two species by the absent or vestigial fossula spongiosa on the midleg and its distinct coloration: uniformly brown scutellum, abducted corium with an anteromedial yellow spot, and uniformly brown dorsal laterotergites.

\section{Type material}

\section{Holotype}

DEMOCRATIC REPUBLIC OF THE CONGO • + ; Haut-Uélé, Moto; $\left[2.90556^{\circ} \mathrm{N}, 29.415^{\circ} \mathrm{E}\right]$; [elev. 898 m]; 1920; L. Burgeon leg.; USI: UCR_ENT 00070525; RMCA ENT 000018004. 


\section{Redescription}

Female (Figs 8, 10)

Body LENGTH. About $11.6 \mathrm{~mm}$; macropterous.

Coloration. Head: dark brown; labium nearly as dark as head. Thorax: coloration as head; posterior pronotal lobe with posterior margin lighter; scutellum uniformly dark brown. Hemelytron (abducted): clavus dark reddish-brown with distal yellow stripe; corium dark reddish-brown with anteromedial and posteromedial yellow spots; membrane dark with pale V-shaped marking along $\mathrm{R}$ and $\mathrm{M}$ veins; membranal veins proximally pale. Legs: yellowish-brown with distal half of femora dark brown. Abdomen: dark brown; dorsal laterotergites uniformly dark brown.

INTEGUMENT AND VESTITURE. Head and pronotum: finely granulose with sparse, short macrosetae interspersed among dense pubescence; antennifer with macroseta, base not protruded; morphologically ventral surface of labium with dense, short macrosetae. Thorax: anterolateral angles of pronotal collar with macrosetae. Hemelytron: corium with sparse long setation. Legs: posterior row of protuberances on mid and hind femora with three large spines on distal half, middle spine much longer. Abdomen: ventral surface pubescent.

Structure. Head: elongate, about 1.2 times as long as wide; anteocular region about one quarter of head length, shorter than postocular region (measured to anterior margin of neck); postocular region in dorsal view shorter than eye, lateral margins gently rounded; pedicel about 1.5 times length of head width; maxillary plates ellipsoidal, adjacent to and longer than clypeus; apices of maxillary plates in dorsal view directed straight; clypeus in dorsal view wider than maxillary plates; clypeal apex round, not narrowed; interocular glabrous markings anterolaterally curved, joined at interocular sulcus paramedially; interocular sulcus in dorsal view bent anteromedially, subtriangular; eye width in dorsal view wider than synthlipsis, eye not reaching ventral head margin in lateral view; ventrolateral swelling of buccula without lateral protrusion that surpasses buccular margin, flat margin; labial segment I in lateral view straight, not reaching posteroventral eye margin; morphologically dorsal surface of labial segment II nearly straight, about 0.7 times length of segment I. Thorax: pronotal collar wide medially with anterolateral angles short, projected forward; anterior pronotal lobe about 0.7 times length of posterior pronotal lobe, lateral margins almost straight; glabrous markings on pronotum thin and not deeply depressed; median apodeme depression of pronotum deep, circular; scutellar spine long, raised; anteriad-directed process of prosternum smoothly rounded, without paramedial lobes; anterior margin of stridulitrum not elongated into protuberance; proepimeron with smoothly rounded posteroventral margin. Legs: fossula spongiosa present on fore leg, absent or vestigial on mid leg.

\section{Male \\ Unknown.}

Distribution (Fig. 17)

Only known from Moto and Garamba National Park (Villiers 1964) in the Haut-Uélé province of the Democratic Republic of the Congo.

\section{Remarks}

The carinules on the dorsal surface of the abdomen were not examined to prevent damage to the holotype. The synonymy of Microvarus inermiceps proposed by Villiers (1976: 171) was accepted without a reexamination of the type material. 


\section{Voconia nyx sp. nov. \\ urn:1sid:zoobank.org:act:374635C1-1613-483F-A653-17F63F0C9545 \\ Figs $1-2,4 \mathrm{~F}-\mathrm{H}, 8,10,12,14,20$}

\section{Diagnosis}

This species is most similar to other Southeast Asian species of Voconia with a finely granulose head and pronotum and abducted corium with yellow spots on the posteromedial and distal apex. Despite the similarity in color, $V$. nyx sp. nov. is larger than $V$. minima sp. nov. (about $10.0 \mathrm{~mm}$ long) and has uniformly brown legs. It is distinguished from $V$. bakeri $\mathrm{sp}$. nov. by its uniformly brown dorsal laterotergites, pale stripe along the posterior margin of the pronotum, and the abducted corium with an anteroproximal yellowish-brown stripe.

\section{Etymology}

Named after the Greek primordial goddess of the night, Nyx. Refers to the dark legs and antennae of this species, which differ from those of a similar yet lighter colored species, Voconia hemera sp. nov., named after the goddess of day. A proper noun in apposition.

\section{Type material}

\section{Holotype}

PHILIPPINES - $\widehat{\delta}$ (dissected pygophore and aedeagus in vial); Laguna, Mt Maquiling; $\left[14.13^{\circ} \mathrm{N}\right.$, 121.20ํㅡ]; elev. 100 m; 28 Feb. 1949; A.E. Bigornia leg.; USI: AMNH_PBI 00170705; AMNH.

\section{Description}

Male (Figs 8, 10)

Body LENGTH. About $10.0 \mathrm{~mm}$; macropterous.

Coloration. Head: dark brown; postocular region with pale patches adjacent to lateral ocellar margin; labium lighter than head, brown. Thorax (Fig. 4F): as head; posterior pronotal lobe with posterior margin lighter; scutellum uniformly dark brown. Hemelytron (abducted): clavus dark reddish-brown with distal yellow stripe; corium dark reddish-brown with yellowish-brown stripe on anteroproximal margin, posteromedial and distal yellow spots; membrane dark with pale $\mathrm{V}$-shaped marking along $\mathrm{R}$ and $M$ veins; membranal veins $\mathrm{R}$ and $\mathrm{M}$ pale. Legs: dark reddish-brown. Abdomen: dark reddish-brown; dorsal laterotergites dark brown.

INTEGUMENT AND veSTITURE. Head and pronotum: finely granulose with sparse, long macrosetae interspersed among dense pubescence; interocular region with two pairs of macrosetae paramedially; antennifer with short lateral setigerous tubercle; morphologically ventral surface of labium with sparse, long macrosetae. Thorax: anterolateral angles of pronotal collar with macrosetae; scutellar lateral carinae with long setation. Legs: posterior row of protuberances on mid and hind femora with three large spines on distal half and three or fewer small spines. Abdomen: ventral surface pubescent.

Structure. Head: elongate, about 1.3 times as long as wide; anteocular region about one third of head length, about as long as postocular region (measured to anterior margin of neck); postocular region in dorsal view shorter than eye, lateral margins gently rounded; pedicel about 1.2 times length of head width; maxillary plates ellipsoidal, adjacent to and longer than clypeus; apices of maxillary plates in dorsal view directed straight; clypeus in dorsal view about as wide as maxillary plates; clypeal apex round, narrowed; interocular glabrous markings anterolaterally curved, joined at interocular sulcus paramedially; interocular sulcus in dorsal view bent anteromedially, subtriangular; eye width in dorsal view about as wide as synthlipsis; eye reaching ventral head margin in lateral view; ventrolateral swelling 
of buccula without lateral protrusion that surpasses buccular margin, flat margin; labial segment I in lateral view straight, not reaching posteroventral eye margin; morphologically dorsal surface of labial segment II nearly straight, about 0.6 times length of segment I. Thorax: pronotal collar in dorsal view narrow medially with anterolateral angles short, projected forward; anterior pronotal lobe about 0.6 times length of posterior pronotal lobe, lateral margins rounded; glabrous markings on pronotum thin and not deeply depressed; median apodeme depression of pronotum shallow, elongated transversely; scutellar spine long, raised (Fig. 4F); anteriad-directed process of prosternum smoothly rounded, without paramedial lobes; anterior margin of stridulitrum not elongated into protuberance; proepimeron with acute protuberance on posteroventral margin. Legs (Fig. 4G-H): fossula spongiosa present on fore and mid legs. Pygophore (Fig. 12): transverse bridge with triangular posterior margin; posterior region of ventral surface of pygophore in lateral view with large swelling; short median apical process bent posteriorly in lateral view; lateral pygophore margin with protuberance; posterior pygophore margin with clustered macrosetae on protuberance; parameres sinusoidal, apex tapered into squarely rounded tip. Aedeagus (Fig. 14): endosoma almost entirely covered with spicules; apex of dorsal phallothecal sclerite tongue-shaped in dorsal view; basal plate extension 4.6 times as long as wide.

\section{Female}

Unknown.

Distribution (Fig. 17)

This species is only known from the type locality on the Philippine island of Luzon.

\section{Remarks}

The holotype locality of Mt Maquiling is about $10 \mathrm{~km}$ from the holotype locality of $V$. hemera sp. nov. at Los Baños.

Voconia ornata (Distant, 1903) comb. nov.

Figs $1-2,8,10,20$

Gerbelius ornatus Distant, 1903a: 59.

\section{Diagnosis}

Distinguished from other species of Voconia by the following combination of characters: slender and short body ( 7.8-8.7 mm long); proepimeron with protuberance on posteroventral margin; legs yellow with distal half of femora brown; scutellum dark with contrasting yellow apical spine; and dark abducted corium with anteromedial, posteromedial, and distal yellow spots.

\section{Type material}

Lectotype (present designation)

SRI LANKA • đ̄; “Ceylon” [Sri Lanka]; E.E. Green leg.; Distant coll. 1911-383; USI: UCR_ENT $00048381 ; \mathrm{BMNH}$.

\section{Additional material examined}

INDIA - Madhya Pradesh • 1 q; Jahalpur; elev. "1600 ft" [488 m]; Oct. 1957; P.S. Nathan leg.; dissected abdomen in vial; USI: AMNH_PBI 00170698; AMNH • 1 क ; same collection data as for preceding; Susai Nathan leg.; dissected abdomen in vial; USI: AMNH_PBI 00170697; AMNH. - Tamil Nadu • 1 P; Tranquebar, Madras; 30 Mar. 1969; K. Krishna leg.; USI: AMNH_PBI 00170699; AMNH. - Uttar Pradesh • 1 ô; Maldevta, Dehra Dun; elev. "3500ft” [1067 m]; 15 Apr. 1942; Jai K. Uniyal leg.; USI: AMNH_PBI 00170696; AMNH. 


\section{Description}

Male (Figs 8, 10)

Body LENGTH. 8.0-9.0 mm; macropterous.

Coloration. Head: light brown; postocular region with pale patches adjacent to lateral ocellar margin; labium lighter than head, brown to yellow. Thorax: as head; scutellum dark with contrasting yellow apical spine. Hemelytron (abducted): clavus reddish-brown with distal yellow stripe; corium reddishbrown with anteromedial, posteromedial, and distal yellow spots; membrane dark with pale V-shaped marking along $\mathrm{R}$ and $\mathrm{M}$ veins; membranal veins $\mathrm{R}$ and $\mathrm{M}$ proximally pale. Legs: yellow, distal half of femora brown. Abdomen: light brown; dorsal laterotergites dark brown with faint pale bands on posterior margins.

INTEGUMENT AND Vestiture. Head and pronotum: finely granulose with dense, short macrosetae interspersed among dense pubescence; interocular region with two pairs of macrosetae paramedially; antennifer with short lateral setigerous tubercle; morphologically ventral surface of labium with sparse, short macrosetae. Thorax: anterolateral angles of pronotal collar with macrosetae. Hemelytron: corium with dense, long macrosetae. Legs: posterior row of protuberances on mid and hind femora with three large spines on distal half and many small spines. Abdomen: ventral surface pubescent.

StRUCTURE. Head: elongate, about 1.3 times as long as wide; anteocular region about one third of head length, about as long as postocular region (measured to anterior margin of neck); postocular region in dorsal view about as long as eye, lateral margins gently rounded; pedicel 1.3-1.4 times length of head width; maxillary plates ellipsoidal, adjacent to and longer than clypeus; apices of maxillary plates in dorsal view directed straight or diverging; clypeus in dorsal view about as wide as maxillary plates; clypeal apex round, not narrowed; interocular glabrous markings anterolaterally curved, joined at interocular sulcus paramedially; interocular sulcus in dorsal view nearly straight; eye width in dorsal view narrower than synthlipsis; eye reaching ventral head margin in lateral view; ventrolateral swelling of buccula with lateral protrusion that surpasses buccular margin, setigerous tubercles along apical margin; labial segment I in lateral view straight, reaching posteroventral eye margin; morphologically dorsal surface of labial segment II nearly straight, about 0.5 times length of segment I. Thorax: pronotal collar in dorsal view narrow medially with anterolateral angles short, projected forward; anterior pronotal lobe $0.7-0.8$ times length of posterior pronotal lobe, lateral margins almost straight; glabrous markings on pronotum thin and deeply depressed; median apodeme depression of pronotum deep, circular; scutellar spine long, subhorizontal; anteriad-directed process of prosternum smoothly rounded, without paramedial lobes; anterior margin of stridulitrum not elongated into protuberance; proepimeron with acute protuberance on posteroventral margin. Legs: fossula spongiosa present on fore and mid legs.

\section{Female}

Mostly as male, distinguished from males by the following. Body length: 7.8 $-8.5 \mathrm{~mm}$. Head: elongate, 1.3-1.4 times as long as wide; pedicel 1.3-1.5 times length of head width. Legs: fossula spongiosa absent or vestigial on mid leg.

Distribution (Fig. 20)

Distributed in India and Sri Lanka.

\section{Remarks}

Originally described as Gerbelius ornatus based on an unspecified number of specimens (syntypes) from Sri Lanka (Distant 1903a). Cladistic analyses (Weirauch 2008; present study: Figs 1-2) confirm that this 
species is nested within Voconia, and hence it is hereby transferred to the latter genus. The abdomen of pinned specimen USI: AMNH_PBI 00170697 was removed for DNA extraction, but insufficient DNA was acquired in the NGS library for Illumina sequencing.

A single male pertaining to the type series (Fig. 8), here designated as the lectotype, was examined from a unit tray image at the BMNH, along with six other specimens for which we can only distinguish the locality for one specimen as Halwaldi, India and is not included in our distribution map nor material examined (Fig. 20). While the locality and date for the lectotype are not specified, we are confident that this specimen was studied by Distant. Kirby (1891) notes that the collector E.E. Green shared his collection of Hemiptera with the BMNH, most of which were collected at Pundaloya and could be inferred as the locality where no locality is mentioned. Less likely localities include Nitagala, Nawalapitya, Kandy, Colombo, or other.

Voconia pallidipes Stål, 1866

Figs 1-2, 3C, 8, 10, 13-14, 18

Voconia pallidipes Stål, 1866b: 165.

\section{Diagnosis}

Distinguished from most other species of Voconia by the tuberculate and coarsely granulose head and pronotum, tuberculate lateral protrusion of the buccula, the anterolateral angles of the pronotal collar with many (more than two) setigerous tubercles, and the abducted corium with the proximal half entirely yellow and distal half dark with distal yellow spot. This species resembles another Australian species, V. grandioculata sp. nov., in coloration but is easily distinguished by its larger size (10.5-11.3 mm long), smaller eyes and ocelli (ocellus does not occupy half-length of postocular region), $\mathrm{M}-\mathrm{Cu}$ cell partially or entirely yellow, membranal veins forming $\mathrm{Cu}-\mathrm{An}_{1}$ and $\mathrm{M}-\mathrm{Cu}$ cells mostly or entirely yellow, and yellow clavus with a dark medial spot.

\section{Type material}

Lectotype (present designation)

AUSTRALIA • 1 \%; Queensland, Moreton Bay; Stevens leg.; NHRS-GULI000007827.

\section{Additional material examined:}

AUSTRALIA - New South Wales - 1 o ; Inverell; $\left[29.78^{\circ} \mathrm{S}, 151.12^{\circ} \mathrm{E}\right]$; Armstrong leg.; USI:

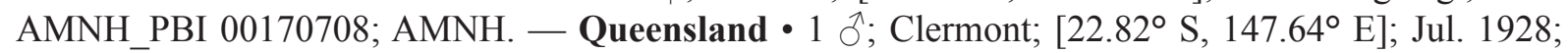
K.K. Spence leg.; USI: AMNH_PBI 00088008; AMS K 156495 • 1 ¿ ; Condamine River, 10 km WSW of Dalby; [27.21ํ S, $151.18^{\circ}$ E]; 5 Nov. 1990; M. Baehr leg.; USI:AMNH_PBI 00127094; ZSMC• 1 ○; Mackenzie River Fitzroy Developmental Road; [22.94 S, 148.92 E]; 11 Nov. 1990; M. Müller leg.; USI: AMNH_PBI 00127093; ZSMC.

\section{Description}

Male (Figs 8, 10)

Body LENGTH. 10.5-11.3 mm; macropterous.

Coloration. Head (Fig. 3C): dark brown; postocular region with pale patches adjacent to lateral ocellar margin; labium lighter than head, yellow. Thorax: as head; scutellum dark with contrasting yellow apical spine. Hemelytron (abducted): clavus yellow with dark medial spot; corium proximal half yellow, distal half dark reddish-brown with yellow spot at distal apex; membrane dark with pale V-shaped marking along $\mathrm{R}$ and $\mathrm{M}$ veins, $\mathrm{M}-\mathrm{Cu}$ cell entirely or partially yellow; membranal veins forming $\mathrm{Cu}-\mathrm{An}_{1}$ and $\mathrm{M}-\mathrm{Cu}$ cells mostly or entirely yellow. Legs: yellow. Abdomen: light brown, laterotergites uniformly yellow. 
InTEGUMENT AND Vestiture. Head (Fig. 3C) and pronotum: coarsely granulose with dense, short setigerous tubercles interspersed among sparse pubescence; antennifer with long and 1-2 adjacent short lateral setigerous tubercles; morphologically ventral surface of labium with sparse, short macrosetae. Thorax: anterolateral angles of pronotal collar with setigerous tubercles; scutellar lateral carinae with short macrosetae on setigerous tubercles. Hemelytron: corium with short macrosetae. Legs: posterior row of protuberances on mid and hind femora with four or more large spines on distal half. Abdomen: ventral surface pubescent.

StRUCTURe. Head (Fig. 3C): elongate, 1.2-1.3 times as long as wide; anteocular region about one third of head length, about as long as postocular region (measured to anterior margin of neck); postocular region in dorsal view longer than eye, lateral margins gently rounded; pedicel 1.4-1.6 times length of head width; maxillary plates ellipsoidal, adjacent to and longer than clypeus; apices of maxillary plates in dorsal view diverging; clypeus in dorsal view about as wide as maxillary plates; clypeal apex bifid, not narrowed; interocular glabrous markings anterolaterally curved, joined at interocular sulcus paramedially; interocular sulcus in dorsal view nearly straight; eye width in dorsal view about as wide as synthlipsis; ventral eye margin surpassed by setigerous tubercles in lateral view; ventrolateral swelling of buccula with large lateral setigerous tubercles that surpass buccular margin; labial segment I in lateral view straight, surpassing posteroventral eye margin; morphologically dorsal surface of labial segment II curves ventrally, about 0.4 times length of segment I. Thorax: pronotal collar in dorsal view narrow medially with anterolateral angles short, flared laterally; anterior pronotal lobe about 0.8 times length of posterior pronotal lobe, lateral margins rounded; glabrous markings on anterior pronotal lobe depressed near posterolateral margins of pronotum; median apodeme depression of pronotum deep, elongated transversely; scutellar spine long, subhorizontal; anteriad-directed process of prosternum with paramedial lobes; anterior margin of stridulitrum projected into small protuberance; proepimeron with smoothly rounded posteroventral margin. Legs: fossula spongiosa present on fore and mid legs. Abdomen: anterior margin of terga weakly carinulate, tergum II without carinules laterally; terga II and III with paired prominent longitudinal carinae, reaching about one-third of tergum III. Pygophore (Fig. 13): transverse bridge with rounded posterior margin; posterior region of ventral surface of pygophore in lateral view with large swelling; short median apical process, bent posteriorly in lateral view; lateral pygophore margin with protuberance; posterior pygophore margin with clustered macrosetae on decline; parameres sinusoidal, apex tapered sharply. Aedeagus (Fig. 14): endosoma almost entirely covered with spicules; apex of dorsal phallothecal sclerite bifid in dorsal view; basal plate extension about 5.8 times as long as wide.

\section{Female}

As male. Body length: about $10.7 \mathrm{~mm}$. Head: elongate, about 1.3 times as long as wide; pedicel about 1.5 times length of head width. Legs: fossula spongiosa absent or vestigial on mid leg.

\section{Distribution}

Only known from Eastern Australia.

\section{Remarks}

We were unable to physically examine the type material of Voconia pallidipes (photographs available on the NHRS website) and we thus based our redescription and character coding on a specimen deposited at the AMNH that was identified as V. pallidipes (USI: AMNH_PBI 00170708) by P. Wygodzinsky and that matches the diagnostic features visible in the type photographs. The specimen in the NHRS photographs is the only specimen in the series and thus designated as the lectotype. Characters of the dorsal part of the abdomen (i.e., carinules and carinae), pygophore, and aedeagus are based on a single specimen (USI: AMNH_PBI 00127093), to limit damage to specimens. This species is nested within the well supported Australian clade (Figs 1-2). The record and illustration of V. pallidipes by Swanson 
(2015: 268-269, fig. 10) is based on misidentification and pertains to V. brachycephala sp. nov. (see under the latter species).

Voconia schoutedeni (Villiers, 1964) comb. nov.

Figs $1-2,3 \mathrm{D}, 4 \mathrm{D}, 8,10,17$

Pseudocethera schoutedeni Villiers, 1964: 112, fig. 31.

Pseudocethera schoutedeni forme alata Villiers, 1964: 112, fig. 32; infrasubspecific, permanently unavailable under ICZN Article 45.6.3.

\section{Diagnosis}

Distinguished from other species of Voconia by the following combination of characters: coarsely granulose head and pronotum; maxillary plates not adjacent to and far surpassing clypeal apex; maxillary plates in lateral view wide, about twice the width of the scape and not toothed apically; antennifer with long lateral spine; eyes in lateral view do not reach ventral head margin; pedicel short, about 0.6 times length of head width. The macropterous morph is recognized from $V$. tridens sp. nov. by the almost entirely dark brown head and pronotum, the scutellar spine is slightly raised, and the hemelytra are blackish with pale coloration at the base and apex of the corium.

\section{Type material}

\section{Holotype}

DEMOCRATIC REPUBLIC OF THE CONGO • 1 § ; "P. N. G." [Garamba National Park], "AkaGar/4" [confluence of rivers Aka and Garamba south of Mt Bawezi, locality no. 4]; [3.88 $\mathrm{N}, 29.21^{\circ} \mathrm{E}$; 2 Feb. 1951; Miss. H. De Saeger and J. Verschuren leg.; No. 1195; USI: UCR_ENT 00070524; RMCAENT-000018003.

\section{Paratype}

DEMOCRATIC REPUBLIC OF THE CONGO • 1 +; Garamba National Park; 1952; Miss. H. De Saeger leg.; No. 3283; MNHN.

\section{Material examined from original description}

DEMOCRATIC REPUBLIC OF THE CONGO • 1 ô; Garamba National Park; No. 1281; repository not specified in description.

\section{Redescription}

Male (Figs 8, 10)

Body LENGTH. About $6.7 \mathrm{~mm}$, micropterous; about $6.7 \mathrm{~mm}$, macropterous.

Coloration. Head (Fig. 3D): yellow; labium as remainder of head (micropterous); almost entirely dark brown (macropterous). Thorax: as head; posterior pronotal lobe darker than anterior lobe; scutellum brown with darker lateral margins. Wing stumps: yellow with brown posterior margins. Hemelytra: blackish, slightly cleared up at the base and apex of corium. Legs: yellow, distal third of femora dark brown. Abdomen (Fig. 4D): dark brown, dorsal laterotergites with anterior half yellow.

InTEGUMENT AND Vestiture. Head (Fig. 3D) and pronotum: coarsely granulose with dense, short macrosetae on setigerous tubercles; interocular region with two pairs of large setigerous tubercles paramedially; antennifer with long lateral spine; morphologically ventral surface of labium with sparse, short macrosetae. Thorax: anterolateral angles of pronotal collar without macrosetae or setigerous tubercles; scutellar lateral carinae with pubescent tubercles. Legs: posterior row of protuberances on 
mid and hind femora with three large spines on distal half and three or fewer small spines. Abdomen (Fig. 4D): ventral surface pubescent.

STRUCTURE. Head (Fig. 3D): elongate, about 1.4 times as long as wide, narrower in macropterous morph; anteocular region two-fifths of head length, longer than postocular region (measured to anterior margin of neck); postocular region in dorsal view longer than eye, lateral margins subrectangular; scape not reaching apex of head, about 0.4 times length of pedicel; pedicel about 0.6 times length of head width; maxillary plates conical, not adjacent to or longer than clypeus; apices of maxillary plates in dorsal view directed straight; clypeus in dorsal view narrower than maxillary plates; clypeal apex round, narrowed; interocular glabrous markings V-shaped, joined medially at interocular sulcus; interocular sulcus in
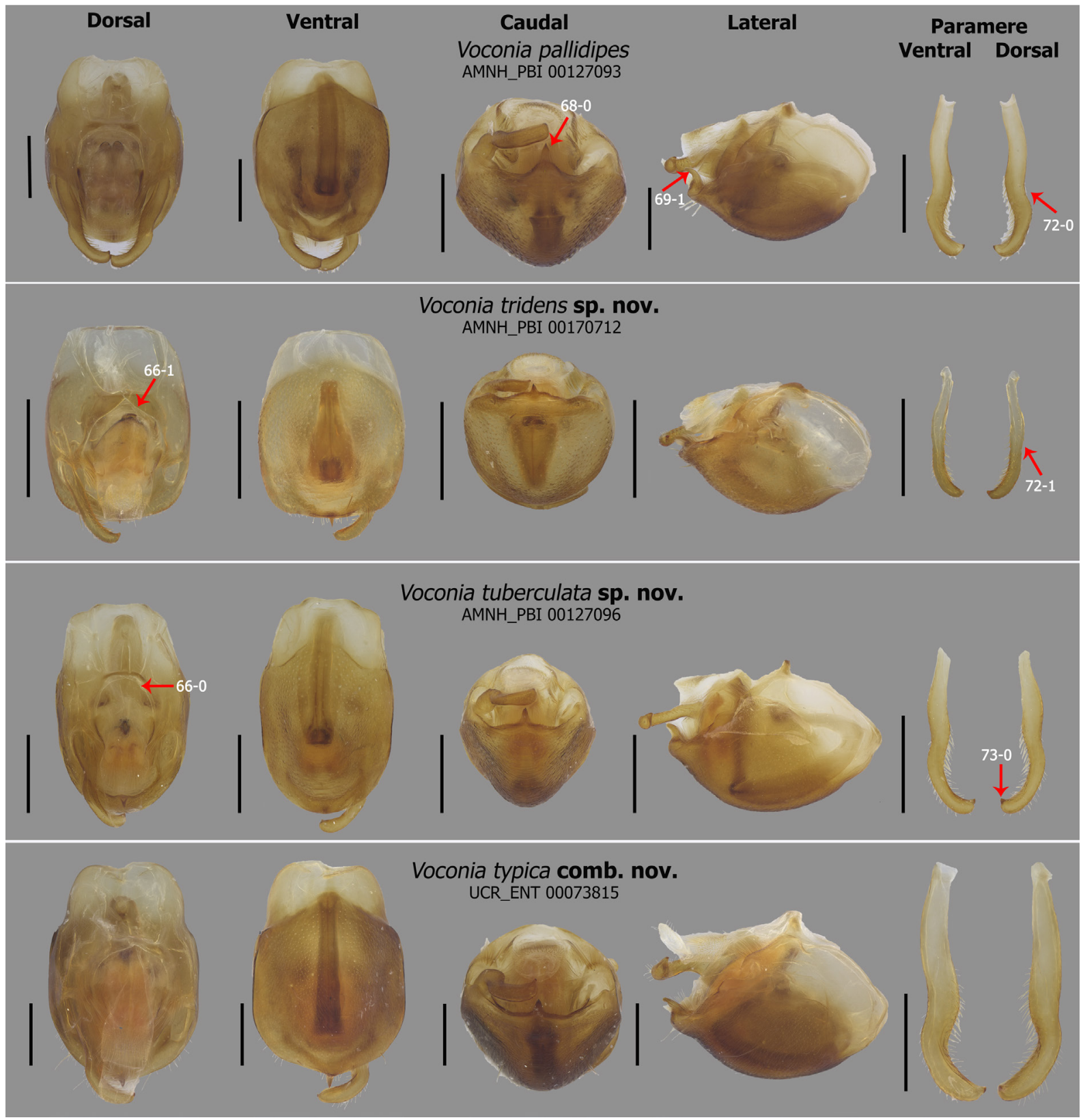

Fig. 13. Pygophore of species of Voconia Stål, 1866. Scale bars $=0.5 \mathrm{~mm}$. 
dorsal view nearly straight; eye width in dorsal view narrower than synthlipsis in micropterous morph, eyes considerably larger in macropterous morph; eye not reaching ventral head margin in lateral view; ocelli minute, occupying about 0.16 times length of postocular region in micropterous morph, ocelli considerably larger in macropterous morph; ventrolateral swelling of buccula with acute protrusion surpassing buccular margin, small setigerous tubercles along margin of protrusion; labial segment I in lateral view straight, not reaching posteroventral eye margin; morphologically dorsal surface of labial segment II nearly straight, about 0.4 times length of segment I. Thorax: pronotal collar in dorsal view wide medially with anterolateral angles long, flared laterally; anterior pronotal lobe about 1.3 times length of posterior pronotal lobe, lateral margins rounded in micropterous morph; anterior pronotal lobe shorter than posterior pronotal lobe in macropterous morph; glabrous markings on pronotum deeply depressed; median apodeme depression of pronotum shallow, elongated longitudinally; scutellar spine reduced and subhorizontal in micropterous morph; scutellum about 2 times as long as wide at base, with

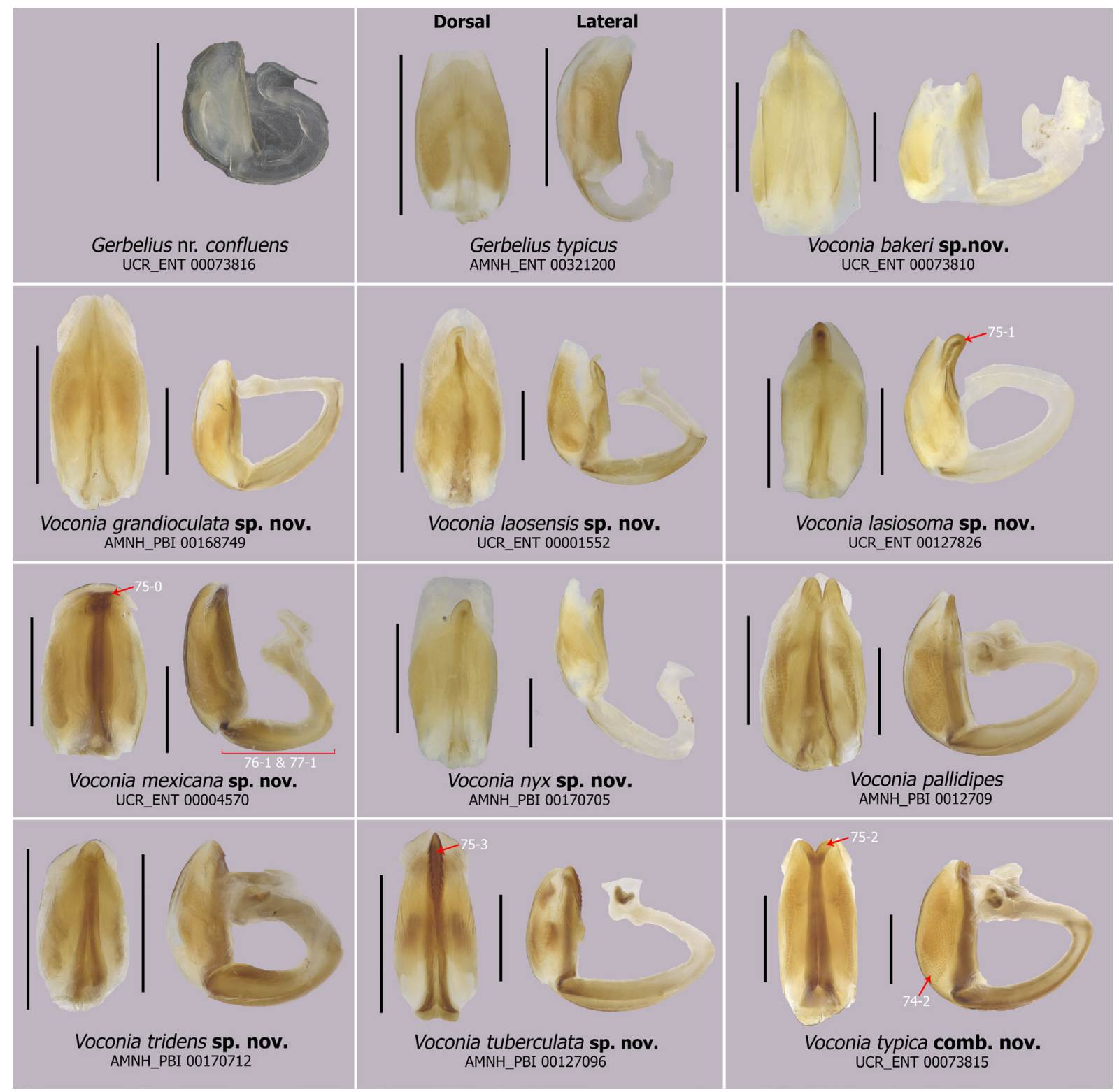

Fig. 14. Aedeagus of species of Gerbelius Distant, 1903 and Voconia Stål, 1866. Scale bars $=0.5 \mathrm{~mm}$. 
long slightly raised scutellar spine in macropterous morph; anteriad-directed process of prosternum with paramedial lobes; anterior margin of stridulitrum not elongated into protuberance; proepimeron with smoothly rounded posteroventral margin. Legs: fossula spongiosa present on fore and mid legs. Abdomen (Fig. 4D): anterior margin of terga prominently carinulate, terga II and III with deeper and longer carinules; terga II with paired prominent longitudinal carinae reaching posterior margin of segment.

\section{Female}

As micropterous male. Body length: about $7.0 \mathrm{~mm}$.

\section{Distribution}

Distributed in Garamba National Park in the Democratic Republic of the Congo.

\section{Remarks}

This description of $V$. schoutedeni is based on the micropterous male holotype (UCR_ENT 00070524), which was the only type specimen available for examination. Any descriptive information of the micropterous female or macropterous form is taken directly from the original description by Villiers (1964). A lectotype was also designated for the macropterous morph, Pseudocethera schoutedeni forme alata Villiers, 1964. However, this infrasubspecific name is permanently unavailable under ICZN Article 45.6.3, therefore this specimen (referred to as No. 1281 by Villiers) has no type status. A drawer image of specimens at the BMNH in 2011 suggests that the macropterous morph may be distributed as far north as Sierra Leone, but this specimen and the macropterous paratype need to be properly examined.

Voconia smithae sp. nov. urn:lsid:zoobank.org:act:6E950EB8-E03F-4F9F-B422-BD1D7A1A1594

Figs 12,14

\section{Diagnosis}

Distinguished from other species in Voconia by its Afrotropical distribution and stout body. This species most closely resembles $V$. motoensis and $V$. conradti. Voconia smithae sp. nov. differs from $V$. motoensis by its distinct coloration: yellow scutellar spine; abducted corium with a yellow spot at proximal and distal apex, and brown dorsal laterotergites with contrasting yellow anterior spots. Despite the strong superficial resemblance to $V$. conradti due its to coloration and stoutness, closer examination reveals that $V$. smithae sp. nov. is distinguishable by the following: shorter body (9.7-9.8 $\mathrm{mm}$ long); light brown dorsal laterotergites with weakly contrasting yellow anterior spots; antennifer with long, laterally projecting setigerous tubercle; paired interocular setigerous tubercles; maxillary plates globular, directed straight anteriorly; longer anteocular region than postocular region (measured to where the posterior margin of the granulations meet the anterior margin of the smooth neck); and eyes do not bulge strongly laterally in dorsal view and do not reach ventral head margin in lateral view.

\section{Etymology}

Named after one of the collectors of the holotype and colleague from the Weirauch lab, Samantha Smith.

\section{Type material}

\section{Holotype}

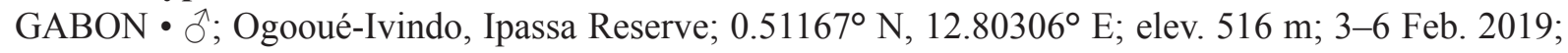
S. Smith, Y. Pacheco, S. Bybee, G. Svenson and G. Powell leg.; collecting event: GA19_L8_H; light trap; lowland forest; DNA voucher R_CW 5801; USI: UCR_ENT 00127891; UCR. 
Paratypes

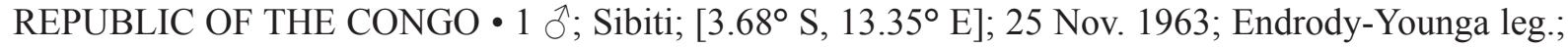
Soil-Zoological Exped.; lamplight; USI: AMNH_PB 00213936; HNHM.

\section{Description}

Male (Figs 8, 10)

Body LENGTH. 9.7-9.8 mm; macropterous.

COLORATION. Head: dark brown; postocular region with dark patches adjacent to medial ocellar margin, pale patches adjacent to lateral ocellar margin; labium lighter than head. Thorax: coloration as head, posterior margin of posterior pronotal lobe lighter; scutellum dark with contrasting yellow apical spine. Hemelytron (abducted): clavus brown with distal yellow stripe; corium dark or light brown with proximal, anteromedial, posteromedial, and distal yellow spots; membrane dark with pale V-shaped marking along $\mathrm{R}$ and $\mathrm{M}$ veins; membranal veins $\mathrm{R}$ and $\mathrm{M}$ proximally pale. Legs: yellowish-brown. Abdomen: yellowish-brown; dorsal laterotergites light brown with yellow spots anteriorly.

INTEGUMENT AND VESTITURE. Head and pronotum: coarsely granulose with sparse, short macrosetae interspersed among sparse pubescence; interocular region with two pairs of stout setigerous tubercles paramedially; antennifer with long lateral setigerous tubercle; morphologically ventral surface of labium with sparse, short macrosetae. Thorax: anterolateral angles of pronotal collar without macrosetae or setigerous tubercles. Hemelytron: corium with dense long setation. Legs: posterior row of protuberances on mid and hind femora with three large spines on distal half and three or fewer small spines. Abdomen: ventral surface pubescent.

STRUCTURE. Head: elongate, 1.3-1.4 times as long as wide; anteocular region about one third of head length, longer than postocular region (measured to anterior margin of neck); postocular region in dorsal view about as long as eye, lateral margins gently rounded and subrectangular; pedicel 1.4-1.5 times length of head width; maxillary plates ellipsoidal, adjacent to and longer than clypeus; apices of maxillary plates in dorsal view directed straight; clypeus in dorsal view narrower than maxillary plates; clypeal apex round, narrowed; interocular glabrous markings anterolaterally curved, joined at interocular sulcus paramedially; interocular sulcus in dorsal view curved and smoothly rounded anteriorly; eye width in dorsal view narrower than synthlipsis; eye not reaching ventral head margin in lateral view; ventrolateral swelling of buccula with tuberculate protrusion that surpasses buccular margin; labial segment I in lateral view straight, reaching posteroventral eye margin; morphologically dorsal surface of labial segment II nearly straight, about 0.6 times length of segment I. Thorax: pronotal collar narrow medially with anterolateral angles short and flared laterally; anterior pronotal lobe about 0.6 times length of posterior pronotal lobe, lateral margins almost straight; glabrous markings on pronotum slightly depressed; median apodeme depression of pronotum deep, circular; scutellar spine long, subhorizontal; anteriad-directed process of prosternum with paramedial lobes; anterior margin of stridulitrum not elongated into protuberance; proepimeron with smoothly rounded posteroventral margin. Legs: fossula spongiosa present on fore and mid legs. Abdomen: anterior margin of terga weakly carinulate; terga II and III with paired prominent longitudinal carinae, reaching about one-third of tergum III.

\section{Female}

Unknown.

Distribution (Fig. 17)

Only known from Congo and Gabon in Africa. 


\section{Remarks}

The male paratype varies from the holotype in the following: head and pronotum finely granulose, postocular region subrectangular, buccula without lateral tuberculate protrusion. The holotype was preserved in ethanol when the mid and hind legs were dissected for DNA extraction but was not Illumina sequenced.

Voconia tridens sp. nov. urn:1sid:zoobank.org:act:82E67D5A-E019-40EE-A019-E3BCD5E781DA

Figs $1-2,8,10,13-14,17$

\section{Diagnosis}

Distinguished from other species of Voconia by the following combination of characters: coarsely granulose head and pronotum; maxillary plates not adjacent to and far surpass clypeal apex; and antennifers with a long, lateral spine. This species is recognized from the macropterous morph of $V$. schoutedeni by the yellow head and pronotum; the maxillary plates in lateral view are not wide, about the width of the scape; scutellar spine is subhorizontal; and the hemelytra is not blackish, it is a light brown with pale coloration at the base and apex of the corium.

\section{Etymology}

The specific epithet is the Latin adjective 'tridens, -, -', meaning 'three-toothed, three-pronged', derived from the prefix 'tri-' combined with the Latin noun 'dens', referring to the elongated and separated maxillary plates and clypeus that form three prongs.

\section{Type material}

\section{Holotype}

SUDAN $-\hat{\partial}$ (dissected pygophore and aedeagus in vial); Blue Nile, Abu Hashim-Galegu; [12.25 $\mathrm{N}$, 34.69 E]; 23-24 Nov. 1962; R. Linnavuori leg.; USI: AMNH_PBI 00170712; AMNH.

\section{Description}

Male (Figs 8, 10)

Body LENGTH. About $8.0 \mathrm{~mm}$; macropterous.

Coloration. Head: yellow; postocular region with red patches adjacent to medial ocellar margin; labium as head. Thorax: uniformly yellow; scutellum yellow. Hemelytron (abducted): clavus uniformly yellow; corium proximal half mostly yellow, distal half brown with yellow spot at distal apex; membrane dark with pale V-shaped marking along R and M veins. Legs: yellow. Abdomen: yellow, dorsal laterotergites with a pale brown stripe on posterior margin.

INTEGUMENT AND VESTITURE. Head and pronotum: coarsely granulose with dense, short setigerous tubercles; interocular region with two pairs of stout setigerous tubercles paramedially; antennifer with long lateral spine; morphologically ventral surface of labium with sparse, short macrosetae. Thorax: anterolateral angles of pronotal collar without macrosetae or setigerous tubercles; scutellar lateral carinae with pubescent tubercles. Hemelytron: corium with short macrosetae. Legs: posterior row of protuberances on mid and hind femora with three large spines on distal half. Abdomen: ventral surface pubescent.

Structure. Head: elongate, about 1.3 times as long as wide; anteocular region two-fifths of head length, longer than postocular region (measured to anterior margin of neck); postocular region in dorsal view longer than eye, lateral margins subrectangular; scape not reaching head apex; pedicel about 0.9 times length of head width; maxillary plates ellipsoidal, not adjacent to or longer than clypeus; 

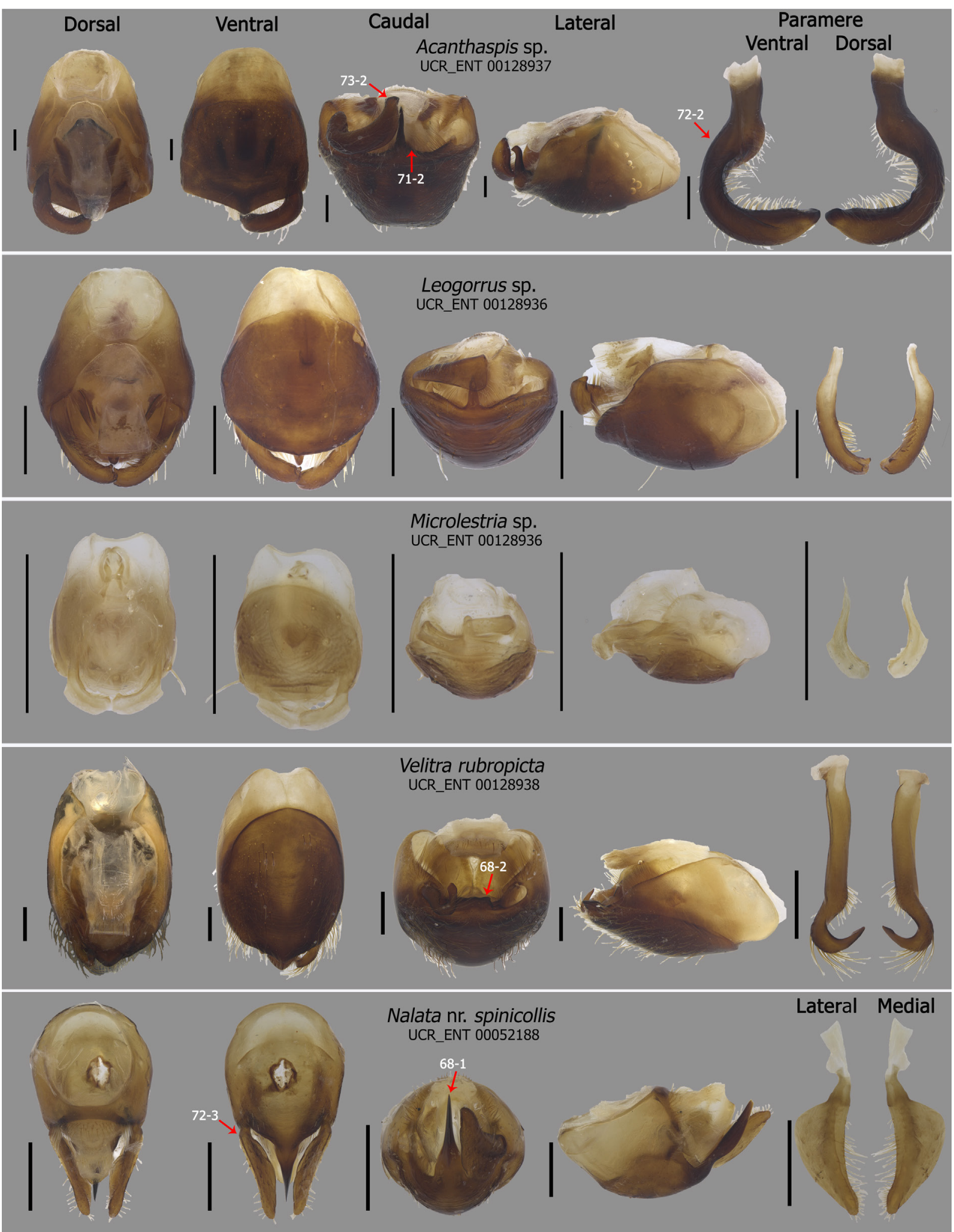

Fig. 15. Pygophore of outgroup species. Scale bars $=0.5 \mathrm{~mm}$. 
apices of maxillary plates in dorsal view diverging; clypeus in dorsal view narrower than maxillary plates; clypeal apex round, narrowed; interocular glabrous markings V-shaped, joined medially at interocular sulcus; interocular sulcus in dorsal view curved and smoothly rounded anteriorly; eye width in dorsal view narrower than synthlipsis; eye reaching ventral head margin in lateral view; ventrolateral swelling of buccula with acute protrusion surpassing buccular margin, small setigerous tubercles along margin of protrusion; labial segment I in lateral view straight, surpassing posteroventral eye margin; morphologically dorsal surface of labial segment II nearly straight, about 0.4 times length of segment I. Thorax: pronotal collar in dorsal view wide medially with anterolateral angles long, flared laterally; anterior pronotal lobe about 0.7 times length of posterior pronotal lobe, lateral margins almost straight; glabrous markings on pronotum deeply depressed; median apodeme depression of pronotum shallow, elongated longitudinally; scutellar spine long, subhorizontal; anteriad-directed process of prosternum with paramedial lobes; anterior margin of stridulitrum not elongated into protuberance; proepimeron with smoothly rounded posteroventral margin. Legs: fossula spongiosa present on fore and mid legs. Pygophore (Fig. 13): transverse bridge with triangular posterior margin; posterior region of ventral surface of pygophore in lateral view straight, not swollen; short median apical process sharply bent posteriorly in lateral view; lateral pygophore margin with protuberance; posterior pygophore margin with clustered macrosetae on protuberance; parameres round, apex tapered into squarely rounded tip. Aedeagus: endosoma almost entirely covered with spicules; apex of dorsal phallothecal sclerite tongueshaped in dorsal view; basal plate extension about 4.6 times as long as wide.

\section{Female}

Unknown.

Distribution (Fig. 17)

Only known from the type locality in Northeastern Africa, Sudan.

\section{Remarks}

The antennifer spine on the right side of the head of the holotype is absent. We assume it was damaged since three species, $V$. schoutedeni, $V$. monodi, and $V$. ifana, have similar long spines that are paired. The pygophore of specimen AMNH_PBI 00170712 was used for DNA extraction, but we did not get sufficient DNA in our NGS library for Illumina sequencing.

Voconia trinidadensis sp. nov. urn:lsid:zoobank.org:act:F5E8C8C5-6BD2-4544-A81D-0F31F846EF2E

Figs 1-2, 8, 10, 19

\section{Diagnosis}

One of two New World species of Voconia. Recognized by the finely granulose head and prothorax; proepimeron with protuberance on posteroventral margin; pronotum dark with contrasting yellow posterior margin; corium dark with anteroproximal yellow stripe, posteromedial and distal white spots; labial segment I in lateral view not surpassing posteroventral eye margin.

\section{Etymology}

Named after the collecting locality of the holotype in Trinidad. A proper noun with the Latin adjectival suffix '-ensis' meaning 'belonging to'. To be treated as an adjective.

\section{Type material}

Holotype

TRINIDAD AND TOBAGO • क; Trinidad; J.W. Chapman leg.; USI: AMNH_PBI 00170700; AMNH. 


\section{Description}

Female (Figs 8, 10)

Body LeNGTH. $10.5 \mathrm{~mm}$; macropterous.

Coloration. Head: dark brown; maxillary plates light brown; postocular region with pale patches adjacent to lateral ocellar margin; labium lighter than head, yellow. Thorax: as head; posterior pronotal lobe with posterior margin lighter; scutellum dark with contrasting yellow apical spine. Hemelytron (abducted): clavus reddish-brown with distal white stripe; corium reddish-brown with anteroproximal yellow stripe, posteromedial and distal white spots; membrane dark with white V-shaped marking along $\mathrm{R}$ and $\mathrm{M}$ veins; membranal veins $\mathrm{R}$ and $\mathrm{M}$ proximally white. Legs: yellow. Abdomen: dark brown, dorsal laterotergites brown medially, with black stripe adjacent to yellow lateral margin.

INTEGUMENT AND VESTITURE. Head and pronotum: finely granulose with sparse, long macrosetae interspersed among dense pubescence; interocular region with two pairs of macrosetae paramedially; antennifer with short lateral setigerous tubercle; morphologically ventral surface of labium with dense, short macrosetae. Thorax: anterolateral angles of pronotal collar with macrosetae; scutellar lateral carinae with long setation. Hemelytron: corium with sparse, long setation. Legs: posterior row of protuberances on mid and hind femora with three large spines on distal half and many small spines. Abdomen: ventral surface pubescent.

StRUCTURE. Head: elongate, about 1.4 times as long as wide; anteocular region about one third of head length, about as long as postocular region (measured to anterior margin of neck); postocular region in dorsal view about as long as eye, lateral margins gently rounded; pedicel about 1.3 times length of head width; maxillary plates ellipsoidal, adjacent to and longer than clypeus; apices of maxillary plates in dorsal view directed straight; clypeus in dorsal view wider than maxillary plates; clypeal apex round, not narrowed; interocular glabrous markings anterolaterally curved, joined at interocular sulcus paramedially; interocular sulcus in dorsal view curved and smoothly rounded anteriorly; eye width in dorsal view wider than synthlipsis; eye reaching ventral head margin in lateral view; ventrolateral swelling of buccula without lateral protrusion that surpasses buccular margin, flat margin; labial segment I in lateral view straight, reaching posteroventral eye margin; morphologically dorsal surface of labial segment II nearly straight, about 0.6 times length of segment I. Thorax: pronotal collar in dorsal view narrow medially with anterolateral angles short, projected forward; anterior pronotal lobe about 0.5 times length of posterior pronotal lobe, lateral margins almost straight; glabrous markings on pronotum thin, not deeply depressed; median apodeme depression of pronotum deep, elongated transversely; scutellar spine long, subhorizontal; anteriad-directed process of prosternum smoothly rounded, without paramedial lobes; anterior margin of stridulitrum not elongated into protuberance; proepimeron with acute protuberance on posteroventral margin. Legs: fossula spongiosa of fore leg present, absent or vestigial on mid leg. Abdomen: anterior margin of terga prominently carinulate, posterior margin of terga III-VI weakly carinulate; terga II and III with paired prominent longitudinal carinae, reaching about two-thirds of tergum III; medial region between carinae on tergum II coarsely granulose.

\section{Distribution (Fig. 19)}

This species is only known from the type locality, Trinidad.

Voconia tuberculata sp. nov. urn:lsid:zoobank.org:act:B50D3ECC-82C1-431B-95C1-6C8326049678

Figs 12, 14, 17-18

\section{Diagnosis}

Distinguished from most species of Voconia by its tuberculate and coarsely granulose head and pronotum. This species most closely resembles another Australian species, $V$. dolichocephala sp. nov. These two 
species are recognized from other Australian species by the acute protuberance on the posteroventral margin of the proepimeron, the long macrosetae of the setigerous tubercles, the elongate head (1.4-1.6 times as long as wide), and the yellow spots antero- and posteromedially on the abducted corium. Voconia tuberculata sp. nov. differs from $V$. dolichocephala sp. nov. by its overall light brown coloration and males are as long as about $7.9 \mathrm{~mm}$. Females are smaller than the examined $V$. dolichocephala sp. nov. females (about 8.8 and $9.0 \mathrm{~mm}$ ).

\section{Etymology}

The specific epithet is the Latin adjective 'tuberculatus, $-a$, -um', meaning 'warty' or 'tuberculate'. Refers to the densely tuberculate surfaces of the body.

\section{Type material}

Holotype

AUSTRALIA • $\widehat{~}$ (dissected pygophore and aedeagus in vial); Northern Territory, $17 \mathrm{~km}$ NE of Willeroo; [15.23ํ S, $131.67^{\circ}$ E]; 8-9 Nov. 1984; M. and B. Baehr leg.; USI: AMNH_PBI 00127096; ZSMC.

\section{Paratypes}

AUSTRALIA - Northern Territory $• 1$; same collection data as for holotype; USI: AMNH_PBI 00127095; ZSMC • 1 adult sex unknown (abdomen missing); $30 \mathrm{~km}$ ESE of Victoria R. Downs; $16.19^{\circ} \mathrm{S}$, $131.17^{\circ}$ E; 18 Jun. 1969; M. Mendum leg.; USI: AMNH_PBI 00168741; ANIC • 1 đ; Elsey Ck, 19 km SSE of Mataranka; $15.05^{\circ} \mathrm{S}, 133.07^{\circ}$ E; 15 Oct. 1972; Upton and Barrett leg.; USI: AMNH_PBI 00168742; ANIC. - Queensland • 1 क ; Burketown, site of old Broom Hotel: [17.85 $\left.{ }^{\circ} \mathrm{S}, 139.62^{\circ} \mathrm{E}\right]$; 18 May 1931; T.G. Campbell leg.; light trap; USI: AMNH_PBI 00168743; ANIC • 1 \%; same collection data as for preceding; USI: AMNH_PBI 00168744; ANIC • 1 §’; Kunkulla Station, Gregory River; 25 May 1931; I.M. Mackerras leg.; USI: AMNH_PBI 00168746; ANIC.

\section{Description}

Male (Figs 8, 10)

Body LENGTH. 7.9-8.9 mm; macropterous.

Coloration. Head: dark brown; postocular region with dark patches adjacent to medial ocellar margin and pale patches adjacent to lateral ocellar margin; labium lighter than head. Thorax: coloration as head; scutellum uniformly brown. Hemelytron (abducted): clavus reddish-brown with distal yellow stripe; corium reddish-brown with anteromedial, posteromedial, and distal yellow spots; membrane dark with pale $\mathrm{V}$-shaped marking along $\mathrm{R}$ and $\mathrm{M}$ veins; membranal veins $\mathrm{R}$ and $\mathrm{M}$ proximally pale. Legs: yellowish-brown. Abdomen: light brown, dorsal laterotergites I and II paler than remainder.

INTEGUMENT AND VESTITURE. Head and pronotum: coarsely granulose with sparse, long setigerous tubercles interspersed among sparse pubescence; interocular region with two pairs of stout setigerous tubercles paramedially; antennifer with long lateral setigerous tubercle; morphologically ventral surface of labium with sparse, short macrosetae. Thorax (Fig. 3L): anterolateral angles of pronotal collar with setigerous tubercles; scutellar lateral carinae with setigerous tubercles with long macrosetae. Hemelytron: corium with dense long setation. Legs: posterior row of protuberances on mid and hind femora with four or more large spines on distal half. Abdomen: ventral surface pubescent, long macrosetae interspersed.

Structure. Head: elongate, 1.4-1.6 times as long as wide; anteocular region about one third of head length, shorter than postocular region (measured to anterior margin of neck); postocular region in dorsal view longer than eye, lateral margins gently rounded; pedicel about 1.5-2.2 times length of head width; maxillary plates ellipsoidal, adjacent to and longer than clypeus; apices of maxillary plates in dorsal view diverging; clypeus in dorsal view about as wide as maxillary plates; clypeal apex bifid, not narrowed; 
interocular glabrous markings anterolaterally curved, joined at interocular sulcus paramedially or medially forming a V-shaped marking; interocular sulcus in dorsal view nearly straight; eye width in dorsal view narrower than synthlipsis; eye reaching ventral head margin in lateral view; ventrolateral swelling of buccula without lateral protrusion that surpasses buccular margin, flat margin; labial segment I in lateral view straight, surpassing posteroventral eye margin; morphologically dorsal surface of labial segment II curves ventrally, about 0.3 times length of segment I. Thorax (Fig. 3L): pronotal collar in dorsal view wide medially with anterolateral angles long, flared laterally; anterior pronotal lobe 0.6-0.8 times length of posterior pronotal lobe, lateral margins almost straight; glabrous markings on pronotum conspicuous, not depressed; median apodeme depression of pronotum shallow, elongated transversely; scutellar spine long, raised; anteriad-directed process of prosternum with paramedial lobes; anterior margin of stridulitrum projected into small protuberance; proepimeron with acute protuberance on posteroventral margin. Legs: fossula spongiosa present on fore and mid legs. Abdomen: anterior margin of terga weakly carinulate, terga II and III with deeper and longer carinules; terga II and III with paired prominent longitudinal carinae, reaching about two-thirds of tergum III. Pygophore (Fig. 13): transverse bridge with rounded posterior margin; posterior region of ventral surface of pygophore in lateral view with large swelling; short median apical process, sharply bent posteriorly in lateral view; lateral pygophore margin with protuberance; posterior pygophore margin with clustered macrosetae on protuberance; parameres sinusoidal, apex tapered sharply. Aedeagus (Fig. 14): endosoma almost entirely covered with spicules; apex of dorsal phallothecal sclerite serrated; basal plate extension about 5.7 times as long as wide.

\section{Female}

Mostly as male, distinguished from males by the following. Body length: 8.4-8.8 mm. Head: elongate, 1.5 times as long as wide; pedicel about 1.5-1.7 times length of head width. Legs: fossula spongiosa present on fore leg, absent or vestigial on mid leg.
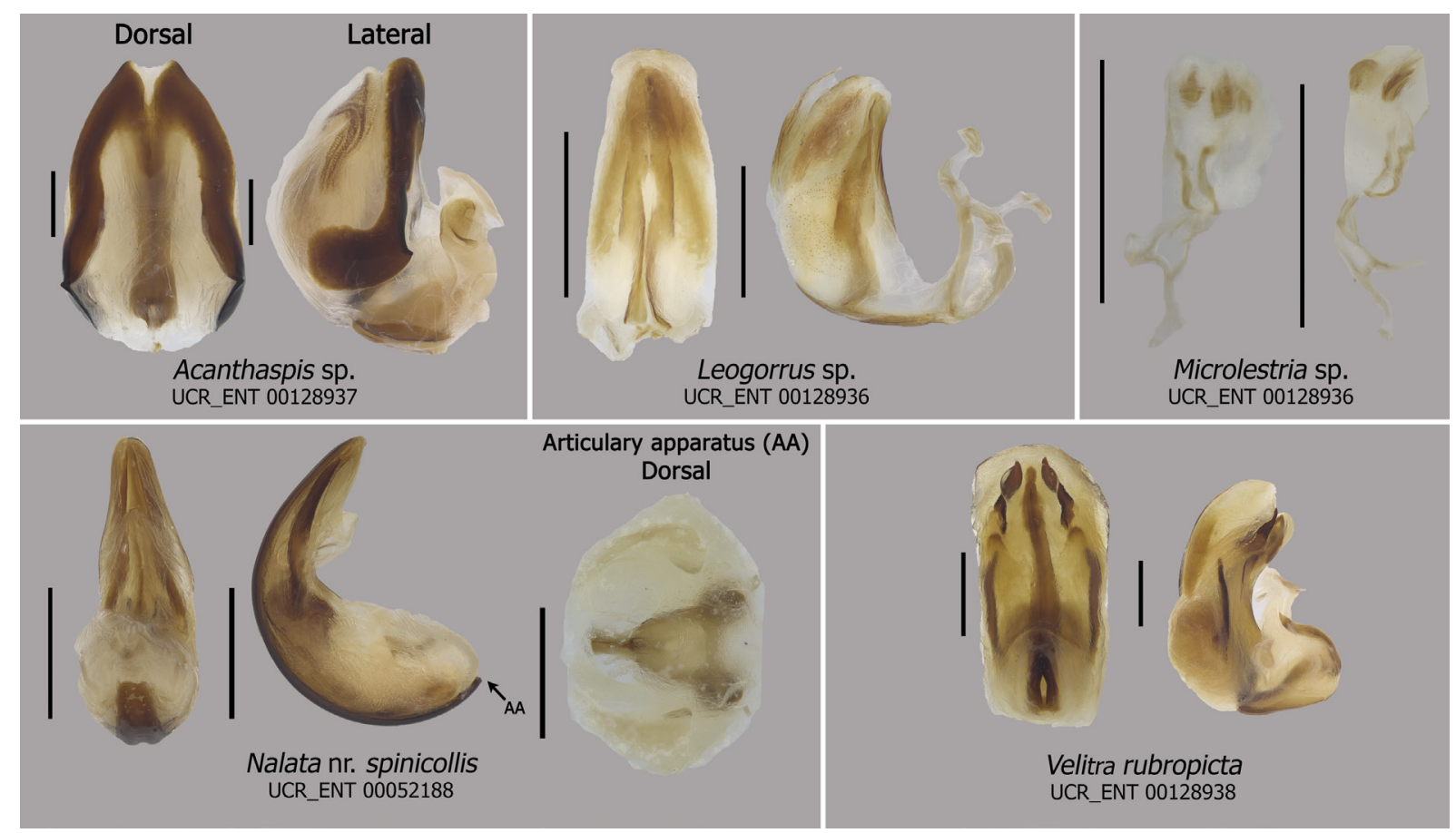

Fig. 16. Aedeagus of outgroup species. Scale bars $=0.5 \mathrm{~mm}$. 


\section{Distribution (Fig. 18)}

This species is distributed across Northern Territory and Queensland in Australia. The nearest Voconia species is V.dolichocephala sp. nov., found about $100 \mathrm{~km}$ northwest of specimen AMNH_PBI 00168742.

\section{Remarks}

The direction of the maxillary plates in dorsal view varies from nearly straight or parallel (e.g., AMNH PBI 00168741) to strongly diverging (e.g., AMNH_PBI 00168746). Voconia tuberculata sp. nov. is nested within the Australian clade. According to our phylogeny (Figs 1-2), V. tuberculata sp. nov. was recovered as the sister taxon to $V$. dolichocephala sp. nov. The abdomen of specimen AMNH_PBI 00127096 was used for DNA extraction, but we did not get sufficient DNA in our NGS library for Illumina sequencing.

Voconia typica (Miller, 1958) comb. nov.

Figs $1-2,8,10,13-14,18$

Paragerbelius typicus Miller, 1958: 66, figs 88-92.

\section{Revised diagnosis}

This species is most similar to $V$. bracata sp. nov. They are distinguished from other species of the genus Voconia by the slender body, long head (1.7 times as long as wide), the ventral surface of the hind leg with four large spines in the posterior row, the large pale spot between the $\mathrm{R}$ and $\mathrm{M}$ veins, and the dorsal laterotergites I and II being yellow, the remainder dark brown. The following differentiate $V$. typica: largest species of Voconia (12.4-12.7 mm long); uniformly brown legs; anterior pronotal lobe is gently rounded, posterolateral margins nearly straight.

\section{Type material}

\section{Holotype}

INDONESIA • đa; "North New Guinea" [Papua], Jayapura Co., Cyclops Mts, Sabron camp; [2.50 N, $140.42^{\circ}$ E]; elev. "2200 ft" [671 m]; Jun. 1936; L.E.C. leg.; coll. B.M. 1936-271; USI: UCR_ENT 00048384; NHMUK 013588138 (previously BMNH(E) 1255222).

\section{Paratype}

INDONESIA • 1 ○ं; same collection data as for holotype; BMNH.

\section{Additional material examined:}

INDONESIA • 1 ô; "West New Guinea" [Papua], Central Mountains, Archbold Lake; [3.41 S, $138.53^{\circ}$ E]; elev. 760 m; 26 Nov.-3 Dec. 1961; S. Quate and L. Quate leg.; dissected pygophore and aedeagus in vial; USI: UCR_ENT 00073815; BPBM.

\section{Redescription}

Male (Figs 8, 10)

Body LENGTH. 12.4-12.7 mm; macropterous.

Coloration. Head: dark brown; postocular region with dark patches adjacent to medial ocellar margin and pale patches adjacent to lateral ocellar margin; labium lighter than head, light brown. Thorax: as head; pronotum uniformly coloured; scutellum dark with contrasting yellow apical spine. Hemelytron (abducted): clavus dark reddish-brown with distal yellow stripe; corium reddish-brown with anteromedial, posteromedial, and distal yellow spots; membrane dark with large pale spot between $\mathrm{R}$ and $\mathrm{M}$ veins; 
membranal veins $\mathrm{R}$ and $\mathrm{M}$ proximally pale, remainder as membrane. Legs: dark brown. Abdomen: dark brown, dorsal laterotergites I and II yellow.

INTEGUMENT AND VESTITURE. Head and pronotum: finely granulose with sparse, short macrosetae interspersed among dense pubescence; interocular region with two paired macrosetae; antennifer with short lateral setigerous tubercle; morphologically ventral surface of labium with dense, short macrosetae. Thorax: anterolateral angles of pronotal collar without macrosetae or setigerous tubercles. Hemelytron: corium with sparse, long setation. Legs: posterior row of protuberances on mid and hind femora with four large spines on distal half. Abdomen: ventral surface pubescent.

StRUCTURE. Head: elongate, about 1.7 times as long as wide; anteocular region about one third of head length, about as long as postocular region (measured to anterior margin of neck); postocular region in dorsal view longer than eye, lateral margins gently rounded; pedicel about 1.8 times length of head width; maxillary plates ellipsoidal, adjacent to and reaching apex of clypeus; apices of maxillary plates in dorsal view directed straight; clypeus in dorsal view narrower than maxillary plates; clypeal apex round, not narrowed; interocular glabrous markings V-shaped, joined medially at interocular sulcus; interocular

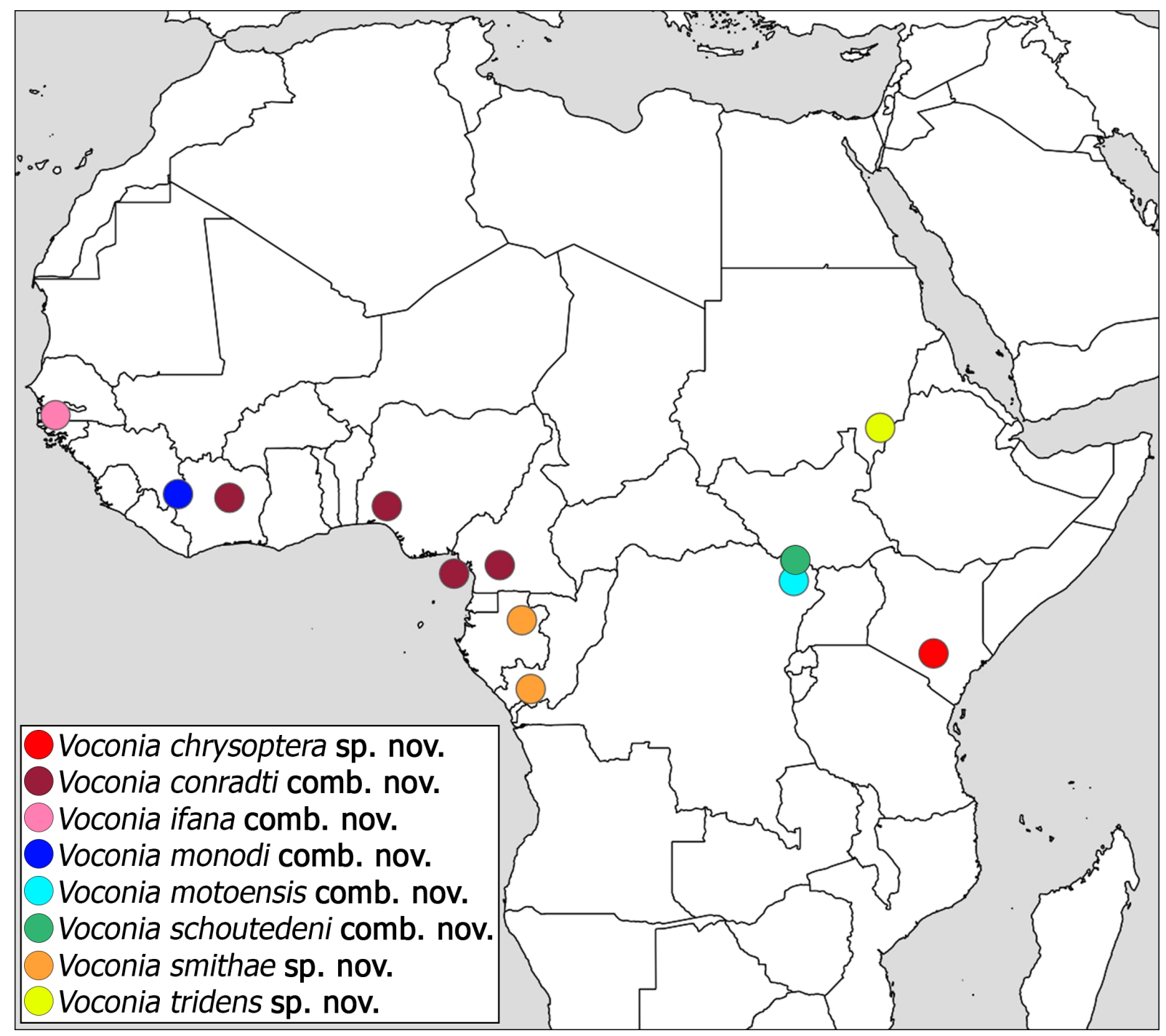

Fig. 17. The distribution of species of Voconia Stål, 1866 in Africa. 
sulcus in dorsal view bent anteromedially, subtriangular; eye width in dorsal view wider than synthlipsis; eye reaching ventral head margin in lateral view; ventrolateral swelling of buccula without lateral protrusion that surpasses buccular margin, flat margin; labial segment I in lateral view straight, surpassing posteroventral eye margin; morphologically dorsal surface of labial segment II nearly straight, about 0.4 times length of segment I. Thorax: pronotal collar in dorsal view narrow medially with anterolateral angles short, projected forward; anterior pronotal lobe subequal in length to posterior pronotal lobe, lateral margins almost straight; glabrous markings on pronotum thin and deeply depressed; median apodeme depression of pronotum deep and elongated transversely; scutellar spine long, subhorizontal; anteriad-directed process of prosternum smoothly rounded, without paramedial lobes; anterior margin of stridulitrum not elongated into protuberance; proepimeron with smoothly rounded posteroventral margin. Legs: fossula spongiosa present on fore and mid legs. Abdomen: anterior margin of terga weakly carinulate, tergum II without carinules laterally; terga II and III with paired prominent longitudinal carinae, almost reaching posterior margin of tergum III. Pygophore (Fig. 13): transverse bridge with rounded posterior margin; posterior region of ventral surface of pygophore in lateral view with large swelling; short median apical process sharply bent posteriorly in lateral view; lateral pygophore margin with protuberance; posterior pygophore margin with clustered macrosetae on decline; parameres sinusoidal, apex tapered into squarely rounded tip. Aedeagus (Fig. 14): endosoma almost entirely covered with spicules; apex of dorsal phallothecal sclerite bifid in dorsal view; basal plate extension about 7.9 times as long as wide.

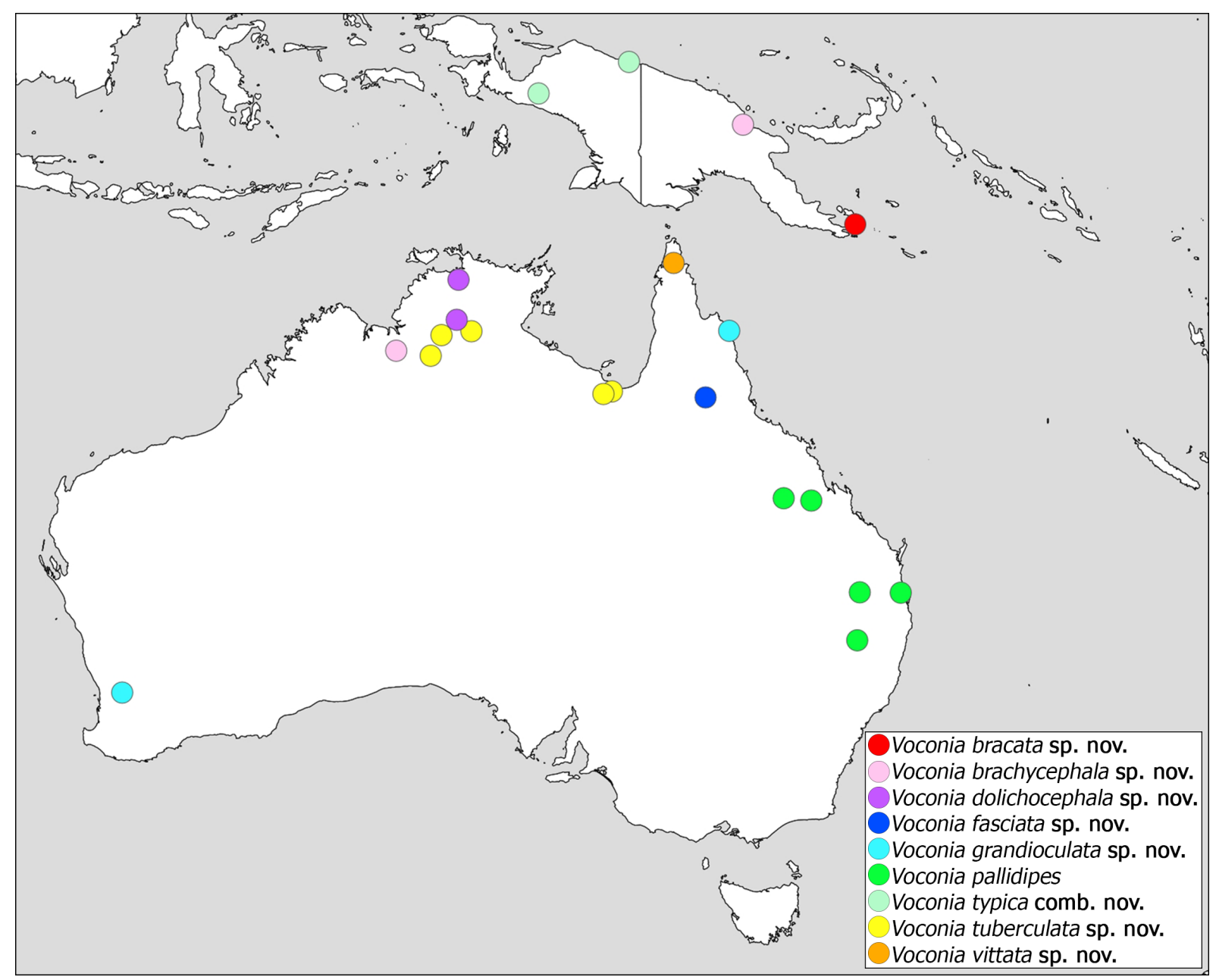

Fig. 18. The distribution of species of Voconia Stål, 1866 in the Australasian region. 
Female

Unknown.

Distribution (Fig. 18)

This species is distributed on the island of New Guinea, in Papua.

\section{Remarks}

This description is based largely on UCR_ENT 00073815, since the holotype (Fig. 8) and paratype remain at the BMNH. Images of the types in their unit trays at the BMNH were used to evaluate this species concept. The abdomen of specimen UCR_ENT 00073815 was used for DNA extraction, but we did not get sufficient DNA in our NGS library for Illumina sequencing.

Voconia vittata $\mathrm{sp}$. nov.

urn:1sid:zoobank.org:act:772BEB7A-1101-4AD1-91C0-8EED38AE4516

Figs $1-2,8,10,12,14,18$

\section{Diagnosis}

Distinguished from other species of Voconia by the following combination of characters: short body length (about $7.1 \mathrm{~mm}$ long); globose head; tuberculate and coarsely granulose head and pronotum; interocular region with two setigerous tubercles medially; apex of clypeus bifid; corium dark with thick medial yellow stripe; and dark brown femora with contrasting yellowish-brown tibiae and tarsi. This species most closely resembles another Australian species, $V$. fasciata sp. nov., but $V$. vittata sp. nov. is about $1.6 \mathrm{~mm}$ shorter and the yellow medial stripe on the corium is opaque.

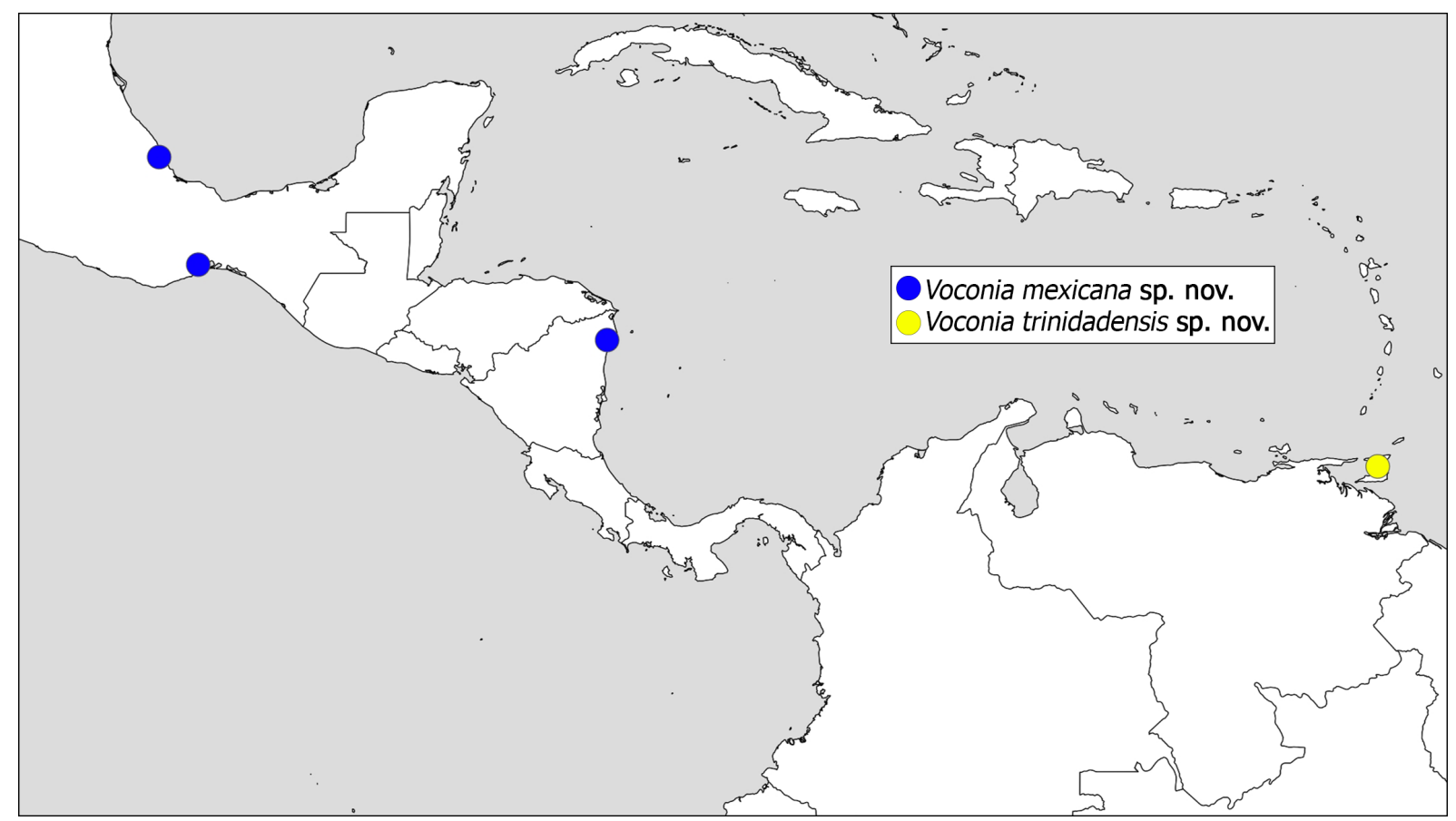

Fig. 19. The distribution of species of Voconia Stål, 1866 in Central America. 


\section{Etymology}

The specific epithet is the Latin adjective 'vittatus, $-a$, -um', meaning 'banded'. Refers to the yellow band or color pattern that crosses the middle of the corium and scutellar spine.

\section{Type material}

\section{Holotype}

AUSTRALIA • $\overbrace{}^{\top}$; Queensland, Cape York Peninsula, Dulhunty Rd; $11.86666^{\circ} \mathrm{S}, 142.5^{\circ} \mathrm{E} ; 22$ Mar. 1992; G. Cassis leg.; at light; USI: AMNH_PBI 00088406; AMS K 156496.

\section{Description}

Male (Figs 8, 10)

Body LENGTH. About $7.1 \mathrm{~mm}$; macropterous.

Coloration. Head: uniformly dark brown; labium lighter than head, labial segment I brown, II and III yellowish-brown. Thorax: as head; scutellum dark with contrasting yellow apical spine. Hemelytron (abducted): clavus dark reddish-brown with distal yellow stripe; corium dark reddish-brown with thick medial yellow stripe; membrane dark with pale V-shaped marking along $\mathrm{R}$ and $\mathrm{M}$ veins; membranal veins $\mathrm{An}_{1}$ and $\mathrm{R}$ proximally pale. Legs: femora dark brown, tibiae and tarsi yellowish-brown. Abdomen: yellowish-brown medially, dark reddish-brown laterally; dorsal laterotergites I and II paler than remainder.

INTEGUMENT AND VESTITURE. Head and pronotum: coarsely granulose with dense, short setigerous tubercles interspersed among sparse pubescence; interocular region with two pairs of stout setigerous tubercles paramedially and two medially; antennifer with long lateral setigerous tubercle; morphologically ventral surface of labium with sparse, long macrosetae. Thorax: anterolateral angles of pronotal collar with setigerous tubercles; scutellar lateral carinae with short macrosetae on setigerous tubercles. Hemelytron:

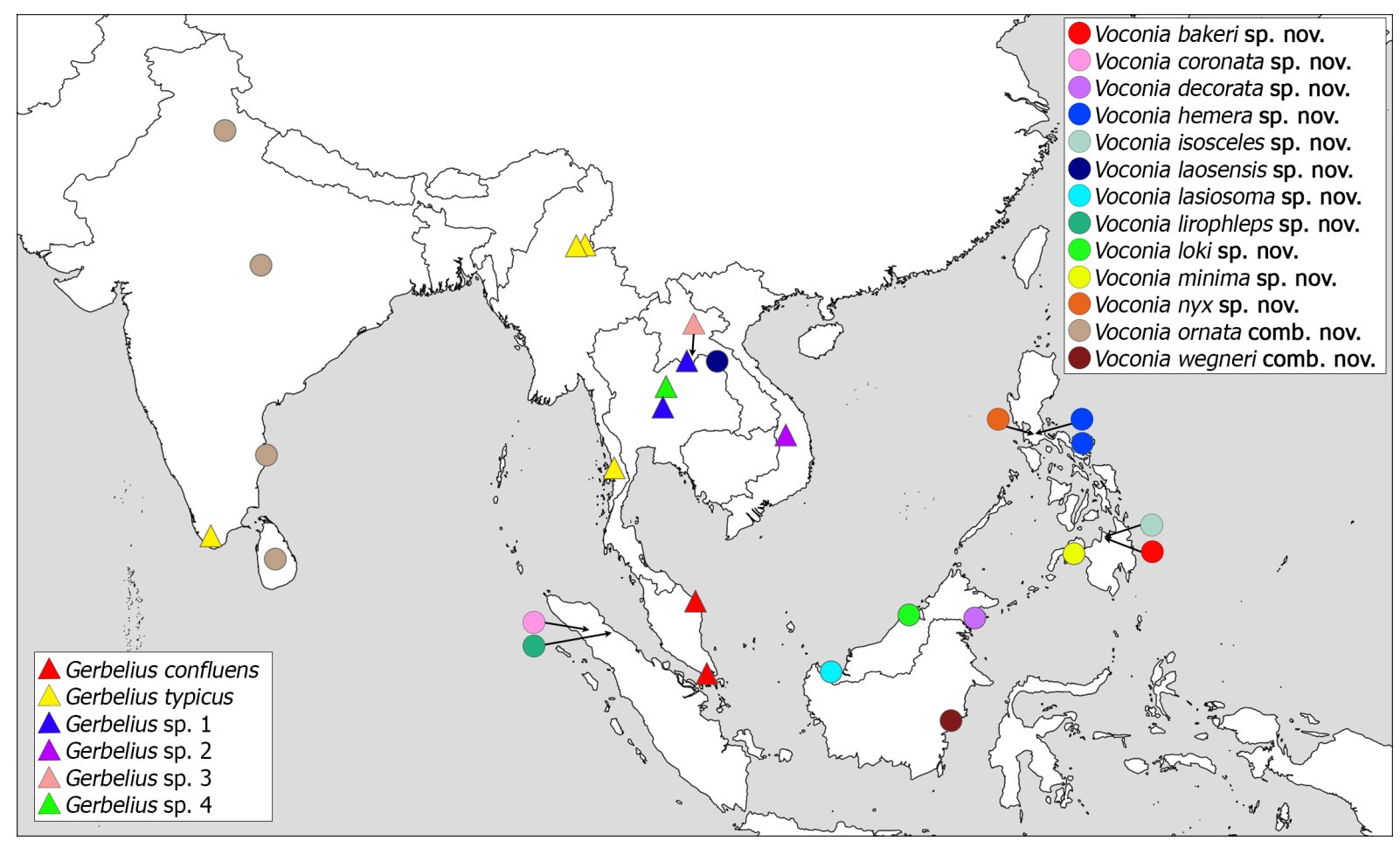

Fig. 20. The distribution of species of Gerbelius Distant, 1903 and Voconia Stål, 1866 in Southeast Asia. 
corium with dense, long macrosetae. Legs: posterior row of protuberances on mid and hind femora with three or four spines on distal half. Abdomen: ventral surface pubescent, long macrosetae interspersed.

STRUCTURE. Head: globose, about as long as wide; anteocular region about one quarter of head length, shorter than postocular region (measured to anterior margin of neck); postocular region in dorsal view about as long as eye, lateral margins gently rounded; pedicel about 1.4 times length of head width; maxillary plates ellipsoidal, adjacent to and reaching apex of clypeus; apices of maxillary plates in dorsal view converging; clypeus in dorsal view wider than maxillary plates; clypeal apex bifid, narrowed; interocular glabrous markings anterolaterally curved, joined at interocular sulcus paramedially; interocular sulcus in dorsal view bent anteromedially, subtriangular; eye width in dorsal view narrower than synthlipsis; eye reaching ventral head margin in lateral view; ventrolateral swelling of buccula with lateral protrusion that surpasses buccular margin; labial segment I in lateral view straight, surpassing posteroventral eye margin; morphologically dorsal surface of labial segment II curves ventrally, about 0.4 times length of segment I. Thorax: pronotal collar in dorsal view wide medially with anterolateral angles short, flared laterally; anterior pronotal lobe about 0.9 times length of posterior pronotal lobe, lateral margins almost straight; glabrous markings on pronotum conspicuous and not depressed; median apodeme depression of pronotum shallow, elongated longitudinally; scutellar spine long, raised; anteriad-directed process of prosternum with paramedial lobes; anterior margin of stridulitrum projected into small protuberance; proepimeron with smoothly rounded posteroventral margin. Legs: fossula spongiosa present on fore and mid legs.

\section{Female}

Unknown.

Distribution (Fig. 18)

This species is only known from the type locality in Northern Australia.

\section{Remarks}

Nested within the well supported Australian clade (Figs 1-2).

Voconia wegneri (Miller, 1954) comb. nov.

Figs $1-2,3 \mathrm{E}, 8,10,20$

Kayanocoris wegneri Miller, 1954: 6, fig. 3.

\section{Revised diagnosis}

Distinguished from other species of Voconia by the minute ocelli, occupying 0.12 times length of postocular region; labial segment I swollen subapically on ventral surface; labial segment II swollen ventrobasally and narrowed apically; labial segment III very short (about $0.14 \mathrm{~mm}$ long), about 0.2 times length of segment II.

\section{Type material}

Holotype

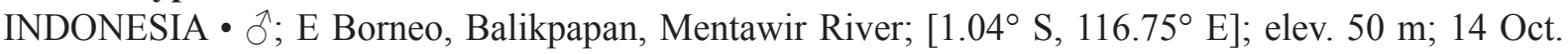
1950; A.M.R. Wegner leg.; USI: RMNH.INS 1091587; NBCN (previously RMNH).

\section{Redescription}

Male (Figs 8, 10)

Body LENGTH. $\sim 9.1 \mathrm{~mm}$; macropterous. 
COLORATION. Head: dark brown with a semicircular pale stripe encircling both ocelli; labium lighter than head, brown. Thorax: as head; scutellum dark with brown apical spine. Hemelytron (abducted): clavus dark with distal yellow stripe; corium dark with anteroproximal yellow stripe, posteromedial and distal yellow spots; membrane dark with pale V-shaped marking along $\mathrm{R}$ and $\mathrm{M}$ veins; membranal veins $\mathrm{R}$ and M proximally pale. Legs: dark brown. Abdomen: dark brown; dorsal laterotergites dark brown.

INTEGUMENT AND VeSTITURE. Head and pronotum: finely granulose with dense, long macrosetae interspersed among dense pubescence; antennifer with short lateral setigerous tubercle; morphologically ventral surface of labium with dense, short macrosetae. Thorax: anterolateral angles of pronotal collar without macrosetae or setigerous tubercles. Legs: posterior row of protuberances on mid and hind femora with four spines on distal half. Abdomen: ventral surface pubescent.

Structure. Head (Fig. 3E): elongate, about 1.5 times as long as wide; anteocular region about half of head length, longer than postocular region (measured to anterior margin of neck); postocular region in dorsal view longer than eye, lateral margins gently rounded; pedicel about 1.1 times length of head width; maxillary plates ellipsoidal, adjacent to and shorter than clypeus; apices of maxillary plates in dorsal view directed straight; clypeus in dorsal view about as wide as maxillary plates; clypeal apex round, not narrowed; interocular glabrous markings anterolaterally curved, joined at interocular sulcus paramedially; interocular sulcus in dorsal view curved and smoothly rounded anteriorly; eye width in dorsal view narrower than synthlipsis; eye reaching ventral head margin in lateral view; ocelli minute, occupying 0.12 times length of postocular region; ventrolateral swelling of buccula without lateral protrusion that surpasses buccular margin, flat margin; labial segment I swollen subapically on ventral surface, surpassing posteroventral eye margin; labial segment II swollen ventrobasally, narrowed apically; morphologically dorsal surface of labial segment II curves ventrally, $\sim 0.2$ times length of segment I; labial segment III short, $\sim 0.2$ times length of segment II. Thorax: pronotal collar in dorsal view narrow medially with anterolateral angles short, projected forward; anterior pronotal lobe $\sim 0.8$ times length of posterior pronotal lobe; glabrous markings on pronotum thin and not deeply depressed; median apodeme depression of pronotum deep, elongated transversely; scutellar spine long, subhorizontal; anteriad-directed process of prosternum smoothly rounded, without paramedial lobes; anterior margin of stridulitrum not elongated into protuberance; proepimeron with smoothly rounded posteroventral margin. Legs: fossula spongiosa present on fore legs, unknown on mid legs.

\section{Female}

Unknown.

\section{Distribution (Fig. 20)}

This species is only known from the type locality in Eastern Borneo.

\section{Remarks}

The holotype remains at the NBCN under loan restrictions; habitus photographs were used to evaluate this species concept. Most closely resembles the two species from New Guinea, V. bracata sp. nov. and V. typica. These three species form a poorly supported clade in our analyses (Figs 1-2). This hypothesis should be further tested with additional material and molecular data.

\section{Discussion}

Pseudocetherinae was originally described based on Pseudocethera (3 spp. from Africa) as having a short, tri-lobed head with the antennal pedicel longer than the scape, small or vestigial ocelli, slender labium with labial segment I long and adpressed against the ventral head surface, the close proximity 
of the coxal cavities of fore and mid legs, and the three-segmented tarsi. We expand this concept of Pseudocetherinae by transferring in five genera from Reduviinae: Gerbelius (three spp. from the Oriental region), Kayanocoris (one sp. from Borneo), Microvarus (two spp. from Africa), Paragerbelius (one sp. from Papua), and Voconia (one spp. from Australia). As part of this revision, Kayanocoris, Microvarus, Paragerbelius, and Pseudocethera are synonymized with Voconia. As pointed out in the results section of the cladistic analysis, Gerbelius in the traditional sense is polyphyletic with respect to G. ornatus. Members of Gerbelius share laterally flattened maxillary plates; long prominent mandibular plates; a stout labium; and the $\mathrm{Cu}-\mathrm{An}_{1}$ cell is slender, tapers apically, and is similar in length to the $\mathrm{M}-\mathrm{Cu}$ cell. Together, G. confluens and G. typicus, with two undescribed species, are part of the sister group of all remaining Pseudocetherinae (Figs 1-2). In contrast, G. ornatus not only closely resembles species of Voconia (anteriorly elongate maxillary plates, gracile labium, and short, triangular $\mathrm{Cu}-\mathrm{An}_{1}$ cell, among other characters) but based on our analyses is nested among them. Therefore, we transfer G. ornatus to Voconia and maintain G. confluens and G. typicus as the only two valid species of Gerbelius, the second genus of Pseudocetherinae.

Though the transfer of Gerbelius into Pseudocetherinae requires significant expansion of the original description, morphological (present study, Figs 1-2; Weirauch 2008), ribosomal (Weirauch 2008; Hwang \& Weirauch 2012), and genomic analyses (Knyshov et al. unpubl. data) strongly support Gerbelius and Voconia as sister taxa. The bent apex of the third visible labial segment, anteriad-directed process of the prosternum, absence of dorsal abdominal glands on terga IV-VI, femora with ventral anterior and posterior rows of spine-like protuberances with macrosetae at the base of the protuberance, and laterally compressed tibiae unite Pseudocetherinae and form part of the new description.

\section{Acknowledgements}

We wish to thank the museum curators that provided us access to specimens either through loans, images, or welcoming us into their collections, namely, Randall T. Schuh and Ruth Salas (AMNH); Max Caspers (NBCN); Stéphane Hanot (RMCA); Eric Guilbert (MNHN); Mick Webb and Valerie Lemaître (BMNH); Daniel Swanson (INHS); Gunvi Lindberg (NHRS); Shepherd Myers and Malia Baron (BPBM); Gerasimos Cassis (AMS); Federica Turco (ANIC); and Herbert Zettel (NHMW). We gratefully acknowledge Austin Baker, John Heraty, the anonymous reviewers, the editors, and Weirauch lab members (Samantha Smith, Madison Hernandez, Yisheng Zhao, and Paul Masonick) for providing insightful comments, Doug Yanega for providing his expert knowledge on ICZN rules, and Alex Knyshov for supervising the NGS library prep protocols. This work was made possible by the National Science Foundation DEB-1655769 to C.W. and the Willi Hennig Society by making TNT widely available.

\section{References}

Distant W.L. 1903a. Contributions to a knowledge of the Rhynchota. Annales de la Société entomologique de Belgique 47 (4): 43-65.

Distant W.L. 1903b. Report on the Rhynchota. Part I. Heteroptera. In: Annandale N. \& Robertson H.C. (eds) Fasciculi Malayenses. Anthropological and Zoological Results of an Expedition to Perak and the Siamese Malay States, 1901-1902. Zoology, Part II: 219-272. University Press of Liverpool by Longmans, Green \& Co., London. https://doi.org/10.5962/bhl.title. 98554

Distant W.L. 1904. Rhynchota.-Vol. II. (Heteroptera) [part 2, pp. [i]-iv, xi-xvii, 243-503]. In: Blanford W.T. (ed.) The Fauna of British India, including Ceylon and Burma. Taylor and Francis, London.

Forero D. \& Weirauch C. 2012. Comparative genitalic morphology in the New World resin bugs Apiomerini (Hemiptera, Heteroptera, Reduviidae, Harpactorinae). Deutsche Entomologische Zeitschrift 59 (1): 5-41. 
Forthman M. \& Weirauch C. 2017. Millipede assassins and allies (Heteroptera: Reduviidae: Ectrichodiinae, Tribelocephalinae): total evidence phylogeny, revised classification and evolution of sexual dimorphism. Systematic Entomology 42 (3): 575-595. https://doi.org/10.1111/syen.12232

Gil-Santana H.R., Costa L.A. \& Marques O.M. 2007. Synopsis of the Chryxinae (Hemiptera, Reduviidae). Revista Brasileira de Zoologia 24 (1): 77-83. https://doi.org/10.1590/S0101-81752007000100010

Goloboff P.A. 1993. Estimating character weights during tree search. Cladistics 9 (1): 83-91. https://doi.org/10.1111/j.1096-0031.1993.tb00209.x

Goloboff P.A. \& Catalano S.A. 2016. TNT version 1.5, including a full implementation of phylogenetic morphometrics. Cladistics 32 (3): 221-238. https://doi.org/10.1111/cla.12160

Goloboff P.A., Farris J.S., Källersjö M., Oxelman B., Ramírez M.J. \& Szumik C.A. 2003. Improvements to resampling measures of group support. Cladistics 19 (4): 324-332.

https://doi.org/10.1111/j.1096-0031.2003.tb00376.x

Goloboff P.A., Carpenter J.M., Arias J.S. \& Esquivel D.R.M. 2008. Weighting against homoplasy improves phylogenetic analysis of morphological data sets. Cladistics 24 (5): 758-773.

https://doi.org/10.1111/j.1096-0031.2008.00209.x

Hwang W.S. \& Weirauch C. 2012. Evolutionary history of assassin bugs (Insecta: Hemiptera: Reduviidae): Insights from divergence dating and ancestral state reconstruction. PLoS ONE 7 (9): e45523. https://doi.org/10.1371/journal.pone.0045523

Jeannel R. 1917. Diagnoses préliminaires de Reduviidae noveaux d'Afrique (Hem.) (deuxième note). Bulletin de la Société entomologique de France 1917 (1): 49-53.

Kirby W.F. 1891. Catalogue of the described Hemiptera Heteroptera and Homoptera of Ceylon, based on the collection formed (chiefly at Pundaloya) by Mr. E. Ernest Green. Zoological Journal of the Linnean Society 24 (149-150): 72-176. https://doi.org/10.1111/j.1096-3642.1891.tb02479.x

Latreille P.A. 1807. Genera Crustaceorum et Insectorum secundum ordinem naturalem in familias disposita, iconibus exemplisque plurimis explicata. Volume 3. A. Koenig, Paris and Strasbourg [Parisiis et Argentorati]. https://doi.org/10.5962/bhl.title.65741

Maldonado J. 1990. Systematic Catalogue of the Reduviidae of the World (Insecta: Heteroptera). Caribbean Journal of Science Special Ed., University of Puerto Rico, Mayaguez.

Maddison W.P. \& Maddison D.R. 2019. Mesquite: a modular system for evolutionary analysis. Ver. 3.61. Available from http://www.mesquiteproject.org [accessed 24 Sep. 2021].

Miller N.C.E. 1954. A new subfamily, new genera, and species of Malaysian Reduviidae (Hemiptera, Heteroptera). Idea 10 (1-2): 1-8.

Miller N.C.E. 1958. On the Reduviidae of New Guinea and adjacent islands (Hemiptera Heteroptera). Part 1. Nova Guinea, New Ser. 9 (1): 33-143.

Nixon K.C. 1999. The parsimony ratchet, a new method for rapid parsimony analysis. Cladistics 15 (4): 407-414. https://doi.org/10.1111/j.1096-0031.1999.tb00277.x

Nixon K.C. 2002. WinClada ver. 1.00.08. Published by the author, Ithaca, NY.

Putshkov V.G. \& Putshkov P.V. 1985. A Catalog of the Reduviidae (Heteroptera) of the World. Unpublished typescript deposited in Viniti, Lyubertsy.

Rueden C.T., Schindelin J., Hiner M.C., DeZonia B.E., Walter A.E., Arena E.T. \& Eliceiri K.W. 2017. ImageJ2: ImageJ for the next generation of scientific image data. BMC Bioinformatics 18: 529.

https://doi.org/10.1186/s12859-017-1934-z 
Schouteden H. 1929. Reduviides africains nouveaux. Revue de Zoologie et de Botanique africaines 18 (2): 250-262.

Schuh R.T. \& Weirauch C. 2020. True Bugs of the World (Hemiptera: Heteroptera): Classification and Natural History (second edition). Siri Scientific Press, Rochdale.

Stål C. 1866a. Hemiptera Africana. Volume 3. Norstedtiana, Stockholm. https://doi.org/10.5962/bhl.title.8566

Stål C. 1866b. Analecta hemipterologica. Berliner Entomologische Zeitschrift 10 (1-3): 151-172. https://doi.org/10.1002/mmnd.18660100112

Swanson D.R. 2015. A new generic synonym in the Reduviinae of Australia, with an updated key to genera (Heteroptera: Reduviidae). Zootaxa 3911 (2): 262-272. https://doi.org/10.11646/zootaxa.3911.2.7

Villiers A. 1948. Faune de l'Empire Français. IX. Hémiptères Réduviides de l'Afrique Noire. Éditions du Muséum, Paris.

Villiers A. 1963a. Contribution à l'étude de la faune de la basse Casamance. Hémiptères Réduviides et Hénicocéphalides. Bulletin de l'Instiut Français d'Afrique Noire, Sér. A 25 (3): 969-994.

Villiers A. 1963b. Hemiptera Reduviidae. In: La réserve naturelle intégrale du Mont Nimba (Fascicule V) (Mémoires de l'Institut Français d'Afrique Noire 66). IFAN [= Institut Français d'Afrique Noire], Dakar.

Villiers A. 1964. Reduviidae (Hemiptera Heteroptera). In: Exploration du Parc National de la Garamba. Mission H. de Saeger, en collaboration avec P. Baert, G. Demoulin, I. Denisoff, J. Martin, M. Micha, A. Noirfalise, P. Schoemaker, G. Troupin et J. Verschuren (1949-1952), Fasc. 43. Institut des Parcs Nationaux du Congo et du Rwanda, Bruxelles.

Villiers A. 1976. Descriptions, localisations et synonymies d'Hémiptères Reduviidae du Musée Royal de l'Afrique Centrale. Revue de Zoologie africaine 90 (1): 162-176.

Weirauch C. 2006. Dorsal abdominal glands in adult Reduviidae (Heteroptera, Cimicomorpha). Deutsche Entomologische Zeitschrift 53 (1): 91-102. https://doi.org/10.1002/mmnd.200600009

Weirauch C. 2008. Cladistic analysis of Reduviidae (Heteroptera: Cimicomorpha) based on morphological characters. Systematic Entomology 33 (2): 229-274.

https://doi.org/10.1111/j.1365-3113.2007.00417.x

Weirauch C. \& Munro J.B. 2009. Molecular phylogeny of the assassin bugs (Hemiptera: Reduviidae), based on mitochondrial and nuclear ribosomal genes. Molecular Phylogenetics and Evolution 53 (1): 287-299. https://doi.org/10.1016/j.ympev.2009.05.039

Weirauch C., Bérenger J., Berniker L., Forero D., Forthman M., Frankenberg S., Freedman A., Gordon E., Hwang W.S., Marshall S., Michael A., Paiero S.M., Udah O., Watson C., Yeo M., Zhang G. \& Zhang J. 2014. An illustrated identification key to assassin bug subfamilies and tribes (Hemiptera: Reduviidae). Canadian Journal of Arthropod Identification 26: 1-115. https://doi.org/10.3752/cjai.2014.26

Weirauch C., Russell K. \& Hwang W.S. 2015. Reduvius frommeri, a new species of Reduviidae from the Western United States (Hemiptera: Reduviidae), with a synopsis of the Nearctic species of Reduvius Fabricius. Zootaxa 3972 (2): 267-279. https://doi.org/10.11646/zootaxa.3972.2.7

Zhang J., Gordon E.R., Forthman M., Hwang W.S., Walden K., Swanson D.R., Johnson K.P., Meier R. \& Weirauch C. 2016. Evolution of the assassin's arms: insights from a phylogeny of combined transcriptomic and ribosomal DNA data (Heteroptera: Reduvioidea). Scientific Reports 6 (1): 1-8. https://doi.org/10.1038/srep22177 
Manuscript received: 8 March 2021

Manuscript accepted: 25 July 2021

Published on: 11 January 2022

Topic editor: Nesrine Akkari

Section editor: Christopher H. Dietrich

Desk editor: Pepe Fernández

Printed versions of all papers are also deposited in the libraries of the institutes that are members of the EJT consortium: Muséum national d'histoire naturelle, Paris, France; Meise Botanic Garden, Belgium; Royal Museum for Central Africa, Tervuren, Belgium; Royal Belgian Institute of Natural Sciences, Brussels, Belgium; Natural History Museum of Denmark, Copenhagen, Denmark; Naturalis Biodiversity Center, Leiden, the Netherlands; Museo Nacional de Ciencias Naturales-CSIC, Madrid, Spain; Real Jardín Botánico de Madrid CSIC, Spain; Zoological Research Museum Alexander Koenig, Bonn, Germany; National Museum, Prague, Czech Republic.

\section{Supplementary material}

Supp. file 1. Comprehensive measurements (in mm) of Pseudocetherinae Villiers, 1963. https://doi.org/10.5852/ejt.2022.788.1625.5795

Supp. file 2. Character matrix for phylogenetic analysis. https://doi.org/10.5852/ejt.2022.788.1625.5797 